Aus der Abteilung Humangenetik

(Prof. Dr. med. Dr. h. c. W. Engel)

im Zentrum Hygiene und Humangenetik

der Medizinischen Fakultät der Universität Göttingen

\title{
Organisation, Expression und Funktion \\ des humanen \\ Peroxisomal-Testis-Specific-1(PXT1)-Gens
}

\author{
INAUGURAL-DISSERTATION \\ zur Erlangung des Doktorgrades \\ der Medizinischen Fakultät \\ der Georg-August-Universität zu Göttingen
}

\author{
vorgelegt von \\ Agneta Auer \\ aus \\ Mühlhausen
}

Göttingen 2013 
Dekan:

I. Berichterstatter:

II. Berichterstatter/in:

Tag der mündlichen Prüfung: $\quad$ 10. Juni 2013
Prof. Dr. rer. nat. H. K. Kroemer

Prof. Dr. med. Dr. h. c. W. Engel

Prof. Dr. med. J. Großhans 


\section{Inhaltsverzeichnis}

I

II

III

1

1.1

1.1.1

1.1.2

1.1.3

1.1 .4

1.1 .5

1.2

1.3

2

2.1

2.1 .1

2.1.1.1

2.1.1.2

2.1.2

2.1 .3

2.1 .4

2.1 .5

2.1.6

2.1 .7

2.1 .8

2.1 .9

2.1.10

2.1 .11

2.1 .12

2.1 .13
Abkürzungen und Symbole

Abbildungsverzeichnis

Tabellenverzeichnis

Einleitung

Das Pxt1-Gen bei der Maus

Von der Identifizierung bis zur Charakterisierung

Genomische Struktur des Pxt1-Gens

Expression des Pxt1-Gens

Subzelluläre Lokalisation des PXT1-Proteins

Zur Funktion des Pxt1-Gens

Organisation, Expression und Funktion des PXT1-Gens beim Menschen 6

Ziele der vorliegenden Arbeit

7

Materialien und Methoden

8

Materialien

8

Verwendete Nukleinsäuren

8

cDNA

8

RNA

8

Mäusestämme für TUNEL-Analysen

8

Oligonukleotide

9

Bakterienstämme

11

$\begin{array}{ll}\text { Chemikalien } & 11\end{array}$

Puffer und Lösungen $\quad 12$

Gebrauchsfertige Reaktionssysteme (Kits) 13

$\begin{array}{ll}\text { Enzyme und Enzymsets } & 14\end{array}$

Vektoren

14

Kulturmedien

16

$\begin{array}{ll}\text { Gebrauchswaren } & 16\end{array}$

$\begin{array}{ll}\text { Geräte } & 17\end{array}$

Computeranalysen

V

$\mathrm{X}$

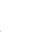

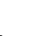

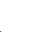

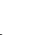

4

5

VIII

2

(1)


2.2.1 Herkunft und Auswahl untersuchter DNA-Proben 18

$\begin{array}{lll}2.2 .2 & 19\end{array}$

2.2.2.1 Isolierung von DNA aus Vollblut 19

2.2.2.2 Vorbereitung der Zellen für RNA-Isolation 19

2.2.2.2.1 Isolierung von Leukozyten aus Vollblut 19

2.2.2.2.2 Kultivierung HeLa-Zellen 19

2.2.2.3 Isolierung von RNA aus HeLa-Zellen und Leukozyten 20

2.2.3 Konzentrationsbestimmung von Nukleinsäuren 20

$\begin{array}{lll}\text { 2.2.4 Polymerasekettenreaktion (PCR) } & 21\end{array}$

2.2.4.1 PCR an genomischer DNA 21

2.2.4.2 RT-PCR 22

2.2.4.3 Sequenz-PCR 23

2.2.4.4 RACE-PCR 24

2.2.4.4.1 Dephosphorylierung der RNA 24

2.2.4.4.2 RNA-Aufreinigung 25

2.2.4.4.3 Entfernung der Cap-Struktur 25

2.2.4.4.4 Ligation eines RNA-Oligonukleotids an die mRNA nach der Entfernung der CAP-Struktur 26

2.2.4.4.5 Reverse Transkription 27

2.2.4.4.6 Amplifikation der cDNA-Enden 27

2.2.4.4.7 Nested-PCR 28

2.2.4.5 Real Time-PCR mit dem ABI Prism® 7900HT Sequence Detection $\begin{array}{ll}\text { System } & 29\end{array}$

2.2.4.5.1 Relative Quantifizierung mittels $\Delta \Delta \mathrm{C}_{\mathrm{T}}-$ Methode 30

2.2.4.5.2 Absolute Quantifizierung 31

2.2.5 Aufreinigung von PCR-Produkten 32

2.2.6 Standard-Agarose-Gelelektrophorese 32

2.2.7 Isolierung von DNA-Fragmenten aus den Agarosegelen 32

2.2.8 Ligation von DNA-Fragmenten 33

2.2.9 Transformation 33

2.2.10 Isolierung von kleinen Plasmid-DNA-Mengen (Minipräparation) 34

2.2.11 Herstellung von Glycerinstocks 34

2.2.12 Restriktionsenzymatische Spaltung 34 
2.2.13 Arraybasierte Comparative Genomische Hybridisierung (aCGH)

2.2.13.1 Fragmentierung der genomische DNA mittels Restriktionsenzymen 35

2.2.13.2 DNA-Fragmentmarkierung (Labelling) 36

2.2.13.3 Aufreinigung der markierten genomischen DNA 37

2.2.13.4 Konzentrationsbestimmung mittels Nanodrop 37

2.2.13.5 Hybridisierung 37

2.2.13.6 Waschen 38

2.2.13.7 Auswertung 38

2.2.14 Isolierung von Spermien aus dem Nebenhodenschwanz 39

2.2.15 TUNEL-Assay zur Analyse von DNA-Strangbrüchen 39

$3 \quad$ Ergebnisse $\quad 41$

$3.1 \quad$ Ausgangslage für die Analysen 41

$3.2 \quad$ Das humane PXT1-Gen 41

3.2.1 Nachweis zusätzlicher Exons 41

3.2.2 Alternatives Spleißen im PXT1-Gen 43

3.2.2.1 Analyse auf weitere Exons in 5'-Richtung und deren Sequenzierung 43

3.2.2.2 Ergebnisse der RT-PCR mit der Primerkombination F1/R1 46

3.2.2.3 Transkripte vom PXT1-Gen und deren Auswirkungen auf die

$\begin{array}{ll}\text { Proteinstruktur } & 48\end{array}$

3.2.3 Überlappung des Exons 1 vom PXT1-Gen mit dem Exon 1 vom

KCTD20-Gen $\quad 50$

3.2.4 Expressionsanalyse des humanen PXT1-Gens in verschiedenen Geweben 53

3.2.4.1 Expressionsanalyse mittels RT-PCR 53

3.2.4.2 Expressionsanalyse mittels Real Time-PCR 55

3.2.4.3 Nachweis vom PXT1-Gen in HeLa-Zellen und Leukozyten 56

3.3 Die Untersuchung von DNA-Strangbrüchen in Spermienköpfen der $\begin{array}{ll}P x t 1-K n o c k o u t-M a u s & 58\end{array}$

3.3.1 TUNEL-Analysen und das Pxt1-Gen 58

3.3.2 Ermittlung der Anzahl der Spermienköpfe mit DNA-Strangbrüchen in der Pxt1-Knockout-Maus $\quad 59$

3.3.3 Induktion von Strangbrüchen mithilfe von DNase I 60

3.4 Mutationsuntersuchungen im PXT1-Gen bei infertilen Männern 62

$\begin{array}{lll}3.4 .1 & \text { Punktmutationsanalysen }\end{array}$ 
3.4.2 Ergebnisse der Deletionsanalysen mittels Real Time-PCR

3.4.3 Ergebnisse der arraybasierten Comparativen Genomischen

Hybridisierung $(\mathrm{aCGH})$

4

$\begin{array}{ll}\text { Diskussion } & \mathbf{7 4}\end{array}$

4.1 Homologie und evolutionäre Konservierung des Pxt1/PXT1-Gens 74

4.2 Expressionsmuster und alternatives Spleißen des PXT1-Gens $\quad 80$

4.3 Funktion und putative Rolle des Pxt1/PXT1-Gens in der Spermatogenese 84

4.4. Ausblick 86 


\section{Abkürzungen und Symbole}

\section{Abkürzungen}

Abb.

$\mathrm{aCGH}$

$\beta G a l$

bp

bzw.

${ }^{\circ} \mathrm{C}$

ca.

cDNA

CIP

$\mathrm{CNV}$

$\mathrm{C}_{\mathrm{T}}$

$\Delta$

DEPC

d. h.

$\mathrm{dH}_{2} \mathrm{O}$

DMSO

DNA

dNTP

dpc

dpp

DTT

E.coli

E-Cup

EDTA

EL-Puffer

etc.

$\mathrm{EtOH}$

$\mathrm{g}$

$\mathrm{x} \mathrm{g}$

GSP

$\mathrm{h}$

HeLa-Zellen
Abbildung

arraybasierte Comparative Genomische Hybridisierung

Beta-Galaktosidase

Basenpaare

beziehungsweise

Grad Celsius

circa

komplementäre DNA

calf intestinal phosphatase

copy number variations

cycle threshold-Schwellenzyklus

Delta, Differenz

Diethylenpyrocarbonat

das heißt

destilliertes Wasser

Dimethylsulfoxid

Desoxyribonukleinsäure

Desoxynukleotidtriphosphat

day post coitum

day post partum

Dithiothreitol

Escherichia coli

Eppendorfcup

Ethylendiamintetraacetat

Erythrozyten-Lysis-Puffer

et cetera

Ethanol

Gramm

Erdbeschleunigung

genspezifischer Primer

Stunde

humane Cervixkarzinomzellen 


\begin{tabular}{|c|c|}
\hline hnRNA & heterogeneous nuclear RNA \\
\hline $\mathrm{H}_{2} \mathrm{O}$ & Wasser \\
\hline IPTG & Isopropyl-ß-D-thiogalactopyranosid, Induktor des lac-Operons \\
\hline $\mathrm{kb}$ & Kilobasen \\
\hline $\mathrm{KHCO}_{3}$ & Kaliumhydrogencarbonat \\
\hline 1 & Liter \\
\hline$\mu$ & mikro- $\left(10^{-6}\right)$ \\
\hline $\mathrm{m}$ & milli $\left(10^{-3}\right)$, Meter \\
\hline M & Molarität \\
\hline $\mathrm{MgCl}_{2}$ & Magnesiumchlorid \\
\hline $\min$ & Minuten \\
\hline miRNA & mikro RNA \\
\hline mRNA & messenger RNA \\
\hline $\mathrm{n}$ & nano $\left(10^{-9}\right)$ \\
\hline $\mathrm{NH}_{4} \mathrm{Cl}$ & Ammoniumchlorid \\
\hline OAT & Oligo-Astheno-Teratozoospermie \\
\hline $\mathrm{OH}$ & Hydroxid \\
\hline ORF & open reading frame (offener Leserahmen) \\
\hline $\mathrm{p}$ & piko $\left(10^{-12}\right)$ \\
\hline PBS & Phosphatgepufferte Salzlösung \\
\hline PCR & Polymerasekettenreaktion \\
\hline PFA & Paraformaldehyd \\
\hline $\mathrm{pH}$ & negativer dekadischer Logarithmus der Wasserstoffionenaktivität \\
\hline RNA & Ribonukleinsäure \\
\hline $\mathrm{rpm}$ & rounds per minute \\
\hline RT & Raumtemperatur/Reverse Transkriptase \\
\hline $\sec$ & Sekunden \\
\hline SNP & single nucleotide polymorphism \\
\hline SOB & Super Optimal Broth, ein komplexes Nährmedium \\
\hline S.O.C. & Nährmedium SOB mit 20 mM Glucose versetzt \\
\hline TAP & tobacco acid pyrophosphatase \\
\hline TBP & tata binding protein \\
\hline $\mathrm{U}$ & Unit (Einheit der Enzymaktivität) \\
\hline u. a. & unter anderem \\
\hline
\end{tabular}


UTR untranslated region

UV Ultraviolett

WT Wildtyp

z. B. zum Beispiel

\section{Symbole}

$\begin{array}{ll}\% & \text { Prozent } \\ \mathrm{x} & - \text { mal }\end{array}$

\section{Symbole für Aminosäuren}

$\begin{array}{lll}\text { A } & \text { Ala } & \text { Alanin } \\ \text { C } & \text { Cys } & \text { Cystein } \\ \text { D } & \text { Asp } & \text { Asparaginsäure } \\ \text { E } & \text { Glu } & \text { Glutaminsäure } \\ \text { F } & \text { Phe } & \text { Phenylalanin } \\ \text { G } & \text { Gly } & \text { Glycin } \\ \text { H } & \text { His } & \text { Histidin } \\ \text { I } & \text { Ile } & \text { Isoleucin } \\ \text { K } & \text { Lys } & \text { Lysin } \\ \text { L } & \text { Leu } & \text { Leucin } \\ \text { M } & \text { Met } & \text { Methionin } \\ \text { N } & \text { Asn } & \text { Asparagin } \\ \text { P } & \text { Pro } & \text { Prolin } \\ \text { Q } & \text { Gln } & \text { Glutamin } \\ \text { R } & \text { Arg } & \text { Arginin } \\ \text { S } & \text { Ser } & \text { Serin } \\ \text { T } & \text { Thr } & \text { Threonin } \\ \text { V } & \text { Val } & \text { Valin } \\ \text { W } & \text { Trp } & \text { Tryptophan } \\ \text { Y } & \text { Thyrosin }\end{array}$


Abb. 1.1: $\quad$ Vollständige genomische Struktur des murinen Pxtl-Gens 2

Abb. 1.2: Vollständige genomische Struktur des menschlichen PXT1-Gens

Abb. 2.1: Darstellung des Vektors pGEM T-easy (Promega)

Abb. 3.1: Lokalisation der verwendeten Primer bei der Expressionsanalyse des PXT1-Gens

Abb. 3.2: $\quad$ RT-PCR-Produkte der 5 Exons

Abb. 3.3: Lokalisation der verwendeten genspezifischen Primer für die 5'-RACE-PCR-Analyse

Abb. 3.4: $\quad$ Ergebnis der 5'-RACE-PCR

Abb. 3.5: Restriktionsanalyse des 5'-RACE-PCR-Produktes, kloniert in den pGEM T-easy-Vektor

Abb. 3.6: Spleiß-Varianten im Bereich der Exons 1-3

Abb. 3.7: RT-PCR-Ergebnisse der Primerkombination FP1/RP1

Abb. 3.8: Transkripte des humanen PXT1-Gens aus den RT-PCR- und 5'-RACE-PCR-Ergebnissen

Abb. 3.9: Genomische Lokalisation von PXT1 und KCTD20 50

Abb. 3.10: Sequenz der beiden Gene mit Darstellung der überlappenden Bereiche 51

Abb. 3.11: Schematische Darstellung der überlappenden Bereiche von Exon 1 der Gene PXT1 und KCTD2O

Abb. 3.12: Die PXT1-Expression in verschiedenen Geweben

Abb. 3.13: Lokalisation der verwendeten genspezifischen Primer für die Expressionsanalyse

Abb. 3.14: Quantitative Analyse der Expression von PXT1 in verschiedenen Geweben

Abb. 3.15: Expression von PXT1 in HeLa-Zellen, Leukozyten und im Testis

Abb. 3.16: Darstellung eines TUNEL-positiven Spermiums

Abb. 3.17: Grafische Darstellung der Anzahl an Strangbrüchen in Abhängigkeit von der Dauer der Inkubation mit DNase I

Abb. 3.18: Position der Amplikons im PXT1-Gen

Abb. 3.19: Lokalisation der verwendeten Primer für die Punktmutationsanalyse im PXT1-Gen 
Abb. 3.20: Darstellung der Amplikons von PXT1 im Agarosegel

Abb. 3.21: Grafische Darstellung aller bekannten Polymorphismen in PXT1 aus der Ensemble-Datenbank

Abb. 3.22: Lokalisation der verwendeten Primer für die Deletionsanalyse

Abb. 3.23: Grafische Darstellung der Oligozoospermieergebnisse

Abb. 3.24: Grafische Darstellung der Azoospermieergebnisse 71

Abb. 3.25: Auszug aus der Analysesoftware des aCGHs

Abb. 4.1: Sequenzvergleich zwischen dem humanen und dem murinen PXT1Protein

Abb. 4.2: Phylogramm von PXT1 der einzelnen Spezies auf Proteinebene 


\section{Tabellenverzeichnis}

Tab 2.1: $\quad$ Genspezifische Primer für PXT1 9

Tab 2.2: $\quad$ Referenzprimer für die Real Time-PCR 19

Tab 2.3: $\quad$ Primer für die Sequenzierung von pGEM® T-Easy-Inserts 11

Tab 2.4: $\quad$ Sonden für die aCGH 11

Tab 2.5: $\quad$ Diagnose bei den untersuchten Patienten 19

Tab 3.1: $\quad$ Ergebnisse der TUNEL-Analysen $\quad 59$

Tab 3.2: $\quad$ Induktion von Strangbrüchen in Abhängigkeit von der Zeit 61

Tab 3.3: Verwendete Primer per Amplikon 63

Tab 3.4: Verwendete Primer per Exon 67

Tab 3.5: $\quad$ Ergebnisse der Analyse bei Patienten mit Oligozoospermie 68

Tab 3.6: $\quad$ Ergebnisse der Analyse bei Patienten mit Azoospermie 70

Tab. 4.1: $\quad$ Vergleich des humanen mit dem murinen PXT1/Pxt1-Gen

(entnommen und modifiziert aus Kaczmarek, 2009) 74

Tab. 4.2: $\quad$ Unterschiedliche Anzahl von Exons des Pxtl-Gens in verschiedenen Spezies 


\section{Einleitung}

\subsection{Das Pxt-Gen bei der Maus}

\subsubsection{Von der Identifizierung bis zur Charakterisierung}

1999 wurde von Carninci und Hayashizaki die cDNA-Sequenz für das Peroxisomal-testisspecific-1 (Pxt1)-Gen beschrieben. Am Institut für Humangenetik der Universität Göttingen erfolgte im Rahmen der Isolation von unbekannten Genen eine vergleichende Darstellung (Differential Display) der Genexpression in Spermatiden, Sertolizellen und deren CoKulturen (Kraszucka et al. 1999). Dabei konnte aus der Spermatidenfraktion ein 550 bp großes cDNA-Fragment ( $P x t 1$, damals unter dem Namen TSGK-1) isoliert werden (Burfeind 1999). 2000 wurde Pxtl mit dem RISA (RIKEN Integrate Sequence Analysis)-System sequenziert (Shibata $\mathrm{K}$ et al. 2000) und in den folgenden Jahren in mehreren testikulären cDNA-Banken (Kawai et al. 2001, Strausberg et al. 2002) und Transkriptomanalysen (Okazaki et al. 2002, Katayama et al. 2005, Carnici et al. 2005) identifiziert. Die Ergebnisse der Charakterisierung des Pxtl-Gens wurden in der Arbeit von Grzmil et al. (2007) veröffentlicht, basierend auf Resultaten der Dissertation von Burfeind (1999) und der Diplomarbeit von Preuss (2002). Von Kaczmarek et al. (2011) erschien eine Publikation mit ersten Ergebnissen zur Funktion des Pxt1-Gens.

\subsubsection{Genomische Struktur des Pxt1-Gens}

Die Bestimmung der vollständigen Sequenz, des aus der Spermatidenfraktion isolierten 550 bp großen cDNA-Fragments, erfolgte mithilfe verschiedener Phagenbibliotheken (Lambda gt11-Maus-Testis-cDNA-Bibliothek, Lambda ZAP-Maus-Testis-cDNA-Bibliothek) (Burfeind 1999).

Die cDNA des murinen Pxtl besitzt eine Länge von 1016 bp. Der offene Leserahmen (ORF, Open Reading Frame) beginnt an der Position 143. Nach einer Länge von 153 bp ist ein TAAStopkodon an der Position 299-301 lokalisiert. Der ORF kodiert für ein Protein mit 51 Aminosäuren und mit einer Größe von etwa $6 \mathrm{kDa}$. Der isoelektrische Punkt (pI) liegt bei 6,9. In $5^{\prime}$-Richtung befindet sich im Vergleich zum 3'-UTR eine relativ kurze UTR-Region mit 142 bp. Hingegen ist die in 3'-Richtung befindliche UTR-Region mit 716 bp etwa um das 5Fache größer. An der Position 994 befindet sich das AATAAA-Polyadenylierungssignal (Burfeind 1999, Grzmil et al. 2007). Nachdem die cDNA-Sequenz des murinen Pxtl in der CELERA-Datenbank abgeglichen war, war es möglich, die komplette genomische Struktur 
des Pxt1-Gens zu ermitteln (Preuss 2002, Grzmil et al. 2007). Es besteht aus 3 Exons und 2 Introns (Abb.1.1).

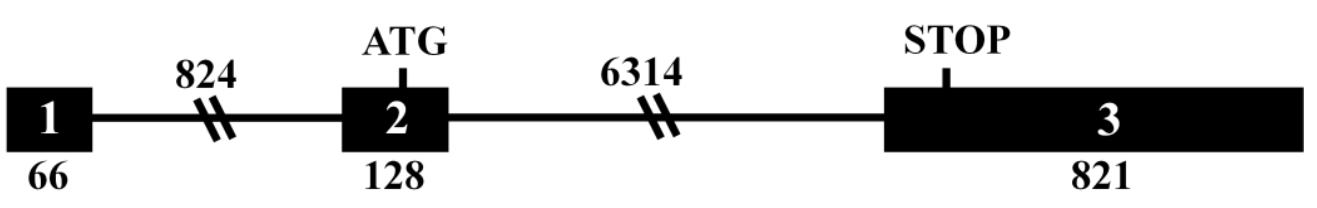

\begin{abstract}
Abb. 1.1: Vollständige genomische Struktur des murinen Pxt1-Gens
Die Abbildung zeigt die 3 Exons (1-3) anhand von schwarzen Boxen und die 2 Introns anhand von horizontalen Linien. Die angegebenen Zahlen entsprechen der exakten Länge in bp. Des Weiteren sind die Start- (ATG) und Endpunkte (STOP) der Translation eingezeichnet. Das Gen umfasst eine Größe von 8,2 kb.
\end{abstract}

Entnommen und modifiziert aus Grzmil et al. (2007, S. 76).

Das Exon 1 besteht aus 66, Exon 2 aus 128 und schließlich Exon 3 aus 821 Nukleotiden. Zwischen den Exons befinden sich das Intron 1 mit 824 Nukleotiden und das Intron 2 mit 6314 Nukleotiden. Das gesamte Gen erstreckt sich über 8,2 kb. Der Startpunkt der Translation befindet sich im Exon 2 und endet zu Beginn des Exons 3. FISH-Untersuchungen (Burfeind 1999, Grzmil et al. 2007) bestätigten die in der DNA-Datenbank gezeigte Lokalisation von Pxt1 (ID: 69307) auf dem Chromosom 17 im Bereich A3-B.

\title{
1.1.3 Expression des Pxt1-Gens
}

Für die Expressionsuntersuchung mithilfe des Northern Blots wurde Maus-RNA aus Uterus, Gehirn, Testis, Ovar, Lunge, Milz, Niere, Herzmuskel, Skelettmuskel und Thymus untersucht. Lediglich mit RNA aus Testis konnte ein positives Hybridisierungssignal (1,3 kb) detektiert werden. In den übrigen Geweben konnte keine Expression nachgewiesen werden (Burfeind 1999, Grzmil et al. 2007). Für eine zellspezifische Pxtl-Expressionsanalyse (Burfeind 1999, Grzmil et al. 2007) wurde zunächst RNA aus Leydig- und Sertolizellen isoliert. Da bei der Keimzellseparation keine reine Spermatidenfraktion erhalten wurde, erfolgte die weitere RNA-Isolation aus einem Spermatiden/Spermatozyten-Gemisch. Ebenso wurde RNA aus einer Co-Kultur, bestehend aus Sertoli-Zellen und Spermatiden/Spermatozyten, gewonnen. Mithilfe von Northern-Blot-Analysen konnte in Spermatiden/Spermatozyten und in der CoKultur ein 1,3 kb großes Hybridisierungssignal detektiert werden. Der Expressionsnachweis in den somatischen Zellen fiel negativ aus.

Für Northern-Blot-Analysen mit verschiedenen Mausmutanten wurde RNA aus Testis isoliert (Burfeind 1999, Grzmil et al. 2007). Bei den verwendeten Mutanten findet $\mathrm{zu}$ unterschiedlichen Zeiten ein Spermatogenesearrest statt. Für $W / W^{v}$-Mutanten ist es 
charakteristisch, dass sie keine Keimzellen besitzen (Lyon und Searle 1989, Ohta et al. 2003). Bei den Tfm/Y- (Lyon und Hawkes 1970) und Insl3 ${ }^{-/}$-Mutanten (Zimmermann et al. 1997) sind Keimzellen bis zum Stadium der primären Spermatozyten nachweisbar und die $C R E M^{-1}$ Knockout-Tiere (Blendy et al. 1996, Nantel et al. 1996) besitzen sie bis zum sekundären Spermatozytenstadium. Die olt/olt-Mäuse (Moutier 1976) haben Keimzellen bis zum Stadium der runden Spermatiden und schließlich entwickeln sich bei den $q k / q k$-Mutanten (Bennett et al. 1971) die Keimzellen bis zu den elongierten Spermatiden. Als Kontrolle wurde testikuläre RNA aus adulten Wildtyp-Mäusen verwendet. Anhand der verschiedenen Zeitpunkte des Spermatogenesearrests konnte eine Zuordnung der Expression von Pxtl zu einem Spermatogenesestadium erfolgen. Bei den Wildtyp-Kontrollen und bei den Mutanten CREM-/ , qk/qk, olt/olt (Spermatogenesearrest ab den sekundären Spermatozyten) konnte ein 1,3 kb starkes Hybridisierungssignal detektiert werden. Ein sehr schwaches Signal konnte bei den Mutanten $T f m / Y$ und $I n s / 3^{-/-}$(Arrest im Stadium der primären Spermatozyten) identifiziert werden. Hingegen fehlte bei den $W / W^{\nu}$-Mutanten (keine Keimzellen) das Hybridisierungssignal.

In einer Postnatal-Studie mithilfe von Northern-Blot-Analysen wurde die Pxt1-Expression im Verlauf der Testisentwicklung untersucht (Burfeind 1999, Grzmil et al. 2007). RNA aus Testisgewebe von postnatalen Mäusen wurde am 5., 9., 10., 11., 12., 13., 15., 17., 20., 25. dpp (day post partum) und im adulten Zustand analysiert. Parallel wurde der Filter des Northern Blots mit diversen bekannten, stadienspezifischen Markern der Spermatogenese ( $L D H X$, Akrosin, PGK 2, TP 2, Protamin 1) hybridisiert. Ab dem 15. dpp war in den Northern-BlotAnalysen eine Expression von Pxtl zeitgleich mit zwei Markern für das Stadium der pachytänen Spermatozyten (Acrosin und PGK-2 (Phosphoglyceratkinase 2)) nachzuweisen (Burfeind 1999).

Basierend auf RNA-in-situ-Hybridisierung wurde im Jahr 2011 ein anatomisch-basiertes Expressionsprofil von Mausembryonen am 14,5. dpc (day post coitum) im Internet veröffentlicht. Eine Expression von Pxtl im Testis der untersuchten Embryonen am Tag 14,5. dpc konnte dabei nicht nachgewiesen werden (Diez-Roux et al. 2011, http://www.eurexpress.org). 


\subsubsection{Subzelluläre Lokalisation des PXT1-Proteins}

Mithilfe von Motifscan-Analysen (http://expasy.org) konnte am C-Terminus der PXT1Aminosäuresequenz eine spezifische Domäne, die sich aus den Aminosäuren Asparagin $(\mathrm{N})$, Histidin (H) und Leucin (L) zusammensetzt und somit als NHL-Domäne (Mohan et al. 2002) bezeichnet wird, identifiziert werden. Die NHL-Domäne, auch CMTS-Motiv ( $C$ Terminal Microbody Targeting Signal) oder PTS 1 (Peroxisomal Targeting Signal type 1) genannt, ist allgemein verantwortlich für den Proteintransport in kleine Zellorganellen des Zytoplasmas, den sogenannten Microbodies (Holroyd und Erdmann 2001), zu denen u. a. Peroxisomen zählen. Zur Klärung der subzellulären Lokalisation wurden Fusionsproteine hergestellt. Für die Untersuchung der Spezifität des NHL-Motivs wurde dieses nativ (WT) oder in modifizierter Form (NQL, WQK, mutiert oder komplett deletiert) in das pEGFP-C1-Pxt1Konstrukt kloniert. Mit diesen Konstrukten wurden NIH3T3-Zellen transfiziert. Unter dem Fluoreszenzmikroskop konnte bei der Substitution von Histidin zu Glutamin (NQL) im Vergleich zum nicht-modifizierten NHL-Motiv (WT) kaum eine Veränderung der subzellulären Lokalisation festgestellt werden. Hingegen ist bei den anderen Modifikationen (WQK, delNHL) die punktuelle Verteilung im Zytoplasma (WT) aufgehoben, die Proteine sind homogen verteilt. Die spezifische Funktion des NHL-Motivs konnte nachgewiesen werden (Preuss 2002, Grzmil et al. 2007).

Um die Lokalisation des PXT1-Proteins in den Peroxisomen zu bestätigen, erfolgte eine CoLokalisationsanalyse von EGFP-C1-Pxt1-Fusionsprotein mit bekannten peroxisomalen Markern. Die mit dem EGFP-C1-Pxt1-Konstrukt transfizierten NIH3T3-Zellen wurden zunächst mit Antikörpern gegen Acetyl-CoA-Oxidase und dem Peroxisomalen MembranProtein 70 inkubiert (Preuss 2002, Grzmil et al. 2007). Im Verlauf wurden an einem murinen Testis-Suspensionspräparat Antikörper gegen Catalase und Acetyl-CoA-Oxidase und schließlich an murinen Testis-Paraffinschnitten Antikörper gegen Catalase inkubiert. Mit allen peroxisomalen Markern konnte eine Co-Lokalisation gezeigt werden (Kaczmarek et al. 2011).

Mit Yeast-two-Hybrid(Y2H)-Analysen konnte CCDC33 als Interaktionspartner von PXT1 identifiziert werden (Kaczmarek 2009). Das Ccdc33 (Coiled-coil domain containing 33)-Gen wird ähnlich wie Pxt1 testisspezifisch, ab den pachytänen Spermatozyten exprimiert und ist in Peroxisomen nachweisbar (Kaczmarek et al. 2009). Bis heute ist es neben Pxtl das einzige keimzellspezifische Gen, das für ein putatives peroxisomales Protein bei männlichen Säugern kodiert. 


\subsubsection{Zur Funktion des Pxt1-Gens}

Mit in-silico-Analysen (http://pfam.sanger.ac.uk/) konnte am N-Terminus von PXT1 eine BH3(Bcl-2 Homology 3)-ähnliche Domäne, die für Proteine aus der BCL-2(B cell leukemia/lymphoma-2)-Familie charakteristisch ist, identifiziert werden. Mitglieder dieser Familie sind in die Regulation der Apoptose involviert (Adams und Cory 2001, Skommer et al. 2007). Gerade Proteinen, die nur die BH3-Domäne enthalten (BH3-only Proteine), wird eine apoptoseinduzierende Wirkung nachgesagt (Lomonosova und Chinnadurai 2008). Für die in-vivo-Analyse wurden ein transgenes Konstrukt (c-myc-Pxt1) und eine transgene Mauslinie hergestellt (Kaczmarek et al. 2011). Die adulten, männlichen, transgenen Tiere der P-Generation (Founder) waren infertil. Histologisch konnte man bei ihnen eine testikuläre Atrophie erkennen. Ein Spermatogenesearrest fand ab dem Stadium der pachytänen Spermatozyten statt. In den Tubuli seminiferi konnten wenige abnormale Spermien mit pyknotischer Kernmorphologie und einige kernhaltige Riesenzellen nachgewiesen werden. Bei den älteren Tieren steigerte sich die Anzahl an histologischen Veränderungen bis hin zu einem Sertoli-cell-only-Syndrom. Eine massive Vakuolisierung war histologisch in den Keimzellen zu sehen. Neben unreifen Keimzellen konnten im Lumen vereinzelt Riesenkernzellen nachgewiesen werden (Kaczmarek et al. 2011). Aufgrund der Infertilität der männlichen Founder-Tiere wurde die Linie über weibliche Founder etabliert. Im weiteren Verlauf wurde die testikuläre Histologie zu verschiedenen Zeitpunkten (10., 16., 26. und 28. dpp) der Spermatogenese bei den transgenen Männchen untersucht. Am 10. dpp ist die Histologie noch normal, ab dem 16. dpp (vor der meiotischen Teilung) sind wenige Abnormalitäten nachzuweisen. Ab dem 26. dpp entspricht das histologische Bild etwa dem bei den männlichen transgenen Foundern. Der Anzahl an apoptotischen Zellen aufgrund der testikulären Atrophie wurde mit einer TUNEL-Färbung quantifiziert. Ähnlich dem histologischen Bild war bei den transgenen Tieren im Vergleich zu den Wildtyp-Kontrollen am 10. und 16. dpp keine signifikante Anzahl an apoptotischen Zellen nachweisbar. Dieser Nachweis erfolgte erst ab dem 30. dpp (Kaczmarek et al. 2011).

Mit einem Fusionsprotein (E2-PXT1-BH3del), bei dem die BH3-Domäne deletiert ist, konnte das proapoptotische Potential dieser Domäne demonstriert werden. Transfizierte HeLa-Zellen mit dem deletierten BH3-Fusionsprotein zeigten unter dem Fluoreszenzmikroskop etwa 31\% degenerierte, Annexin-V-positive Zellen. Im Unterschied dazu zeigten Zellen, die ein komplettes PXT1-Protein exprimiert haben (E2-PXT1), 73\% degenerierte, Annexin-Vpositive Zellen (Kaczmarek et al. 2011). 
Mit Yeast-two-Hybrid(Y2H)-Analysen konnten zwei Interaktionspartner von PXT1 identifiziert werden. Zum einen interagiert es mit dem CCDC33-Protein (Kaczmarek 2009) und zum anderen konnte anhand dieser Methode eine Interaktion mit dem apoptoseregulierenden BAT3 (HLA-B-Associated Transcript 3)/Scythe (Thress et al. 1998, Sasaki et al. 2008, Tsukahara et al. 2009), einem Mitglied der BCL-2-Associated-Athanogene (BAG)-Familie, nachgewiesen werden (Kaczmarek et al. 2011). Für die Interaktion beider Proteine ist die Sequenz Leu-Ala-Pro-Phe (LAPF) an der Position 27-30 essentiell. CoLokalisationsstudien von EGFP-PXT1 und BAT3-dsRED zeigten, dass das normal punktförmig im Zytoplasma nachzuweisende PXT1 in Verbindung mit BAT3 im Nukleus transfizierter HeLa und NIH3T3 zu identifizieren ist (Kaczmarek et al. 2011). Bei diesen Zellen besteht eine normale Zellmorphologie ohne Apoptose.

\subsection{Organisation, Expression und Funktion des PXT1-Gens beim}

\section{Menschen}

In der NCBI-Datenbank konnte die Sequenz des humanen PXT1-Gens gefunden werden. Es ist auf dem Chromosom 6p21.31 (ID: 222659) lokalisiert. Diese chromosomale Position entspricht Chromosom 17 A3-B bei der Maus. Der Vergleich beider Sequenzen zeigt eine 74 \%ige Homologie. Die 1405 bp große menschliche cDNA von PXT1 setzt sich aus einem 30 bp langen 5'-UTR und einem 1222 bp langen 3'-UTR zusammen. Ebenso wie der ORF der Maus besteht der humane aus 153 bp, der für ein 51 Aminosäure langes Protein kodiert. Das entspricht etwa einer Größe von 6 kDa. Insgesamt erstreckt sich das humane PXT1-Gen über $10 \mathrm{~kb}$. Es setzt sich aus zwei Exons und einem Intron zusammen (Abb.1.2).

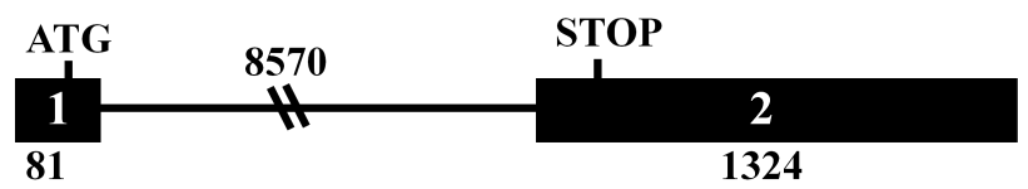

Abb. 1.2: Vollständige genomische Struktur des menschlichen PXT1 Gens

Die Abbildung zeigt die 2 Exons (1-2) anhand von schwarzen Boxen und das Intron mit einer horizontalen Linie. Die angegebenen Zahlen entsprechen der exakten Länge in bp. Des Weiteren sind die Start- (ATG) und Endpunkte (STOP) der Translation eingezeichnet. Das Gen umfasst eine Größe von $10 \mathrm{~kb}$. Entnommen und modifiziert aus Grzmil et al. (2007, S.76).

In der Abbildung 1.2 ist das Exon 1 mit einer Größe von 81 bp und das Exon 2 mit 1324 bp dargestellt. Beide Exons werden durch ein 8570 bp langes Intron unterbrochen. An der 
Position 31-33 der Nukleotidsequenz des Exon 1 befindet sich das Startkodon (ATG) und an Position 101-103 das Stopkodon (Preuss 2002, Grzmil et al. 2007). Analysen in den DNADatenbanken ließen einen cDNA-Klon BC031105 (IMAGE: 5297409) mit drei zusätzlichen Exons in 5'-Richtung finden, zu denen es aber keine wissenschaftliche Daten gibt. Des Weiteren gibt es bisher keine Informationen über die Expression und Funktion des humanen PXT1-Gens. Das einzige, was die Funktion des PXT1 erahnen lässt, ist die mittels SMARTAnalysen (http://smart.embl-heidelberg.de/) identifizierte BH3-ähnliche Domäne. Im 3'-UTR konnten mittels eines miRNA-Bindungsscanners (http://microrna.org) zwei putative miRNABindungsstellen identifiziert werden. Über eine Bindung von miRNA an bestimmte Bindungsstellen ist eine Regulation der Translation möglich (Vasudevan 2011).

\subsection{Ziele der vorliegenden Arbeit}

Bisher gibt es in der Literatur keine Informationen über die Expression und Funktion des humanen PXT1-Gens. Mausuntersuchungen haben gezeigt, dass dieses Gen für die Spermatogenese wichtig ist. Das proapoptotische Potential bei Überexpression konnte demonstriert werden. Beim Menschen könnte es eine ähnliche Rolle spielen und somit ein Kandidatengen für Mutationsanalysen bei Männern mit Fertilitätsstörungen, wie Oligo- oder Azoospermie, sein.

Für diese Arbeit ergaben sich folgende Fragestellungen:

1. Analyse der Expression der drei weiteren Exons von PXT1 in 5'-Richtung, die im cDNA-Klon BC031105 identifiziert wurden.

2. Expressionsanalyse des humanen $P X T 1$ in verschiedenen Geweben.

3. Untersuchung von DNA-Strangbrüchen in Spermienköpfen der Pxtl-Knockout-Maus, zur weiteren Analyse der Funktion von Pxt1.

4. Sequenzierung und Suche nach Mutationen im PXT1-Gen bei Patienten mit Fertilitätsstörungen (Azoo- und Oligozoospermie). 
Materialien und Methoden

\subsection{Materialien}

\subsubsection{Verwendete Nukleinsäuren}

\subsubsection{1 cDNA}

Für die Expressionsuntersuchung des humanen PXT1-Gens wurden folgende Kits der Firma Clontech Laboratories Incorporation verwendet:

Human MTC ${ }^{\mathrm{TM}}$ Panel I (cDNA Konzentration 1,0 ng/ $\left.\mu \mathrm{l}\right)$ :

$\begin{array}{lll}\text { Herz } & \text { Gehirn } & \text { Plazenta } \\ \text { Lunge } & \text { Leber } & \text { Skelettmuskel } \\ \text { Niere } & \text { Pankreas } & \end{array}$

Human MTC ${ }^{\mathrm{TM}}$ Panel II (cDNA Konzentration 1,0 ng/ $\left.\mu \mathrm{l}\right)$ :

$\begin{array}{lll}\text { Milz } & \text { Thymus } & \text { Prostata } \\ \text { Testis } & \text { Ovar } & \text { Intestinum/Mukosa } \\ \text { Colon } & \text { Leukozyten } & \end{array}$

\subsubsection{RNA}

Humane Testis-RNA mit der Konzentration $1 \mu \mathrm{g} / \mu \mathrm{l}$ wurde von der Firma Clontech Laboratories Incorporation bezogen.

\subsubsection{Mäusestämme für TUNEL-Analysen}

Zur Untersuchung von DNA-Strangbrüchen wurden Männchen von den Stämmen C57BL/6J, 129S1/SvImJ und die Knockout-Tiere für Pxt1 (Pxt1-Knockout-Maus) verwendet. Alle untersuchten Tiere stammen aus der Tierzucht des Instituts für Humangenetik, Göttingen. Sie werden unter kontrollierten Umweltbedingungen $\left(21^{\circ} \mathrm{C}, 12 \mathrm{~h}\right.$ Tag/12h Nacht-Zyklus $)$ mit freiem Zugang zu standardisiertem Futter und Wasser gehalten. Zum Zeitpunkt der Untersuchungen waren die Tiere mindestens zwei Monate alt und fortpflanzungsfähig. 


\subsubsection{Oligonukleotide}

Die verwendeten Primer stammten von der Firma „Eurofins MWG Operon“, Ebersberg. Die

Primerstocks $(100 \mathrm{pmol} / \mu \mathrm{l})$ wurden vorbereitet und bei $-20{ }^{\circ} \mathrm{C}$ gelagert.

Tab. 2.1: Genspezifische Primer für PXT1

\begin{tabular}{|c|c|}
\hline Name & Sequenz $5^{\prime}-3^{\prime}$ \\
\hline$\overline{\text { PXT1E1f }}$ & GCATCTGGCCAACCCTCTCATTTTC \\
\hline PXT1E1r & CCAAGTGTCTGAGATGCCCAGGAATT \\
\hline PXT1E2.1f & CAGAGGCGTTGTGAGGATATGACCA \\
\hline PXT1E2FP2new & TGACCATATGGAAGGTACTGTCC \\
\hline Pxt1E2FP2new2 & CATTGTGTTGAATTTTTAACTTTGGA \\
\hline Pxt1E2FP2new3 & CCTTTCTCTGTGTCTCCC \\
\hline PXT1E2.3r & GACCTGTTGGCTCCACTCTTGTCACT \\
\hline PXT1E2.4f & CTAAAGGCCACAGAAATGGGCACTAC \\
\hline PXT1E2.5r & TGCTATTATTGGTTGGTGGGCCCT \\
\hline PXT1E2.6f & GCCTGCTTAAAATCGGGAGTGCTTAG \\
\hline PXT1E2.7r & TCTGGCTGACTAGCCCTAAAACTGTC \\
\hline PXT1newExFP & AATGGGGGAAAGCCTCTG \\
\hline PXT1newExRP & ATAGCAAGAAAAACACATGCTAAGTAA \\
\hline PXT1newExRPb & GCAAGAAAAACACATGCTAAGTAAAC \\
\hline Pxt1newExRPc & CTATTTATCTTAGTTTAATCC \\
\hline hPXT1newEx1FP & AGTCACCCAGCGCTTCAC \\
\hline hPXT1newEx1RP & TTTTTGAATGCTGAAATCTTTTACTC \\
\hline hPXT1newEx2FP & ACCCACTGAGCCACCACAGA \\
\hline hPXT1newEx2RP & AGCGCAACACCATGTTTTAATGCAG \\
\hline hPXT1RTFP1 & GAACCCTGATCTCCCCATGC \\
\hline hPXT1RTFP1,5 & AAACAAAGCAAACAAAAGAGGGAAA \\
\hline hPXT1RTFP2 & GGCATACATGACCCAACTTGTCA \\
\hline hPXT1RTFP3 & TTGATCATAGGATGGTTCGAGAGG \\
\hline hPXT1RTRP1 & GAGGGAGACGGAGAAGGGTGT \\
\hline hPXT1qPCRFP1 & GAAGCATCACCAGGAGGAAA \\
\hline hPXT1qPCRRP1 & TTCTTCCCATCTGTCCCAGT \\
\hline hPXT1qPCRFP2 & CCCAAGGAGCATAGCATTGT \\
\hline hPXT1qPCRRP2 & TGCAGCAACACCTGAACTCT \\
\hline
\end{tabular}




\begin{tabular}{ll}
\hline hPXT1qPCRFP3 & CCCAAGGAGCATAGCATTGT \\
hPXT1qPCRRP3 & CAGCAAATGGTTGTTCCAGA \\
hPXT1RACERP1 & TGGCTGGGAGCTGACAAGTTGG \\
hPXT1RACERP2 & TGGGTCATGTATGCCTTCTGAAAACTG \\
qhPXT1E1FP & CTGAGTTGCGCATACCCTCT \\
qhPXT1E1RP & GGTAAGCATTAGCCGTCCTG \\
qhPXT1E1FP2 & CGAGGTTGGAGGTAGCGTAG \\
qhPXT1E1RP2 & CAGTAACTTGCTTCCGGTTGA \\
qhPXT1E1FP3 & GTAAATGGGTGTCGCCTTTC \\
qhPXT1E1RP3 & CCACATTTTCGGGTAAGCA \\
qhPXT1E2FP & CTTTATTTCGCAAGCCCAAG \\
qhPXT1E2RP & TCCAAGTATGTTGAGCCCTCTT \\
qhPXT1E3FP & GAAATGGGGGAAAGCCTCT \\
qhPXT1E3RP & TGGGTCATGTATGCCTTCTG \\
qhPXT1E4FP & CCCAAGGAGCATAGCATTGT \\
qhPXT1E4RP & AACTGAAGCCTCACCTCTCG \\
qhPXT1E5FP & TCCCATTTCCATGCCTAGAG \\
qhPXT1E5RP & GACTTGAAGGGGGTCACAGA \\
\hline
\end{tabular}

Tab. 2.2: Referenzprimer für die Real Time-PCR

\begin{tabular}{ll}
\hline Name & Sequenz $\mathbf{5}^{\prime} \mathbf{- 3}^{\prime}$ \\
\hline $1 \mathrm{p} 008-\mathrm{F}$ & TGCAGTTCCTCCGCTGGCCTCCACG \\
1p008-R & GGGTTTGCAGCTCTGCGCCTGGCAC \\
$3 \mathrm{p} 2-\mathrm{F}$ & AAGATGGGGATGCAGGGTGGGGAGA \\
$3 \mathrm{p} 2-\mathrm{R}$ & GGCAAGGACACTGGCTTAGGTGGCA \\
mhGAPDH-F & CATCACCATCTTCCAGGAGC \\
mhGAPDH-R & ATGACCTTGCCCACAGCCTT \\
hPBGD-F & GCAATGCGGCTGCAACGGCGGAAG \\
hPBGD-R & CCTGTGGTGGACATAGCAATGATT \\
hTBP-F & AGCCTGCCACCTTACGTCCAG \\
\hline hTBP-R & TGCTGCCTTTGTTGCTCTTCC \\
\hline
\end{tabular}


Tab. 2.3: Primer für die Sequenzierung von pGEM T-easy-Inserts

\begin{tabular}{ll}
\hline Name & ${\text { Sequenz } \mathbf{5}^{\prime} \mathbf{- 3}^{\prime}}^{\mathbf{x}^{\prime}}$ \\
\hline SP6 & TTCTATAGTGTCACCTAAAT \\
\hline T7 & TAATACGACTCACTATAGGG \\
\hline
\end{tabular}

Tab. 2.4: Sonden für die aCGH

\begin{tabular}{ll}
\hline Name & Sequenz 5'-3' \\
\hline Vorwärts & GTATTCTACAATTCCGAAAACTACTAACTTTTCCGTCT \\
& GCAACCTTTAATAATTGAGAGG \\
Rückwärts & CCTCTCAATTATTAAAGGTTGCAGACGGAAAAGTTAG \\
& TAGTTTTCGGAATTGTAGAATAC \\
\hline
\end{tabular}

\subsubsection{Bakterienstämme}

E. coli-K12 DH5 $\alpha$-kompetente Zellen Invitrogen, Karlsruhe

\subsubsection{Chemikalien}

$1 \mathrm{~kb}$ DNA ladder

100 bp DNA ladder

Agar-Agar

Agarose

Agilent Oligo aCGH Wash Buffer1 und 2

Ampicillin

Chlorophorm

DEPC

dNTPs

DTT $0,1 \mathrm{M}$

EDTA

Ethanol

Ethidiumbromid $(0,07 \%)$

IPTG
Invitrogen, Karlsruhe

Invitrogen, Karlsruhe

Carl Roth, Karlsruhe

Bio Budget, Krefeld

Agilent, Böblingen

Sigma-Aldrich Chemie, Taufkirchen

Sigma-Aldrich Chemie, Taufkirchen

Carl Roth, Karlsruhe

Invitrogen, Karlsruhe

Biomol, Hamburg

ICN Biomedicals, Eschwege

Carl Roth, Karlsruhe

Applichem, Darmstadt

Applichem, Darmstadt 
Isopropanol

Nagellack

Puffer P1

Puffer P2

Puffer P3

PBS

PFA $4 \%$

peqGOLD TRIFAST

Phenol

Proteinase K

SDS (Sodiumdodecylsulfat)

S.O.C. Medium

Steriles Wasser (Ampuwa)

SYBR Green ${ }^{\circledR}$

Tris (Trizma® Base)
J.T.Baker, Griesheim

Manhattan Cosmetics, Mainz

QIAGEN, Hilden

QIAGEN, Hilden

QIAGEN, Hilden

PAN, Aidenbach

Merck, Darmstadt

PEQLAB Biotechnologie, Erlangen

Biomol, Hamburg

Boehringer Mannheim, Mannheim

ICN Biomedicals, Eschwege

Invitrogen, Karlsruhe

Fresenius AG, Bad Homburg

Invitrogen, Karlsruhe

Sigma-Aldrich Chemie, Taufkirchen

Vectashield Mounting Medium with DAPI Vector Laboratories, Burlingame

$\mathrm{X}-\mathrm{Gal}$

Biomol, Hamburg

\subsubsection{Puffer und Lösungen}

dNTP-Mix

$$
\begin{aligned}
& 10 \text { mM dATP } \\
& 10 \text { mM dCTP } \\
& 10 \text { mM dGTP } \\
& 10 \text { mM dTTP }
\end{aligned}
$$

DNA -Ladepuffer

$50 \%$ (v/v) Glycerol

0,1 M EDTA

0,02\% (w/v) Xylencyanol

$0,02 \%(w / v)$ Bromphenolblau

$0,02 \%$ SDS 
EL-Puffer

SE-Puffer

Stoppmix

TBE-Puffer $(5 \mathrm{x})$
$10 \mathrm{mM} \mathrm{KHCO} 3$

$150 \mathrm{mM} \mathrm{NH}_{4} \mathrm{Cl}$

0,1 mM EDTA

pH 8,0.

$7,5 \mathrm{mM} \mathrm{NaCl}$

1 mM EDTA

mit $\mathrm{NaOH}$ auf $\mathrm{pH} 8,0$.

$95 \%(\mathrm{v} / \mathrm{v})$ Formamid

$50 \mathrm{mM}$ EDTA

$0,05 \%(w / v)$ Bromphenolblau

$0,05 \%$ (w/v) Xylenxyanol

$445 \mathrm{mM}$ Tris

445 mM Borsäure pH 8,0

10 mM EDTA.

\subsubsection{Gebrauchsfertige Reaktionssysteme (Kits)}

Agilent Genomic DNA Labeling Kit

Agilent Oligo aCGH Hybridization Kit

DYEnamic ET Terminator Cycle

Sequencing Kit (ET-Mix)

GeneRacer ${ }^{\mathrm{TM}}$ Kit

MSB Spin PCRapace (500)

pGEM®-T easy Vector System

QIAquick $^{\circledR}$ Gel Extraction Kit

ROCHE® In Situ Cell Death Detection

Kit Fluorescein

Sephadex G50

SurePrint-G3-Human -CGH Microarray-

Kits $4 \times 180$ k
Agilent, Böblingen

Agilent, Böblingen

GE Healthcare, München

Invitrogen, Karlsruhe

Invitek, Berlin

Promega, Mannheim

QIAGEN, Hilden

Boehringer Mannheim, Mannheim

GE Healthcare, München

Agilent, Böblingen 


\subsubsection{Enzyme und Enzymsets}

DNase I

Sigma-Aldrich, Taufkirchen

Ligasen:

T4 DNA Ligase+2xLigation Buffer Promega, Mannheim

T4 DNA Ligase+5xLigase Reaction

Buffer

Invitrogen, Karlsruhe

Polymerasen:

$\begin{array}{ll}\text { Immolase }^{T M} \text { DNA Polymerase } & \text { Bioline, Lückenwalde } \\ \text { Platinum }{ }^{\circledR} \text { Taq DNA Polymerase } & \text { Invitrogen, Karlsruhe }\end{array}$

Restriktionsendonukleasen:
Alu I
Promega, Mannheim
EcoR I
Invitrogen, Karlsruhe
Rsa I
Promega, Mannheim

Reverse Transkriptasen:

SuperScript ${ }^{T M}$ II Reverse

Transcriptase

Invitrogen, Karlsruhe

\subsubsection{Vektoren}

Mit dem pGEM T-easy-Kit der Mannheimer Promega GmbH erfolgte die Klonierung von PCR-Produkten. In diesem Vektor befindet sich ein Ampicillinresistenz-Gen. Mithilfe des LacZ-Operons ist eine Selektion zwischen blauen und weißen Kolonien auf IPTG/X-ßGalSelektionsplatten möglich. 
A:

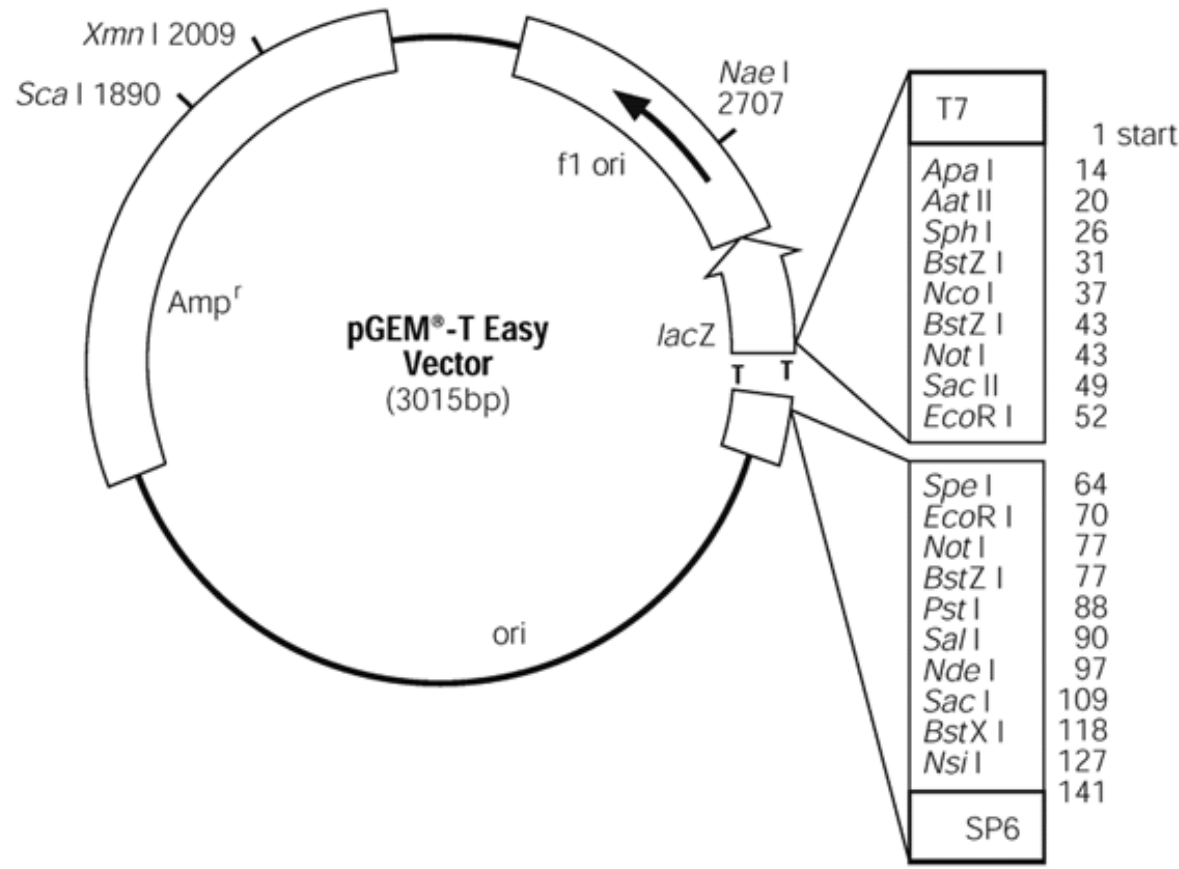

B:

T7 Transcription Start

5'... TGTAA TACGA CTCAC TATAG GGCGA ATTGG GCCCG ACGTC GCATG CTCCC GGCCG CCATG

$3^{\prime} \ldots$... ACATT ATGCT GAGTG ATATC CCGCT TAACC CGGGC TGCAG CGTAC GAGGG CCGGC GGTAC

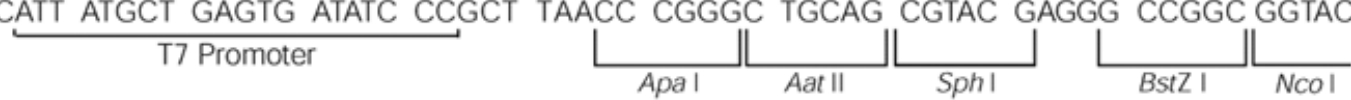

GCGGC CGCGG GAATT CGATT3'(cloned insert) ATCAC TAGTG AATTC GCGGC CGCCT GCAGG TCGAC CGCCG GCGCC CTTAA GCTA (cloned insert) 3'TTAGTG ATCAC TTAAG CGCCG GCGGA CGTCC AGCTG $\|_{\text {Not ILII }}^{\text {Sac II EcoRI }}$

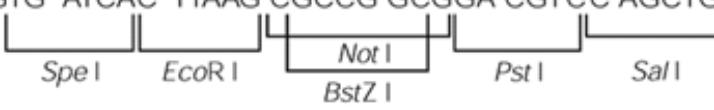

SP6 Transcription Start

CATAT GGGA GAGCT CCCAA CGCGT TGGAT GCATA GCTTG AGTAT TCTAT AGTGT CACCT AAAT . . . 3’ GTATA CCCT CTCGA GGGTT GCGCA ACCTA CGTAT CGAAC TCATA AGATA TCACA GTGGA TTTA . . . 5'

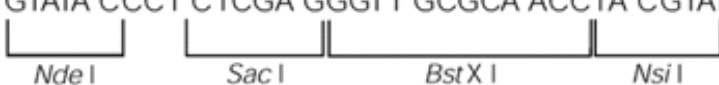
SP6 Promoter

Abb. 2.1: Darstellung des Vektors pGEM T-easy (Promega)

A: $\quad$ Vektorkarte mit den Sequenzreferenzpunkten

B: Darstellung der Promotorregion und der verschiedenen Klonierungssequenzen des Vektors pGEM T-easy. 


\subsubsection{Kulturmedien}

LB-Medium

$$
\begin{aligned}
& 0,5 \% \text { Hefeextrakt } \\
& 0,5 \% \text { Natriumchlorid } \\
& 1 \% \text { Pepton } \\
& \text { pH 7,2 mit Natriumhydroxid }
\end{aligned}
$$

Das Medium wurde autoklaviert und auf ca. $50^{\circ} \mathrm{C}$ herunter gekühlt. Es konnten nun Platten gegossen und die Zusätze hinzugefügt werden. Die Lagerung erfolgte jeweils bei $4^{\circ} \mathrm{C}$.

Agar-Platten

Selektionsantibiotikum

IPTG / X-Gal-Platten

\section{1,5-2 \% Agar-Agar in LB-Medium}

Ampicillin 50-100 $\mu \mathrm{g} / \mu 1$ in LB-Medium

$100 \mu \mathrm{M}$ IPTG

$0,4 \%$ X-Gal

$1,5 \%$ Agar-Agar

in Ampicillin-LB-Medium (Selektionsantibiotikum)

\subsubsection{Gebrauchswaren}

Verbrauchsmaterialien, die nicht steril geliefert wurden, wurden vor dem Gebrauch autoklaviert.

384-Loch-Platte

Deckgläser

E-Cups

EDTA-Röhrchen

Falkon

Färbeküvette

Flask

Kanülen

Millipore Amicon® Ultra $0,5 \mathrm{ml}$

Centrifugal Filters
ABGene Diamond Ultra, UK

Menzel, Braunschweig

Sarstedt, Nümbrecht

Sarstedt, Nümbrecht

Sarstedt, Nümbrecht

Aswerk, Werkheim

Greiner Bio-One, Frickenhausen

Sarstedt, Nümbrecht

Millipore, Schwalmbach 
Objektträger

PCR-Cups

Petrischale

Pipettenspitzen

Quarz-Küvette

Reaktionsgefäße
Menzel, Braunschweig

Sarstedt, Nümbrecht

Greiner Bio-One, Frickenhausen

Sarstedt, Nümbrecht

Hellma, Mühlheim

Eppendorf, Hamburg

Alle nicht gesondert aufgeführten Materialien wurden von den Firmen Schütt Labortechnik, Göttingen und Krannich, Göttingen, bezogen.

\subsubsection{Geräte}

ABI Prism® 7900HT Sequence

Detection System

PE Applied Biosystem, Hamburg

DNA Microarray Scanner

Agilent, Böblingen

Drucker (für Agarosegele) P91

Mitsubishi, Ratingen

Durchlichtmikroskop: Stemi SV 11

Krannich, Göttingen

Elektrophoresenetzgerät

Sarstedt, Langenhagen

Fluoreszenzmikroskop BX60

Olympus, München

Hybridization Oven

Agilent, Böblingen

Inkubator

Sanyo, München

Kamera (zur Aufnahme v. Agarosegelen)

Vilber Lourmat

Kühlschrank $4{ }^{\circ} \mathrm{C},-20^{\circ} \mathrm{C}$

Liebherr, Lindenberg (Allgäu)

Kühlschrank $-80^{\circ} \mathrm{C}$

Sanyo, München

Kühlzentrifuge

Sigma-Aldrich Chemie, Taufkirchen

Magnetrührer IKAMAG® RH

IKA® Labortechnik, Staufen

MegaBace 1000

Amersham Pharm. Biot., Freiburg

Mikrowelle Typ WP800 L20-2 III

Privileg, Stuttgart

NanoDrop (NP-1000 Spectrometer)

PEQLAB Biotechnologie, Erlangen

pH-Messgerät

Schütt Labortechnik, Göttingen

Photometer

Eppendorf, Hamburg

Pipettman Pipetten

Gilson, USA

Sterilbank HERAsafe

Heraeus, Hanau

Thermocycler: 
Primus 96 advanced

2720 Thermocycler

Thermomixer 5436

Tischzentrifuge 5415C

UV-Transilluminator

Vortexer

Waage CP3202 S

Wärmeschrank
PEQLAB Biotechnologie, Erlangen

Applied Biosystems, Weiterstadt

Eppendorf, Hamburg

Eppendorf, Hamburg

PEQLAB Biotechnologie, Erlangen

IKA Labortechnik, Staufen

Sartorius, Göttingen

Memmert, Schwabach

\subsubsection{Computeranalysen}

Die Informationen über Nukleotid- und Proteinsequenzen stammen aus der National Center for Biotechnology Information (NCBI)-Datenbank (http://www.ncbi.nlm.nih.gov) und aus der ENSEMBL-Datenbank (http://www.ensembl.org/index.html).

Die Auswertung der erhaltenen Sequenzen für das PXT1-Gen erfolgte mithilfe der SeqPilotSoftware (JSI Medical Systems GmbH).

Statistische Analysen wurden mit dem t-Test für unabhängige Gruppen durchgeführt. Dafür wurden die Daten, die ein Verhältnis darstellten, winkeltransformiert. Das Programm Statistica, v.9 (StatSoft, Tulsa, USA) wurde für diese Analysen angewendet.

\section{$2.2 \quad$ Methoden}

\subsubsection{Herkunft und Auswahl untersuchter DNA-Proben}

Das Institut für Humangenetik der Universität Göttingen besitzt eine Sammlung genomischer DNA-Proben von infertilen Patienten. Die Daten sind anonymisiert und für Forschungszwecke zugänglich. $\mathrm{Zu}$ den einzelnen DNA-Proben existieren lediglich die Diagnose und die Spermienparameter. Als Referenzen für die Analysen wurden mehrere DNA-Proben von Mitarbeitern des Instituts mit geprüfter Fertilität verwendet, die für die Untersuchung anonymisiert wurden. Die genomische DNA wurde jeweils aus Vollblut isoliert und bei $4{ }^{\circ} \mathrm{C}$ aufbewahrt.

Für die vorliegende Arbeit wurden Patienten mit Azoo- und Oligozoospermie, als auch mit dem OAT(Oligo-Astheno-Teratozoospermie)-Syndrom, ausgewählt.

Die DNA von insgesamt 55 Männern wurde untersucht. In der folgenden Tabelle 2.5 sind die einzelnen Diagnosen der analysierten Patienten zusammengefasst. Die Analysen wurden mit 
Zustimmung der Ethikkommission der Medizinischen Fakultät durchgeführt. Die Aktenzeichennummer lautet 26/3/10 An.

Tab. 2.5: Diagnose bei den untersuchten Patienten

\begin{tabular}{ll}
\hline Diagnose & Anzahl der untersuchten Proben \\
\hline Normozoospermie (WT, Kontrollen) & 4 \\
Azoospermie & 34 \\
Oligozoospermie und OAT & 21 \\
\hline
\end{tabular}

\subsubsection{Nukleinsäurepräparation}

\subsubsection{Isolierung von DNA aus Vollblut}

Das als Ausgangsmaterial dienende Leukozytenpellet (2.2.2.2.1) wurde zur Lyse in $5 \mathrm{ml}$ SEPuffer resuspendiert und anschließend mit $250 \mu 1$ Proteinase K $(10 \mathrm{mg} / \mathrm{ml})$ und $500 \mu 1$ SDS $(10 \%)$ versetzt. Die Inkubation erfolgte über Nacht bei einer Temperatur von $55{ }^{\circ} \mathrm{C}$. Zur Aussalzung der Proteine wurde am nächsten Tag nach der Abkühlung der Proben auf Raumtemperatur 1,5 ml gesättigte NaCl-Lösung hinzugegeben, $15 \mathrm{sec}$ gevortext und im Anschluss daran 15 min bei 3000 x g zentrifugiert. Der Überstand wurde in ein neues E-Cup überführt und mit $100 \%$ igem Ethanol versetzt. Die so ausgefällte DNA wurde nach erneuter Zentrifugation mit $500 \mu 170 \%$ igem Ethanol gewaschen und anschließend bei RT getrocknet. Das DNA-Pellet wurde in Ampuwa gelöst und bis zur weiteren Verwendung bei $4{ }^{\circ} \mathrm{C}$ gelagert.

\subsubsection{Vorbereitung der Zellen für die RNA-Isolation}

\subsection{Isolierung von Leukozyten aus Vollblut}

Für die Leukozytenseparation wurde Blut von einem anonymisierten Patienten abgenommen. Zur Lyse der Erythrozyten wurde das Blut mit $50 \mathrm{ml}$ Erythrozyten-Lysis-Puffer (EL-Puffer) versetzt. Nach 60-minütiger Inkubation auf Eis und Verwurf des Überstandes erfolgte ein 2maliger Waschschritt in je $10 \mathrm{ml}$ EL-Puffer $\left(10 \mathrm{~min}, 525 \mathrm{x} \mathrm{g}, 4^{\circ} \mathrm{C}\right)$. Am Ende wurde das Leukozytenpellet in $1 \mathrm{ml}$ EL-Puffer gelöst.

\subsection{Kultivierung von HeLa-Zellen}

Die HeLa-Zellen wurden in einer Gewebekulturflasche mit $10 \mathrm{ml}$ Zellkulturmedium (2.1.10) und bei $5 \%$ iger $\mathrm{CO}_{2}$-Begasung in feuchter Atmosphäre bei $37{ }^{\circ} \mathrm{C}$ im Brutschrank steril 
kultiviert. In einem Abstand von 3 Tagen wurden die proliferierenden Zellen geteilt. Das Nährmedium (Kulturmedium) wurde entfernt, die am Boden haftenden Zellen mit 10 ml PBS gewaschen und mit einem 1,5-ml-Trypsin/EDTA-Gemisch vom Boden gelöst. Von dieser Zellsuspension wurden jeweils $2 \mathrm{ml}$ in eine neue Zellkulturflasche transferiert.

Für die RNA-Isolierung wurden die Zellen kurz mit 5 ml PBS gewaschen, welches im Anschluss daran verworfen wurde.

\subsubsection{Isolierung von RNA aus HeLa-Zellen und Leukozyten}

$\mathrm{Zu}$ den Zellen (2.2.2.2.1, 2.2.2.2.2) wurde je $1 \mathrm{ml}$ peqGOLD TRIFAST hinzugegeben. Die HeLa-Zellen wurden mit einem Zellschaber von dem Kulturgefäß gelöst. Die Zellsuspension konnte in ein Reaktionsgefäß (E-Cup) überführt werden. Die Zugabe der folgenden Chemikalien erfolgte jeweils pro ml eingesetztem TRI-Reagenz, entsprechend dem Protokoll des Herstellers. Zuerst wurde die Zellsupension mit Hilfe eines Vortexers homogenisiert, bevor $200 \mu \mathrm{l}$ Chloroform hinzugefügt wurden. Es folgte eine Inkubation auf Eis für 5 min. Nach Zugabe von Chloroform wurde die Lösung kurz gevortext und anschließend für 15 min auf Eis inkubiert. Nach Zentrifugation wurde die obere Phase in ein neues E-Cup überführt und mit $500 \mu \mathrm{l}$ Isopropanol versetzt. Ein weiterer 10-minütiger Inkubationsschritt auf Eis folgte. Nachdem die Suspension für $10 \mathrm{~min}$ bei $12.000 \mathrm{x} \mathrm{g}$ und $4{ }^{\circ} \mathrm{C}$ zentrifugiert, der Überstand verworfen und das RNA-Pellet mit $1 \mathrm{ml} 75 \%$ EtOH $_{\text {DEPC }}$ gewaschen wurde, konnte nach weiterer Zentrifugation das Pellet zunächst bei RT trocknen und anschließend mit $30 \mu 1$ $\mathrm{H}_{2} 0_{\text {DEPC }}$ versetzt werden. Bevor eine Lagerung bei $-80{ }^{\circ} \mathrm{C}$ erfolgen konnte, wurde die in $\mathrm{H}_{2} 0_{\text {DEPC }}$ gelöste RNA abschließend für $10 \mathrm{~min}$ bei $55^{\circ} \mathrm{C}$ inkubiert.

\subsubsection{Konzentrationsbestimmung von Nukleinsäuren}

Die Bestimmung der Konzentration von Nukleinsäuren erfolgte mit dem Spektralphotometer der Firma Eppendorf. Anhand des Lambert-Beerschen-Gesetzes, welches die lineare Beziehung zwischen Absorption und Konzentration beschreibt, konnte die Absorption bei einer Wellenlänge von $260 \mathrm{~nm}$ gemessen werden. Die Messung wurde bei $260 \mathrm{~nm}, 280 \mathrm{~nm}$ und $320 \mathrm{~nm}$ Wellenlänge durchgeführt. Die Konzentrationsbestimmung erfolgte nach folgender Formel:

$$
\mathrm{C}[\mu \mathrm{g} / \mu \mathrm{l}]=\left(\mathrm{E}_{260}-\mathrm{E}_{320}\right) \times \mathrm{f} \times \mathrm{c}
$$


C - Konzentration der Probe

E - Extinktion

f - Verdünnungsfaktor

c - Konzentrationsfaktor:

$$
\begin{array}{ll}
\text { doppelsträngige DNA: } & \mathrm{c}=50 \mu \mathrm{g} / \mu \mathrm{l} \\
\text { einzelsträngige DNA: } & \mathrm{c}=33 \mu \mathrm{g} / \mu \mathrm{l} \\
\text { RNA: } & \mathrm{c}=40 \mu \mathrm{g} / \mu \mathrm{l}
\end{array}
$$

Als ein $\mathrm{Ma}$ für die Reinheit der Nukleinsäuren wird der Quotient aus $\mathrm{E}_{260} / \mathrm{E}_{280}$ verwendet. Er sollte für doppelsträngige DNA einen Wert von 2,0 $\pm 0,2$ ergeben.

\subsubsection{Polymerasekettenreaktion (PCR)}

Die PCR (Saiki et al. 1988) ist eine Methode, mit der man geringste Menge an genomischer DNA in vitro exponentiell vervielfältigen kann. Zunächst wird die DNA bei $95{ }^{\circ} \mathrm{C}$ denaturiert, d.h. die Doppelstränge werden getrennt. Ein bestimmter Bereich auf der DNA kann mithilfe von sequenzspezifischen Oligonukleotiden (Primer) synthetisiert werden. Diese binden an die flankierenden Sequenzen (forward (F) und reverse (R) Primer) des entsprechenden DNA-Fragmentes (Annealing). In Abhängigkeit von der Schmelztemperatur des Primers erfolgt dieser Schritt bei $50-65{ }^{\circ} \mathrm{C}$. Im Anschluss daran kann eine hitzestabile DNA-Polymerase mit einem Temperaturoptimum von $72{ }^{\circ} \mathrm{C}$ binden. Sie stammt z. B. von dem Archaebakterium Thermus aquaticus. Während der Elongation synthetisiert die Polymerase den komplementären Strang zu dem vorhandenen Einzelstrang. Die PCR besteht aus zahlreichen Zyklen, die sich jeweils aus Denaturierung, Annealing und Elongation zusammensetzen.

\subsubsection{PCR an genomischer DNA}

Ein Ansatz für die PCR besteht aus folgenden Reagenzien:

Genomische DNA

Primer F

Primer R

dNTPs

Reaktionspuffer

$\mathrm{MgCl}_{2}$ $\mathrm{x} \mu \mathrm{l}$

$0,5 \mu \mathrm{l}(10 \mathrm{pmol} / \mu \mathrm{l})$

$0,5 \mu \mathrm{l}(10 \mathrm{pmol} / \mu \mathrm{l})$

$0,5 \mu \mathrm{l}(\mathrm{je} 10 \mathrm{mM})$

$2,5 \mu 1$

$0,75 \mu 1$ 
$\begin{array}{ll}\text { Polymerase } & 0,2 \mu 1 \\ \mathrm{H}_{2} \mathrm{O} & \mathrm{x} \mu \mathrm{l}\end{array}$

Gesamtvolumen $\quad 25 \mu \mathrm{l}$

Verwendete Polymerasen: Immolase (Bioline)

Platinum Taq (Invitrogen)

Die PCR lief in einem Thermocycler bei folgendem Programm ab:

$\left.\begin{array}{lll}94{ }^{\circ} \mathrm{C} & \text { Denaturierung } & 4 \mathrm{~min} \\ 94{ }^{\circ} \mathrm{C} & \text { Denaturierung } & 30 \mathrm{sec}-1 \mathrm{~min} \\ 60-64{ }^{\circ} \mathrm{C} & \text { Annealing } & 30 \mathrm{sec}-1 \mathrm{~min} \\ 72{ }^{\circ} \mathrm{C} & \text { Elongation } & 30 \mathrm{sec}-1 \mathrm{~min} 30 \mathrm{sec} \\ 72{ }^{\circ} \mathrm{C} & \text { Elongation } & 3-5 \mathrm{~min} \\ 4{ }^{\circ} \mathrm{C} & \text { forever } & \end{array}\right\}$ 35 Zyklen

\subsubsection{RT-PCR}

Bei dieser Form der Polymerasekettenreaktion (Kogan et al. 1987) wird an der als Template dienenden mRNA mithilfe einer Reversen Transkriptase komplementäre cDNA synthetisiert, welche anschließend als Template für eine PCR-Reaktion (2.2.4.1) dient. Für die cDNASynthese wurde das Kit SuperScript ${ }^{\mathrm{TM}}$ II Reverse Transcriptase der Firma Invitrogen, Karlsruhe, verwendet.

RNA

Oligo-DT-Primer $(0,5 \mu \mathrm{g} / \mu \mathrm{l})$

dNTPs

$\mathrm{H}_{2} \mathrm{O}$

Gesamtvolumen
$2 \mu \mathrm{g}$

$1 \mu 1$

$1 \mu 1$

$\mathrm{x}$ ul

$13 \mu \mathrm{l}$

Für die Denaturierung und anschließenden Anlagerung des Oligo-DT-Primers an den Poly-ASchwanz der mRNA wurde der Ansatz für 5 min bei $65^{\circ} \mathrm{C}$ inkubiert. Nach einer 1-minütigen Inkubation auf Eis folgte ein Zentrifugationsschritt. Folgende Chemikalien wurden hinzugefügt: 
5x First Strand Puffer

DTT $0,1 \mathrm{M}$

Gesamtvolumen
$4 \mu 1$

$2 \mu 1$

$19 \mu \mathrm{l}$

Dieser Ansatz wurde für 2 min bei $42{ }^{\circ} \mathrm{C}$ inkubiert. Im Anschluss daran wurde das Enzym Reverse Transkriptase (Superscript II) hinzugefügt:

Superscript II

Gesamtvolumen
$1 \mu 1$

$20 \mu \mathrm{l}$

Das Enzym synthetisierte die cDNA bei einem Temperaturoptimum von $42{ }^{\circ} \mathrm{C}$ für $50 \mathrm{~min}$. In den meisten Fällen wurde eine Kontrolle, die als „-RT“ bezeichnet wurde, für die Spezifität dieser Reaktion parallel synthetisiert, bei der am Ende an Stelle des Enzyms Wasser zum Ansatz zugefügt wurde. Für $15 \mathrm{~min}$ und bei $70{ }^{\circ} \mathrm{C}$ wurde die Reverse Transkriptase inaktiviert, bevor die cDNA bei $-20{ }^{\circ} \mathrm{C}$ gelagert werden konnte.

Spezielle Fragmente können unter der Verwendung sequenzspezifischer Primer von diesem Produkt nach der unter 2.2.4.1 beschriebenen Methode amplifiziert werden.

\subsubsection{Sequenz-PCR}

Die Identifizierung einzelner Nukleotide eines DNA-Strangs erfolgte nach der Kettenabbruchmethode (Sanger et al. 1977). Sie wurde mit dem Mega Bace 1000 der Firma Amersham Pharm. Biot durchgeführt. Ähnlich einer PCR binden zunächst sequenzspezifische Primer an die vorher denaturierten DNA-Stränge. Im Unterschied zu einer herkömmlichen PCR werden fluoreszenzmarkierte ddNTPs in den komplementären Strang eingebaut. Diese ddNTPs besitzen keine 3’-Hydroxylgruppe. Es resultiert ein Abbruch der Strangsynthese mit unterschiedlich langen DNA-Fragmenten. Die Basenbestimmung erfolgt nach einer Elektrophorese aufgrund verschiedener Fluoreszenzen.

Für die Sequenzierung eines DNA-Fragmentes wurde folgender Reaktionsansatz hergestellt: 
Genspezifischer Primer

ET-Mix (DYEnamic ET Terminator

Cycle Sequencing Kit, GE

Healthcare)

$4 \mu 1$

$\mathrm{H}_{2} \mathrm{O}$

$\mathrm{x} \mu \mathrm{l}$

Gesamtvolumen $10 \mu \mathrm{l}$

Nach 2-minütiger Denaturierung bei $95{ }^{\circ} \mathrm{C}$ starteten folgende Reaktionsschritte:

$\left.\begin{array}{ll}94{ }^{\circ} \mathrm{C} & 20 \mathrm{sec} \\ 60{ }^{\circ} \mathrm{C} & 20 \mathrm{sec} \\ 60{ }^{\circ} \mathrm{C} & 3 \mathrm{~min}\end{array}\right\} \quad 30$ Zyklen

Am Ende erfolgte noch eine 3-minütige Elongation bei $60{ }^{\circ} \mathrm{C}$. Anschließend wurden die Proben mit $\mathrm{dH}_{2} \mathrm{O}$ auf $20 \mu \mathrm{l}$ verdünnt und in der SephadexG5-Säule zentrifugiert. Die Analyse der Sequenz erfolgte mit dem Mega Bace 1000 von Amersham Pharm. Biot. Sie war auch mit dem ABI Prism® 7900HT Sequence Detection System der Firma PE Applied Biosystem möglich.

\subsubsection{RACE-PCR}

Die RACE-PCR ermöglicht die komplette Amplifikation von 5'- und 3'- Enden einer mRNA. Dafür wurde das GeneRacer ${ }^{\mathrm{TM}}$ Kit von der Firma Invitrogen verwendet. Die Proben wurden nach Herstellerangaben behandelt. Alle aufgeführten Reagenzien waren im Kit enthalten.

\subsection{Dephosphorylierung der RNA}

Zunächst wurden die Proben mit Calf Intestinal Phosphatase (CIP) behandelt. Dieses Enzym bindet an die 5'-Position von nicht-mRNA (z. B. DNA Reste), wodurch diese dephosphoryliert und verkürzt werden. Normale mRNA-Moleküle mit einer Cap-Struktur am 5 '-Ende werden bei diesem Vorgang nicht gebunden. Der folgende 10- $\mu 1$-Ansatz wurde pipettiert: 
RNA

10x CIP Puffer

RNaseOut (40 U/ $\mu \mathrm{l})$

CIP $(10 \mathrm{U} / \mu \mathrm{l})$

$\mathrm{H}_{2} 0_{\text {DEPC }}$

Gesamtvolumen
$2,5 \mu 1$

$1 \mu 1$

$1 \mu 1$

$1 \mu 1$

$4,5 \mu 1$

$10 \mu \mathrm{l}$

Nach Vermischen des Reaktionsansatzes wurde dieser für $1 \mathrm{~h}$ bei $50{ }^{\circ} \mathrm{C}$ inkubiert.

\subsection{RNA-Aufreinigung}

Zur Reinigung der RNA wurden $90 \mu \mathrm{H}_{2} 0_{\text {DEPC }}$ und $100 \mu 1$ Phenol:Chloroform hinzugefügt und vermischt. Nach einer Zentrifugation bei maximaler Geschwindigkeit (Kühlzentrifuge, Sigma-Aldrich) für $5 \mathrm{~min}$ bei RT wurde die obere, wässrige Phase in ein neues E-Cup überführt. $2 \mu 1$ 10-mg/ml-,,mussel“-(Muschel)-Glykogen und $10 \mu 13$ M Natriumacetat (pH 5,2) wurden $\mathrm{zu}$ dieser Phase hinzugegeben. Anschließend wurden $220 \mu 195 \%$ Ethanol hinzugefügt und kurz gevortext. Auf Trockeneis wurden die Proben für 10 min durchgefroren. Zur Herstellung eines Pellets wurde der Ansatz bei maximaler Geschwindigkeit für 20 min bei $4{ }^{\circ} \mathrm{C}$ zentrifugiert. Das Pellet wurde anschließend in $500 \mu 170 \%$ Ethanol geschwenkt und kurz gevortext. Nach nochmaligem Zentrifugieren (maximale Geschwindigkeit, 2 min, $4{ }^{\circ} \mathrm{C}$ ) konnte das überschüssige Ethanol abgenommen werden. Für 2 min wurde das Pellet bei RT getrocknet und am Ende in $7 \mu 1 \mathrm{H}_{2} 0_{\text {DEPC }}$ resuspendiert.

\subsection{Entfernung der CAP-Struktur}

Bei diesem Arbeitsschritt wurde die CAP-Struktur der mRNA entfernt. In den vorangegangenen Schritten (2.2.4.4.1) wurden die verkürzten und nicht-mRNA Nukleinsäuren dephosphoryliert. In dieser Form sind sie für die weiteren Reaktionsschritte nicht zugänglich.

Mit Hilfe der Tobacco Acid Pyrophosphatase (TAP) wurde die CAP-Struktur am 5'-Ende der „vollständigen“ mRNA entfernt. Die Phosphatgruppe der TAP blieb am 5'-Ende dieser mRNA-Fragmente gebunden.

Der folgende $10-\mu l$-Ansatz wurde in ein neues 1,5 ml-E-Cup pipettiert: 
Dephosphorylierte RNA $\quad 7 \mu 1$

10x TAP Puffer $\quad 1 \mu \mathrm{l}$

RNaseOut $(40 \mathrm{U} / \mu \mathrm{l}) \quad 1 \mu \mathrm{l}$

$\operatorname{TAP}(0,5 \mathrm{U} / \mu \mathrm{l}) \quad 1 \mu \mathrm{l}$

Gesamtvolumen $\quad 10 \mu \mathrm{l}$

Eine 1-stündige Inkubation bei $37^{\circ} \mathrm{C}$ folgte nach dem Vermischen des Reaktionsansatzes. Für den nächsten Arbeitsschritt (2.2.4.4.4) musste die RNA nach dem unter 2.2.4.4.2 beschriebenen Schritt erneut aufgereinigt werden.

\subsection{Ligation eines RNA-Oligonukleotids an die mRNA nach der Entfernung der CAP-Struktur}

In die aliquotierten, lyophyhilisierten GeneRacer RNA-Oligonukleotide (Adaptoren) $(0,25$

$\mu \mathrm{g})$ wurden $7 \mu \mathrm{l}$ der dephosphorylierten RNA nach Entfernung der Cap-Struktur (2.2.4.4.3) hinzugefügt und vermischt. Zur Auflösung der Sekundärstruktur der RNA wurde der Ansatz für 5 min bei $65^{\circ} \mathrm{C}$ inkubiert und anschließend auf Eis für 2 min abgekühlt. Weitere Reagenzien wurden hinzugefügt:

$\begin{array}{ll}\text { mRNA (nach Entfernung des CAPs) } & 6 \mu \mathrm{l} \\ \text { 10x Ligase Puffer } & 1 \mu \mathrm{l} \\ 10 \text { mM ATP } & 1 \mu \mathrm{l} \\ \text { RNaseOut }(40 \mathrm{U} / \mu \mathrm{l}) & 1 \mu \mathrm{l} \\ \text { T4 RNA Ligase } & 1 \mu \mathrm{l} \\ \text { Gesamtvolumen } & \mathbf{1 0} \boldsymbol{\mu l}\end{array}$

Für $1 \mathrm{~h}$ wurde das Gemisch bei $37{ }^{\circ} \mathrm{C}$ inkubiert. Nach kurzer Zentrifugation wurden die Proben auf Eis gestellt, danach erfolgte die Aufreinigung nach der Beschreibung unter 2.2.4.4.2. 


\subsection{Reverse Transkription}

Die cDNA-Synthese erfolgte mittels Reverser Transkription (laut Herstellerangaben). Als Enzym wurde SuperScript III RT verwendet, welches im GeneRacer ${ }^{\mathrm{TM}}$ Kit von Invitrogen enthalten ist.

Folgende Reagenzien wurden zu den $7 \mu$ l der ligierten RNA hinzugefügt:

$\begin{array}{ll}\text { Genspezifischer Primer } & 1 \mu \mathrm{l} \\ \text { dNTP Mix } & 1 \mu \mathrm{l} \\ \mathrm{ddH}_{2} \mathrm{O} & 1 \mu \mathrm{l}\end{array}$

\section{Gesamtvolumen $\quad 10 \mu \mathrm{l}$}

Um die Sekundärstruktur aufzulösen, wurde der Ansatz bei $65{ }^{\circ} \mathrm{C}$ für 5 min inkubiert. Nachdem die Probe für 1 min auf Eis abgekühlt worden war, wurden weitere Reagenzien zum Ansatz hinzugefügt:

5x First Strand Puffer $\quad 4 \mu 1$

0,1 M DTT $1 \mu 1$

RNase Out $(40 \mathrm{U} / \mu \mathrm{l}) \quad 1 \mu \mathrm{l}$

SuperScript III RT $(200 \mathrm{U} / \mu \mathrm{l}) \quad 1 \mu \mathrm{l}$

Gesamtvolumen $\quad 17 \mu \mathrm{l}$

Der Reaktionsansatz wurde für $60 \mathrm{~min}$ bei $50{ }^{\circ} \mathrm{C}$ inkubiert. Bei der Verwendung von genspezifischen Primern wurde die Reaktionstemperatur auf $55{ }^{\circ} \mathrm{C}$ erhöht. Im Anschluss wurde die Reverse Transkriptase für $15 \mathrm{~min}$ bei $70{ }^{\circ} \mathrm{C}$ inaktiviert. Nach 2-minütiger Abkühlung des Ansatzes auf Eis erfolgte ein Zentrifugationsschritt bei maximaler Geschwindigkeit für 5 sec. $1 \mu$ l RNase $H$ wurde zum Reaktionsansatz hinzugegeben und für 20 min bei $37{ }^{\circ} \mathrm{C}$ inkubiert.

\subsection{Amplifikation der cDNA-Enden}

Die cDNA-Enden konnten jetzt mit Platinum Taq DNA-Polymerase von der Firma Invitrogen amplifiziert werden. Für diese Arbeit wurde die Amplifikation in 5'-Richtung verwendet.

Der folgende Reaktionsansatz wurde zur Amplifikation zusammenpipettiert: 
GeneRacer 5'Primer, $10 \mu \mathrm{M} \quad 3 \mu \mathrm{l}$

Reverse (genspezischer) Primer $1,10 \mu \mathrm{M} 1 \mu \mathrm{l}$

RT Template $\quad 1 \mu \mathrm{l}$

10x PCR Rxn Puffer $\quad 5 \mu 1$

dNTP Mix $1 \mu \mathrm{l}$

Platinum Taq DNA-Polymerase $\quad 0,5 \mu 1$

$\mathrm{MgCl}_{2}$

$\mathrm{ddH}_{2} \mathrm{O} \quad 37 \mu \mathrm{l}$

Gesamtvolumen $\quad 50 \mu \mathrm{l}$

Bei den dargestellten Zyklustemperaturen verlief die Reaktion:

\begin{tabular}{|c|c|c|}
\hline $94{ }^{\circ} \mathrm{C}$ & $2 \mathrm{~min}$ & \\
\hline $94{ }^{\circ} \mathrm{C}$ & $30 \mathrm{sec}$ & 5 Zyklen \\
\hline $72^{\circ} \mathrm{C}$ & $3 \mathrm{~min}$ & \\
\hline $94{ }^{\circ} \mathrm{C}$ & $30 \mathrm{sec}$ & 5 Zyklen \\
\hline $70^{\circ} \mathrm{C}$ & $3 \mathrm{~min}$ & \\
\hline $94{ }^{\circ} \mathrm{C}$ & $30 \mathrm{sec}$ & \\
\hline $64^{\circ} \mathrm{C}$ & $30 \mathrm{sec}$ & 25 Zyklen \\
\hline $72^{\circ} \mathrm{C}$ & $3 \mathrm{~min}$ & \\
\hline $68^{\circ} \mathrm{C}$ & $10 \mathrm{~min}$ & \\
\hline
\end{tabular}

Zur Kontrolle der Reaktionsergebnisse wurden $10 \mu \mathrm{l}$ des Produktes auf ein $1 \%$-iges Agarosetestgel aufgetragen und mittels Standard-Gelelektrophorese (2.2.6) analysiert. Beim Erhalt einer einzelnen Bande - eines Genprodukts konnte das Produkt nach der Aufreinigung des Gels mittels Sequenz-PCR (2.2.4.3) analysiert werden. Waren mehrere Bande oder ein DNA-Schmier vorhanden, erfolgte eine Nested-PCR (2.2.4.4.7) mit genspezifischen Primern, um Verunreinigungen auszuschalten.

\subsection{Nested-PCR}

Das PCR-Produkt wurde nach dem unter 2.2.5 beschriebenen Protokoll aufgereinigt. Das Eluat wurde im Verhältnis 1:50 verdünnt. $1 \mu \mathrm{l}$ der Probe wurde für die Nested-PCR verwendet. Die Polymerasekettenreaktion erfolgte nach dem PCR-Ansatz von 2.2.4.4.6. Jedoch wurde anstelle der Platinum-Taq-DNA-Polymerase Immolase Taq verwendet. 
Nach folgendem Programm erfolgte die PCR:

$\begin{array}{ll}94{ }^{\circ} \mathrm{C} & 2 \mathrm{~min} \\ 94{ }^{\circ} \mathrm{C} & 30 \mathrm{sec} \\ 65{ }^{\circ} \mathrm{C} & 30 \mathrm{sec} \\ 68^{\circ} \mathrm{C} & 2 \mathrm{~min} \\ 68{ }^{\circ} \mathrm{C} & 10 \mathrm{~min}\end{array}$

Bei diesem Reaktionsschritt wurden unspezifische Produkte nicht amplifiziert, man erhielt aufgrund der GSP (genspezifischen Primer) ein spezifisches Produkt. Der Ansatz wurde anschließend komplett auf ein 1,5 \%iges Gel aufgetragen und einer Elektrophorese (2.2.6) unterzogen. Mittels Gelextraktion (2.2.7) wurde das amplifizierte Produkt isoliert und in den Vektor pGEM T-easy (2.2.8) kloniert. In kompetenten Bakterien wurde dieser Vektor (2.2.9) vermehrt, die Plasmid-DNA durch Mini-Präparation (2.2.10) isoliert und letztendlich sequenziert (2.2.4.3).

\subsubsection{Real Time-PCR mit dem ABI Prism ${ }^{\circledR}$ 7900HT Sequence Detection System}

Die Methode der Real Time-PCR ermöglicht die Quantifizierung amplifizierter DNAMengen. Während der Elongation bindet der Fluoreszenzfarbstoff SYBR Green in der doppelsträngigen DNA. Mithilfe eines Lasers wird dieser Fluoreszenzfarbstoff angeregt, der daraufhin ein quantifizierbares Signal emittiert. Das Fluoreszenzsignal wird über das ABI Prism ${ }^{\circledR}$ 7900HT Sequence Detection System detektiert. Daher eignet sich das Verfahren sehr gut, um die Menge der PCR-Produkte sichtbar zu machen (Morrison et al. 1998). Nach jedem Reaktionszyklus erfolgt eine Messung und die Amplifikationsergebnisse werden graphisch dargestellt. Im Vergleich zur Bindung an Einzelstrang-DNA fluoresziert SYBR-Green stärker, wenn es in doppelsträngiger DNA gebunden ist. Somit kann man in Echtzeit die Zunahme des PCR-Produktes verfolgen. Ebenso ist auf diese Weise eine Kontrolle des Reaktionszyklusses möglich. Unspezifische Produkte wie z. B. Primer-Dimere, können mithilfe einer Dissoziationskurve nachgewiesen werden. Die Fluoreszenz (F) wird bei langsam ansteigender Temperatur ( $\mathrm{T}$ ) gemessen und die Steigung dF/dT-Wert, das ist die 1. Ableitung, errechnet. Diese 1. Ableitung wird gegen die Reaktionstemperatur aufgetragen und das Maximum der 
speziellen Schmelztemperatur des Produktes veranschaulicht. Weitere Maxima weisen auf unspezifische Produkte hin.

Die Auswertung der Messergebnisse wurde mit der Sequenz-Detectionsystem-Software (SDS Version 2.1, PE Applied Biosystems) durchgeführt, exportiert und mittels Microsoft ExcelTabellenkalkulation ausgewertet. Pro Ansatz wurden folgende Reagenzien pipettiert:

$\begin{array}{ll}\text { SYBR Green } & 5 \mu \mathrm{l} \\ \text { Primer F+R } & 0,8-2,5 \mu \mathrm{l} \\ \text { DNA } & 2-2,5 \mu \mathrm{l} \\ \mathrm{ddH}_{2} \mathrm{O} & 0-2,2 \mu \mathrm{l} \\ \text { Gesamtvolumen } & \mathbf{1 0} \boldsymbol{\mu l}\end{array}$

Folgendes Programm wurde für diese Reaktion verwendet:

$\left.\begin{array}{ll}50{ }^{\circ} \mathrm{C} & 2 \mathrm{~min} \\ 95{ }^{\circ} \mathrm{C} & 2 \mathrm{~min} \text { (Vordenaturierung) } \\ 95{ }^{\circ} \mathrm{C} & 15 \mathrm{sec} \\ 50-60{ }^{\circ} \mathrm{C} & 30 \mathrm{sec} \\ 72{ }^{\circ} \mathrm{C} & 30 \mathrm{sec} \\ 95{ }^{\circ} \mathrm{C} & 15 \mathrm{sec} \\ 60{ }^{\circ} \mathrm{C} & 15 \mathrm{sec} \text { (Schmelzkurve) } \\ 95{ }^{\circ} \mathrm{C} & 15 \mathrm{sec}\end{array}\right\}$ 40 Zyklen

\subsection{Relative Quantifizierung mittels $\Delta \Delta \mathrm{C}_{\mathrm{T}}$-Methode}

Im Rahmen der Expressionsanalyse wurden verschiedene cDNA-Proben aus humanen Geweben auf die Existenz von PXT1 untersucht, wobei endogene Kontrollen verwendet wurden. Die Resultate, welche keine absoluten Werte darstellen, verweisen auf das Verhältnis der verschiedenen cDNA-Proben zueinander, indem die einzelnen Expressionen verglichen werden.

Bei diesem Versuch wurde die Expression des PXT1-Gens in verschiedenen humanen Geweben untersucht. Das Ausgangsmaterial war cDNA aus RNA von humanem Testis. Um eventuelle Unterschiede in den angesetzten cDNA-Mengen ausgleichen zu können, wurden „Housekeeping“-Gene als Referenzen verwendet. Um die Amplifikations-Effizienz der Referenzgene und des PXT1-Gens bestimmen und vergleichen zu können, wurde zunächst 
eine Verdünnungsreihe, bei der 1/5 der cDNA verwendet wurde, angefertigt. Von allen getesteten Referenzgenen waren $P B G D$ und $G A P D H$ dem Expressionsmuster von $P X T 1$ am ähnlichsten.

Zur Vergleichbarkeit der Daten wurde bei der Auswertung ein Schwellenwert festgelegt. Dieser wird als $\mathrm{C}_{\mathrm{T}}-$ Wert (cycle threshold/Schwellenzyklus) bezeichnet. An diesem Punkt im Zyklus erreicht das Fluoreszenzsignal einer Amplifikation eine Intensität, die $\Delta \mathrm{Rn}=1.0$ entspricht. Da an diesem Punkt die Amplifikationskurve einen linearen Anstieg besitzt, wird dieser $\Delta \mathrm{Rn}$-Wert als $\mathrm{C}_{\mathrm{T}}$ festgelegt. An dieser Position ist der $\mathrm{C}_{\mathrm{T}}$-Wert proportional zur Menge der cDNA-Kopien am Anfang der Reaktion.

Um die Expression von PXT1 in den einzelnen Geweben bestimmen zu können, wurden folgende Formeln zur Berechnung verwendet:

1. $\Delta \mathrm{C}_{\mathrm{T}(\mathrm{GAPDH})}=\mathrm{C}_{\mathrm{T}}(\mathrm{PXT1}$ Gewebe $)-\mathrm{C}_{\mathrm{T}}($ Gewebe $\mathrm{GAPDH})$

2. $\Delta \mathrm{C}_{\mathrm{T}(P B G D)} \quad=\mathrm{C}_{\mathrm{T}}(P X T 1$ Gewebe $)-\mathrm{C}_{\mathrm{T}}($ Gewebe $P B G D)$

3. Mean $\Delta \mathrm{C}_{\mathrm{T}}=\left(\Delta \mathrm{C}_{\mathrm{T}(\mathrm{GAPDH})}+\Delta \mathrm{C}_{\mathrm{T}(P B G D)}\right) / 2$

4. Quantity $\quad=2^{(- \text {mean } \Delta C T)}$

\subsection{Absolute Quantifizierung}

Zur Analyse der Kopienanzahl eines genomischen Abschnittes wurde die Absolute Quantifizierung verwendet. Für diese Auswertung wurde für jeden Lauf eine Verdünnungsreihe von einer Kontrolle (eine Probe eines gesunden, fertilen, männlichen Individuums) angefertigt. Folgende Endkonzentrationen wurden verwendet: 2,5 ng/ $\mu 1,1,25$ $\mathrm{ng} / \mu 1,0,625 \mathrm{ng} / \mu \mathrm{l}$ und 0,3125 ng/ $\mu \mathrm{l}$. Die Proben wurden bei einer Konzentration von 2,5 ng/ $\mu 1$ untersucht. Zusätzlich zu den genspezifischen Primern wurden die Standardprimer 3p2 und 1p008 (die Namen der Primer entsprechen der chromosomalen Lokalisationen) verwendet. Für alle Primer galten die gleichen Bedingungen.

Zunächst wurde mithilfe der Kontroll-DNA eine Standardkurve angefertigt und der $\mathrm{C}_{\mathrm{T}}$-Wert berechnet. Eine absolute Quantifizierung war durch die lineare Interpolation in der halblogarithmischen Standardkurven-Darstellung möglich. Die Messung des $\mathrm{C}_{\mathrm{T}^{-}}$-Wertes war für die Auswertung erforderlich $\left(c_{t}\right.$ gegen $\left.\log \left(c_{0}\right)\right)$. Die erhaltenen Ergebnisse wurden in die Excel-Tabellenkalkulation exportiert. Die absoluten Konzentrationen wurden gegen disome Referenz-Amplikons normalisiert (Boehm et. al. 2004). Dabei wurde das Verhältnis $\mathrm{c}_{\text {Testamplikon }} / \mathrm{c}_{\text {Referenzamplikon }}$ berechnet. Ein Verhältnis von 1,0 entspricht dem eines normalen, 
diploiden Genotyps. Werte von 0,5 sprechen nach diesen Berechnungen für eine Deletion und ein Wert von ungefähr 1,5 oder höher verweist auf eine Duplikation.

\subsubsection{Aufreinigung von PCR-Produkten}

Um das PCR-Produkt von überschüssigen Nukleotiden, Primern und anderen Zusätzen, wie z.B. Salzen oder Enzymen, zu reinigen, kam das Kit von Invitek MSB Spin PCRapace zum Einsatz. 20-25 $\mu$ l PCR-Produkt wurden für diese Methode verwendet. Mit entsprechenden Puffern des Reaktionskits erfolgte dieser Reinigungsschritt laut Herstellerangaben. Am Ende wurde die im Filter gebundene DNA mit $15 \mu \mathrm{H}_{2} \mathrm{O}$ gelöst. $1 / 10$ des Eluats wurde anschließend gelelektrophoretisch (2.2.6) analysiert.

\subsubsection{Standard-Agarose-Gelelektrophorese}

Mittels dieser Methode wurden DNA-Fragmente aufgrund ihrer negativen Ladung und ihrer Länge im elektrischen Feld aufgetrennt. Die Konzentration des verwendeten Gels lag je nach Länge des DNA-Fragmentes zwischen $1 \%$ und $2 \%$. Zur Herstellung des Gels wurden zunächst die entsprechende Menge Agarose mit 0,5x-TBE-Puffer aufgekocht, mit einem Tropfen 0,07 \%igem Ethidiumbromid versetzt und in eine Gelkammer gegossen. Die Proben wurden mit einem Stopp-Mix versetzt, bevor sie in die Geltaschen aufgetragen werden konnten. Bei einer konstanten Spannung von 70-120 V trennten sich die DNA-Fragmente aufgrund ihrer Länge im elektrischen Feld auf. Bei einer Wellenlänge von 254 nm bzw. 312 nm konnten unter einem UV-Transilluminator die DNA-Fragmente sichtbar gemacht und dokumentiert werden.

\subsubsection{Isolierung von DNA-Fragmenten aus den Agarosegelen}

Unter der Verwendung des QIAquick Gel Extraction-Kits war es möglich, die DNAFragmente aus einem Agarosegel zu extrahieren. Die extrahierte DNA war dann für weitere Experimente, wie z. B. Klonierung oder Sequenzierung zugänglich.

Entsprechend dem Gewicht des Gelfragments wurden die DNA laut Angaben der Hersteller mit den im Kit enthaltenen QG- und PE-Puffern über verschiedene Löse-, Wasch- und Zentrifugationsschritte vom dem Agarosegel befreit. Am Ende wurde die DNA in $30 \mu 1 \mathrm{H}_{2} 0$ aufgenommen. In der Regel wurden $2 \mu$ des Extraktes per Gelelektrophorese (2.2.6) überprüft. 


\subsubsection{Ligation von DNA-Fragmenten}

Bevor DNA-Fragmente mithilfe von Bakterien vermehrt werden konnten, mussten sie zunächst in einem Vektor kloniert werden. Das Plasmid pGEM T-easy von der Firma Promega diente dabei als Vektor. Die Klonierung basiert in diesem Fall auf der Tatsache, dass eine Taq Polymerase immer ein Adenin am Ende des neusynthetisierten Stranges anhängt. Das pGEM T-easy-Plasmid hat ein freies Thymidin, das komplementär zur Adenin ist. Das zu ligierende DNA-Fragment wird bei einer katalytischen Reaktion mithilfe der enthaltenen T4 Ligase durch eine kovalente Bindung in den Vektor eingefügt. Im Reaktionsansatz waren folgende Komponenten enthalten:

Insert

5x Ligase Puffer

T4 Ligase

pGEM T-easy

$\mathrm{H}_{2} \mathrm{O}$

Gesamtvolumen $\mathrm{x} \mu \mathrm{l}$

$4 \mu 1$

$1 \mu 1$

$0,5 \mu 1$

$\mathrm{x} \mu \mathrm{l}$

$20 \mu \mathrm{l}$

Dieses Gemisch wurde über Nacht bei $4{ }^{\circ} \mathrm{C}$ inkubiert.

\subsubsection{Transformation}

Nach der Integration eines Inserts in einen Vektor (2.2.8) konnte dieses von Bakterien aufgenommen werden.

5-20 $\mu \mathrm{l}$ des Ligationsansatzes (2.2.8) wurden zu $50 \mu 1$ kompetenten E.coli-Bakterien des DH5 $\alpha$-Stamms hinzugefügt und vermischt. Nach einer 15-minütigen Inkubation auf Eis erfolgte ein Hitzeschock für $45 \mathrm{sec}$ bei $42{ }^{\circ} \mathrm{C}$. Bevor $300 \mu \mathrm{l}$ des vorgewärmten S.O.C.Mediums, hinzugefügt und für $1-1,5 \mathrm{~h}$ bei $37^{\circ} \mathrm{C}$ vermischt werden konnte, wurde der Ansatz für 2 min auf Eis gekühlt. Jeweils $50 \mu 1$ und $150 \mu 1$ der Bakteriensuspension wurden auf LB-Platten ausgestrichen, die zusätzlich Ampicillin, IPTG und X-Gal enthielten. Aufgrund dieser Zusätze war am nächsten Tag, eine Blau/Weiß-Selektion möglich. In den blauen Kolonien induziert IPTG die ß-Galactosidase, wodurch das Produkt von X-Gal umgesetzt wird. Hingegen ist in den weißen Kolonien bei erfolgreicher Ligation das LacZGen im Vektor durch das integrierte Insert zerstört. Das Gen kann nicht abgelesen werden. Aus diesem Grund entsteht kein blauer Farbstoff. 


\subsubsection{Isolierung von kleinen Plasmid-DNA-Mengen (Minipräparation)}

Von den mit Bakterien bewachsenen Agarplatten (2.2.9) wurde je eine weiße Kolonie in $5 \mathrm{ml}$ LB-Medium + Ampicillin über Nacht in einem Schüttler bei $37^{\circ} \mathrm{C}$ inkubiert.

Die Übernachtkultur wurde abzentrifugiert (10 min, $1.350 \mathrm{x} \mathrm{g}$ und $\left.4{ }^{\circ} \mathrm{C}\right)$, das Bakterienpellet mit $200 \mu \mathrm{l}$ des kalten, RNase-haltigen P1-Puffers resuspendiert und $200 \mu 1$ P2-Puffer zur Bakterienlyse hinzugegeben. Die Beendigung der Lyse erfolgte durch die Zugabe von $200 \mu 1$ P3 Puffer. Nach Zentrifugation für $10 \mathrm{~min}$, bei $14.200 \mathrm{x}$ g und RT wurde der Überstand in ein neues Reaktionsgefäß überführt und $1 \mathrm{ml}$ Isopropanol hinzugegeben. Ein weiterer Zentrifugationsschritt folgte (30 min, $14.200 \mathrm{x} \mathrm{g}$ und $4^{\circ} \mathrm{C}$ ). Das Pellet wurde anschließend in $200 \mu 170 \%$ igem Ethanol gewaschen. Nach weiterer Zentrifugation ( $\left.5 \mathrm{~min}, 14.200 \mathrm{x} \mathrm{g}, 4{ }^{\circ} \mathrm{C}\right)$ wurde es bei $42{ }^{\circ} \mathrm{C}$ getrocknet. Am Ende wurde es in $30 \mu 1 \mathrm{H}_{2} \mathrm{O}$ resuspendiert.

\subsubsection{Herstellung von Glycerinstocks}

Das Verfahren dient zur Aufbewahrung einer Bakteriensuspension nach erfolgreicher Transformation (2.2.9). Von der Übernachtkultur (2.2.10) wurden $600 \mu \mathrm{l}$ mit $320 \mu \mathrm{l} 50$ \%igem sterilem Glycerin versetzt und durch Schwenken vermischt. Die Lagerung erfolgt bei $-80{ }^{\circ} \mathrm{C}$.

\subsubsection{Restriktionsenzymatische Spaltung}

Restriktionsendonukleasen haben die Fähigkeit, an spezifischen Nukleotidsequenzen die

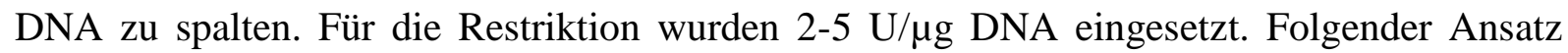
wurde pipettiert:

$\begin{array}{ll}\text { EcoRl }(10 \mathrm{U} / \mu \mathrm{l}) & 1 \mu \mathrm{l} \\ \text { 10x Puffer REACT } 3 & 2 \mu \mathrm{l} \\ \text { Plasmid DNA } & 2 \mu \mathrm{l} \\ \text { Wasser } & \mathrm{x} \mu \mathrm{l}\end{array}$

Gesamtvolumen $\quad 20 \mu \mathrm{l}$

Die Inkubationsdauer betrug $2 \mathrm{~h}$ bei $37{ }^{\circ} \mathrm{C}$ im Brutschrank. Anschließend wurde die Restriktion auf einem 1,5\%igem Agarosegel analysiert. 


\subsubsection{Arraybasierte Comparative Genomische Hybridisierung (aCGH)}

Die aCGH ist eine molekulargenetische Methode zur Analyse der DNA auf Kopiezahlvarianten (Copy Number Variations, CNV). Von der Firma Agilent Technologie wurde ein auf Oligonukleotiden basierender Microarray verwendet. Auf einer Breite von ca. $35 \mathrm{~kb}$ sind sowohl kodierende als auch nicht-kodierende Bereiche des humanen Genoms gespottet. 170.334 Oligonukleotid-Sonden können auf diese Weise mithilfe des SurePrint-G3Human-CGH Microarray-Kits 4x180 k ausgewertet werden. Die Oligonukleotide repräsentieren definierte DNA-Abschnitte von einer Länge von 60 bp. Somit können Gene bzw. Sequenzen auf Insertionen, Duplikationen und Deletionen untersucht werden. Veränderungen, wie z. B. Inversionen oder balancierte Translokationen, können mit dieser Methode nicht nachgewiesen werden, da sie zu keiner numerischen Veränderungen der Nukleotidsequenz führen. Damit die Sonde nicht an repetitive Bereiche der DNA bindet, wurden solche Bereiche mit unmarkierten kurzen Fragmenten (50-300 bp) menschlicher DNA, die angerreicherte, repetitive Sequenzen beinhaltet (so genannte cot-1 DNA), geblockt.

\subsubsection{Fragmentierung der genomischen DNA mittels Restriktionsenzymen}

Für diesen Reaktionsschritt wurde $1 \mu \mathrm{g}$ der zu untersuchenden genomischen DNA verwendet. Mit den Restriktionsenzymen $R s a I\left(\mathrm{GT}^{\wedge} \mathrm{AC}\right)$ und $A l u\left(\mathrm{AG}^{\wedge} \mathrm{CT}\right)$ wurde die Proben-DNA auf eine Fragmentgröße von 200-500 bp zugeschnitten. In einem nukleasefreien Reaktionsgefäß wurde sie mit $\mathrm{H}_{2} \mathrm{O}$ auf ein Volumen von 20,2 $\mu$ l aufgefüllt. Der folgende Reaktionsansatz wurde für diese Reaktion vorbereitet und zur DNA hinzugegeben:

$\begin{array}{ll}\mathrm{H}_{2} 0 \text { (nuklease-frei) } & 2 \mu \mathrm{l} \\ \text { 10x PufferC } & 2,6 \mu \mathrm{l} \\ \text { Acetylated BSA }(10 \mu \mathrm{g} / \mu \mathrm{l}) & 0,2 \mu \mathrm{l} \\ \text { Alu }(10 \mathrm{U} / \mu \mathrm{l}) & 0,5 \mu \mathrm{l} \\ \text { RsaI }(10 \mathrm{U} / \mu \mathrm{l}) & 0,5 \mu \mathrm{l}\end{array}$

Gesamtvolumen

$5,8 \mu \mathrm{l}$

Für $2 \mathrm{~h}$ wurde der Ansatz bei $37{ }^{\circ} \mathrm{C}$ inkubiert. Bei einer Temperatur von $65^{\circ} \mathrm{C}$ wurden die Restriktionsenzyme $20 \mathrm{~min}$ inaktiviert. Optional konnte das Resultat des restriktionsenzymatischen Verdaus mittels Gelelektrophorese (2.2.6) überprüft werden. $2 \mu 1$ 
der DNA und $3 \mu$ l Ladepuffer wurden auf ein 0,8 \%iges Agarosegel aufgetragen. Anhand des DNA-Ladders sollte eine Fragmentgröße von 200-500 bp zu sehen sein.

\subsubsection{DNA-Fragmentmarkierung (Labelling)}

Bei diesem Schritt, dem sogenannten Labelling, wurden die geschnittenen DNA-Fragmente der Patienten-DNA mit Cyanine-5-Farbstoff (Cy5) und die Kontroll-DNA (Ko 20 m) mit dem Farbstoff Cyanine 3 (Cy3) markiert. Zur Unterscheidung dieser beiden Fluoreszenzfarbstoffe, welche zum Nachweis von DNA dienen, besitzen sie ein unterschiedliches Emissionsmaximum. Das Maximum von Cy5 liegt bei 670 nm, wohingegen das Maximum von Cy3 bei einer Wellenlänge von $570 \mathrm{~nm}$ liegt.

In dem verwendeten Agilent Genomic DNA Labelling-Kit PLUS befindet sich neben den Random Primern, welche kurze Oligonukleotide zufälliger Sequenz sind, auch sogenannte Klenow-Fragmente. Dabei handelt es sich um die große Untereinheit der DNA-Polymerase I von E. coli. Sie helfen bei der Markierung der genomischen DNA-Fragmente.

Als Grundlage für die Fragmentmarkierung der DNA dient das von Feinberg und Vogelstein (1983) entwickelte Random-Priming. Das Klenow-Fragment bindet an DNA gebundene Random-Primer und baut schließlich die Fluoreszenzfarbstoffe in den neusynthetisierten Strang ein.

Bei diesem Arbeitsschritt wurden $5 \mu 1$ des Random-Primers zu den $24 \mu 1$ der restringierten DNA hinzugefügt und vermischt. Für die Hybridisierung der Primer wurde die DNA zunächst bei $95^{\circ} \mathrm{C}$ für 3 min denaturiert, abgekühlt und mit dem folgenden Reaktionsansatz vermischt:

\section{Cy5dUTP}

$\mathrm{H}_{2} \mathrm{O}$

5x Buffer

10xdNTP

Cy5dUTP

Cy3dUTP

Exo Klenow

Gesamtvolumen
$2 \mu 1$

$10 \mu \mathrm{l}$

$5 \mu 1$

$3 \mu \mathrm{l}$

-

$1 \mu 1$

$21 \mu \mathrm{l}$
Cy3dUTP

$2 \mu 1$

$10 \mu \mathrm{l}$

$5 \mu 1$

$3 \mu 1$

$1 \mu 1$

$21 \mu \mathrm{l}$

Der Cy5dUTP-Ansatz wurde zu der Patienten-DNA gegeben und der Cy3dUTP-Mastermix zu der Kontroll-DNA. Bei dem anschließenden Inkubationsschritt für $2 \mathrm{~h}$ bei $37^{\circ} \mathrm{C}$ fand die 
Elongation statt. Die DNA-Polymerase I wurde am Ende für 10 min bei $65^{\circ} \mathrm{C}$ inaktiviert. Die Proben konnten bei $-20^{\circ} \mathrm{C}$ gelagert werden.

\subsubsection{Aufreinigung der markierten genomischen DNA}

Die Aufreinigung der markierten DNA erfolgte 2-mal mit $450 \mu 1$ 1x TE-Puffer in einer Amicon® Ultra -0.5 Millipore Säule für jeweils $10 \mathrm{~min}$ bei $14.000 \mathrm{x}$ g. Anschließend wurde die Säule für 2 min bei 1000 x g zentrifugiert. Der Durchfluss betrug etwa $20 \mu 1$.

\subsubsection{Konzentrationsbestimmung mittels Nanodrop}

Die Konzentration der aufgereinigten DNA wurde mittels eines Nanodrop-Photometers (ND1000 Spectrometer) bestimmt. Um den Nullwert (Blank) zu ermitteln, wurden 1,5 $\mu 1 \mathrm{H}_{2} \mathrm{O}$, alternativ auch 1x TE-Puffer, auf den Kontakt gegeben. Von der zu untersuchenden DNA wurde anschließend die gleiche Menge auf die Kontaktstelle gegeben.

Mit der folgenden Gleichung wurde anhand der gemessenen Werte die Konzentration berechnet:

$($ pmol / $\mu$ l (Farbstoff $)) /(p g / \mu l($ Genomischer DNA $))$

\subsubsection{Hybridisierung}

Bei diesem Schritt hybridisierten die Fluoreszenz-markierten DNA-Fragmente an ihre komplementären Oligonukleotide im Array. Für die Hybridisierung wurden die markierten DNA-Fragmente der zu untersuchenden Probe mit der Kontrolle zusammengeführt und mit 1x TBE auf ein Gesamtvolumen von $39 \mu 1$ aufgefüllt. $\mathrm{Zu}$ den $39 \mu 1$ (=Cy3/5labelled DNA Mix) wurden folgende Reagenzien hinzugefügt:

Cot-1 DNA $(1.0 \mathrm{mg} / \mu \mathrm{l})$

Agilent 10x Blocking Agent

Agilent 2x Hybridisierungspuffer

\section{Gesamtvolumen}

$5 \mu 1$

$11 \mu 1$

$55 \mu 1$

$71 \mu \mathrm{l}$

Nach kurzer Zentrifugation, 3-minütiger Inkubation bei $95{ }^{\circ} \mathrm{C}$ und anschließender Kühlung für 30 min auf $30{ }^{\circ} \mathrm{C}$ wurden der Reaktionsansatz unter ozonfreien Bedingungen auf einen Objektträger unter ein Deckglas gegeben (SurePrint-G3-Human-CGH Microarray-Kits 
4x180k von Agilent), wobei die beschichtete Seite innen liegen soll. Der Objektträger wurde in einem Gestell fixiert und in den Hybridisierungsofen geklemmt. Für 24 h, 20 rpm und 65 ${ }^{\circ} \mathrm{C}$ fand die eigentliche Hybridisierung statt.

\subsubsection{Waschen}

Verwendete Gefäße wurde mit milli-Q $\mathrm{H}_{2} \mathrm{O}$ gereinigt. Der beschichtete Arrayteil wurde als erstes im Agilent Oligo-aCGH-Wash-Buffer-1 für 5 min bei RT gewaschen. Danach erfolgte die Reinigung mit dem auf $37{ }^{\circ} \mathrm{C}$ vorgewärmten Agilent Oligo-aCGH-Wash-Buffer-2 für 1 min. Bevor der Arrayteil bei RT getrocknet wurde, wurde er für $10 \mathrm{sec}$ in Acetonitril gestellt.

\subsubsection{Auswertung}

Die Auswertung der erhaltenen Daten erfolgte mit der Agilent Software Feature Extraction. Der hybridisierte Microarray wurde zunächst mithilfe eines Laserscanners ausgelesen. Der Fluoreszenzfarbstoff Cy3 emittiert ein grünes Signal. Er repräsentierte die Kontrolle. Cy5, der Farbstoffe der an der Probe bindet, gibt hingegen ein rotes Signal. Bei ungefährer gleicher Verteilung der Fluoreszenzen resultierte ein gelbes Signal.

In dem erhaltenen Falschfarbenbild repräsentierte jeder Punkt einen 60 bp großen Abschnitt des menschlichen Genoms. Von jedem Oligonukleotid wurde der 2er Logarithmus aus der Intensität der Referenz und der Probe ermittelt. Erhielt man nun folgende Ergebnisse, so war mit der dargestellten Veränderung zu rechnen:

Intensität Cy3 (Kontrolle) = Cy5 (Probe) keine Kopienzahlvarianten

Intensität Cy3 (Kontrolle) > Cy5 (Probe) grünes Signal; es ist mit einer Deletion zu rechnen

Intensität Cy3 (Kontrolle) < Cy5 (Probe) rotes Signal; es deutete auf eine Duplikation bzw. Triplikation in der Patienten-DNA hin.

Mit der CGH-Analytics-Software von der Firma Agilent wurden die normalisierten Rohdaten veranschaulicht und mit der Software DNA Analytics 4.0 ausgewertet. 


\subsubsection{Isolierung von Spermien aus dem Nebenhodenschwanz}

Der präparierte Nebenhodenschwanz und ein Teil des Ductus deferens wurden in eine Petrischale mit $2000 \mu \mathrm{l}$ auf $37^{\circ} \mathrm{C}$ vorgewärmtes PBS gegeben. Mit einer Kanüle wurde das Gewebe perforiert und für 10 min bei $37{ }^{\circ} \mathrm{C}$ inkubiert, damit die Spermien in dem Medium ausschwimmen und sich vereinzeln konnten. Mithilfe eines Durchlichtmikroskopes (Stemi SV 11, Krannich) wurde die Anzahl der Spermien geschätzt und der Nebenhodenschwanz entfernt. Die Spermiensuspension wurde in $2 \mathrm{ml}$ E-Cups überführt und für $10 \mathrm{~min}$ bei $1.350 \mathrm{x}$ g (ggf. anschließend 2 min bei 12.100 x g) zentrifugiert. Das Spermienpellet wurde mit ca. $150 \mu \mathrm{l}$ PBS auf ein Gesamtvolumen von etwa $200 \mu 1$ aufgefüllt und resuspendiert. Zur Aufbewahrung wurde die Lösung nochmals für $10 \mathrm{~min}$ bei $1.350 \mathrm{x} \mathrm{g}$ zentrifugiert, der Überstand verworfen und bei $-20{ }^{\circ} \mathrm{C}$ aufbewahrt.

\subsubsection{TUNEL-Assay zur Analyse von DNA-Strangbrüchen}

Der TUNEL-Assay ist eine Methode, mit der man direkt DNA-Strangbrüche in Spermienköpfen nachweisen kann. Dabei wird das freie $3^{\prime} \mathrm{OH}-E n d e$ mithilfe des Enzyms Terminale Desoxynucleotidyl-Transferase (TdT) identifiziert. Das Enzym kann ein Fluoreszenz-markiertes Nucleotid (dUTP-fluorescein) an die freie 3'OH-Gruppe binden. Als Resultat wird ein grünes Signal emittiert. Somit können Einzel- und Doppelstrangbrüche nachgewiesen werden, wobei kein quantitativer Unterschied zwischen beiden Brucharten gemacht werden kann.

Von der hergestellten Spermiensuspension (2.2.14) wurden jeweils $20 \mu \mathrm{l}$ auf einem Objektträger ausgestrichen und bei RT getrocknet. Pro Versuch wurden zusätzlich zwei Kontrollen angefertigt. Zunächst wurden die Spermien für 30 min bei RT in $4 \%$ PFA fixiert. Danach wurden die Proben 3-mal für je 10 min mit PBS gewaschen und anschließend bei RT getrocknet. Nach jeder Behandlung der Objektträger mit Chemikalien erfolgte dieser Waschschritt.

Um die Membran für das Enzym durchlässig zu machen, wurden die Keimzellen mit einer Permeabilisationslösung, aus PBS und Proteinase K im Verhältnis 1:5, behandelt. $20 \mu 1$ wurden pro Objektträger aufgetragen und für $15 \mathrm{~min}$ bei RT in einer feuchten Kammer inkubiert. In der oben beschriebenen Weise wurden die Objektträger gewaschen und zunächst nur die als Kontrollen bezeichneten Proben getrocknet. Die übrigen Proben verblieben bis zur weiteren Bearbeitung in der feuchten Kammer. Mit dem Enzym DNase I wurden bei den Kontrollen Chromatinschäden in den Spermien induziert. Sie dienten zur Überprüfung der 
Funktionsweise des Versuches. Pro Objektträger der beiden Kontrollen wurde folgendes Gemisch aufgetragen:

$\begin{array}{lc}\text { DNase I (4 U) } & 4 \mu \mathrm{l} \\ \text { 10x Puffer } & 4 \mu \mathrm{l} \\ \mathrm{dH}_{2} \mathrm{O} & \mathrm{x} \mu \mathrm{l} \\ \text { Gesamtvolumen } & \mathbf{5 0} \boldsymbol{\mu l}\end{array}$

Unter einem Deckglas inkubierte dieser Reaktionsansatz für 10 min bei RT in einer feuchten Kammer. In oben genannter Weise wurden die Objektträger im Anschluss mit PBS gereinigt und mit den übrigen Kontrollen bei RT getrocknet. Für die „TUNEL-Färbung“ wurden folgende Reagenzien verwendet und pro Objektträger aufgetragen:

$\begin{array}{lc}\text { Label-Solution } & 13,5 \mu 1 \\ \text { Enzym-Solution } & 1,5 \mu l\end{array}$

Gesamtvolumen $\quad 15 \mu \mathrm{l}$

Bei einer Kontrolle wurde die Enzym-Solution durch $\mathrm{dH}_{2} \mathrm{O}$ ersetzt (Negativkontrolle). Sie gilt als Nachweis für die Spezifität der Enzymbindung. Hingegen wurde bei der anderen Kontrolle der beschriebene „TUNEL-Färbung“ aufgetragen. Durch die induzierten Strangbrüche wird sie als Positivkontrolle bezeichnet. Für $1 \mathrm{~h}$ wurden die Proben bei $37{ }^{\circ} \mathrm{C}$ aufbewahrt und nochmals, wie beschrieben, mit PBS gewaschen. Am Ende wurden $20 \mu 1$ der VectaShield Mounting Solution mit DAPI aufgetragen, die im Verhältnis 1:2 mit $\mathrm{dH}_{2} \mathrm{O}$ verdünnt wurde. Die Proben wurden mit dem Fluoreszenzmikroskop (Olympus BX60) mit dem FITC-Filter ausgezählt. Anhand des Kernfarbstoffes DAPI waren alle Spermien mit blauer Fluoreszenz markiert und waren besser aus zählbar. 


\subsection{Ausgangslage für die Analysen}

Das keimzell-/testisspezifische Gen Pxt1 wurde erstmals bei der Maus identifiziert (Grzmil et al. 2007). Dieses Gen spielt möglicherweise eine Rolle in der Spermatogenese. Das menschliche Homolog ist auf Chromosom 6p21.31 lokalisiert. Bisher gibt es allerdings keine Informationen über die Expression und Funktion des humanen PXT1-Gens (ID 222659). Eine Homologie von $74 \%$, einschließlich des ORF (open reading frame, offener Leserahmen), weisen jedoch das humane und murine PXT1/Pxt1 auf. Zu Beginn dieser Doktorarbeit war bekannt, dass PXT1 aus zwei Exons und einem Intron besteht. Aus Untersuchungen in der DNA-Datenbank ist ein cDNA-Klon BC031105 (IMAGE:5297409) mit drei zusätzlichen Exons in 5'-Richtung bekannt.

Untersuchungen bei der transgenen Mauslinie haben ergeben, dass die Überexpression des PXT1-Proteins in den Keimzellen Apoptose induziert (Kaczmarek 2009, Kaczmarek et al. 2011). Die transgenen Tiere waren infertil, im Lumen der Samenkanälchen (Tubuli seminiferi) konnten keine Keimzellen nachgewiesen werden (Kaczmarek 2009, Kaczmarek et al. 2011). Beim Menschen ähnelt das dem Azoospermie-Phänotyp. Somit konnte man annehmen, dass eine aberrante PXT1-Expression Fertilitätsprobleme beim Menschen verursachen könnte. Da die Ergebnisse aus den Untersuchungen am Mausmodell nicht einfach auf den Menschen übertragen werden können, wurden in dieser Arbeit neben Patienten mit Azoospermie auch solche mit Oligozoospermie berücksichtigt.

In der Arbeit von Behre et al. (1994) wurde gezeigt, dass $9 \%$ der untersuchten männlichen Patienten mit Fertilitätsproblemen eine Azoospermie und weitere $45 \%$ eine Oligozoospermie aufweisen. Bei $31 \%$ der untersuchten Männer ist die Ursache für ihre Infertilität ungeklärt (Nieschlag und Behre 2000). In dieser Arbeit wurde das humane PXT1-Gen auf Mutationen bei 55 Patienten untersucht. Die Patienten wurden nach dem Azoo- oder OligozoospermiePhänotyp, entsprechend den WHO-Normen (Cooper et al. 2010), ausgewählt.

\subsection{Das humane PXT1-Gen}

\subsubsection{Nachweis zusätzlicher Exons}

Die bereits erwähnten drei neu identifizierten Exons wurden im Rahmen einer in-silicoAnalyse gefunden. Als erstes wurde die Expression dieser Exons bestätigt, indem die Testis RNA zunächst mittels RT-PCR (2.2.4.2, S.22) in cDNA umgeschrieben und diese anschließend mithilfe der PCR (2.2.4.1, S.21) bei einer Annealingtemperatur von $63{ }^{\circ} \mathrm{C}$ 
amplifiziert wurde. Als genspezifische Vorwärtsprimer wurden hPXT1RTFP1, hPXT1RTFP1,5, hPXT1RTFP2 und hPXT1RTFP3 verwendet. hPXT1RTRP1 diente bei jeder Amplifikation als Rückwärtsprimer. In Abbildung 3.1 ist die Lokalisation der verwendeten Primer veranschaulicht. Nach der PCR wurden die Produkte auf ein Agarosegel aufgetragen (2.2.6, S.32).

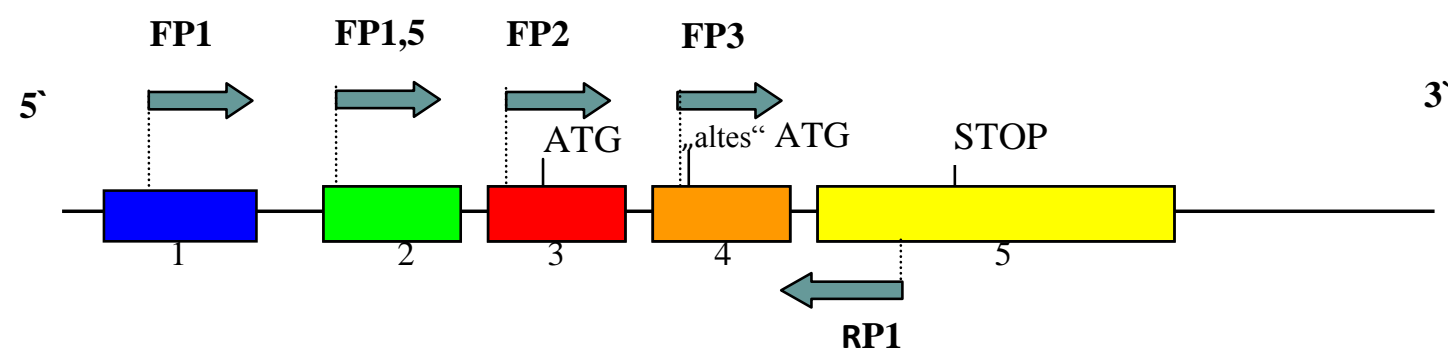

Abb. 3.1: Lokalisation der verwendeten Primer bei der Expressionsanalyse des PXT1-Gens

In dieser Abbildung sind die fünf Exons (1-5) von PXT1 farbig dargestellt. Die Pfeile veranschaulichen die Position der verwendeten genspezifischen Primer. Dabei handelt es sich um vier Vorwärtsprimer (FP1-3) und einen Rückwärtsprimer (RP). ATG - Startkodon, ,,altes“ ATG - alternatives Startkodon, STOP - Stopkodon.

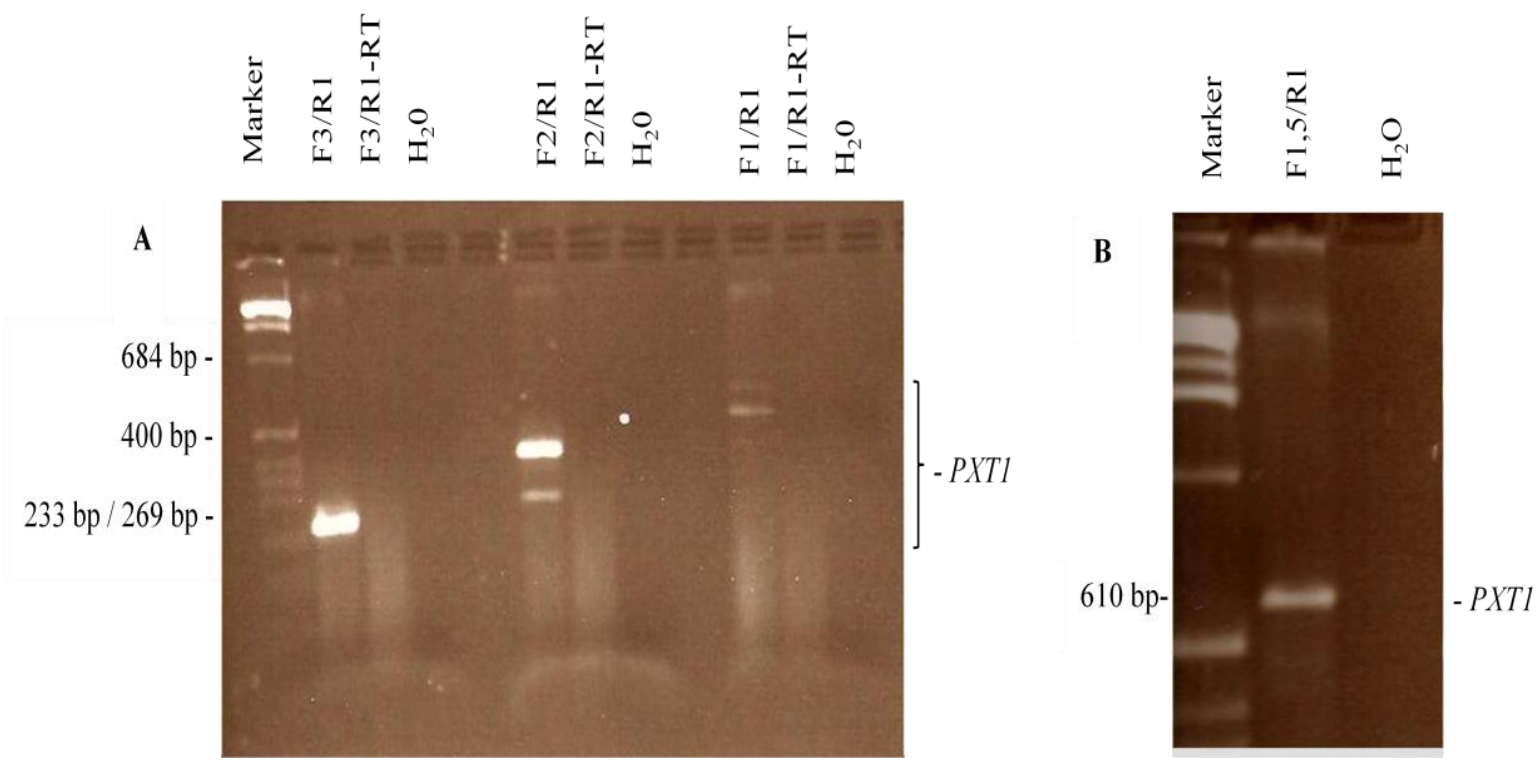

Abb. 3.2: RT-PCR-Produkte der 5 Exons.

1,5 \%iges Agarosegel mit den Amplifikaten der RT-PCRs. Neben den Proben befinden sich zwei Negativkontrollen (-RT und $\mathrm{H}_{2} \mathrm{O}$ ). Die -RT-Kontrolle verweist auf die Spezifität der cDNA-Herstellung, da bei der Synthese des komplementären cDNA-Stranges kein Enzym hinzugefügt wurde. F3/R1 repräsentiert die PCR-Produkte für die Exons 4-5, F2/R1 die Exons 3-5, F1/R die Exons 1-5 und F1,5/R1 die Exons 2-5. 
Bei allen Primerkombinationen entstanden Reaktionsprodukte, die in der Abbildung 3.2 veranschaulicht sind. Durch Verwendung einer Negativkontrolle, bei welcher die cDNASynthese ohne Zugabe von Reverser Transkriptase durchgeführt wurde (-RT), kann eine Kontamination während der Testis-cDNA-Synthese oder der PCR-Reaktion ausgeschlossen werden. Für das Amplifikat von F1,5/R1 ist keine -RT-Kontrolle abgebildet. Für diese Reaktion wurde dieselbe Testis cDNA wie in der F3/R1-Reaktion verwendet.

Die in Abbildung 3.2 dargestellten Fragmente wurden im weiteren Verlauf aus dem Gel extrahiert (2.2.7, S.32), in den Vektor pGEM T-easy kloniert (2.2.8, S.33) und mithilfe der Primer SP6 und T7 sequenziert (2.2.4.3, S.23).

Nach der Sequenzierung des PCR-Produkts F3/R1 mit einer Größe von 233 bp konnten die Exons 4 und 5 identifiziert werden. Mit den Primern F2/R1 wurden zwei PCR-Produkte amplifiziert. In dem Produkt mit einer Größe von 400 bp waren die Exons 3-5 enthalten, das kleinere Fragment mit einer Größe von 269 bp enthielt die Exons 3 und 5, aber nicht Exon 4. In dem Produkt der Primerkombination F1,5/R1 mit einer Größe von 610 bp waren, wie zu erwarten, die Exons 2-5. Bei dem Primerpaar F1/R1 wurden bei der Gelelektrophorese (2.2.6, S.32) zwei starke und mehrere schwache, unterschiedlich große DNA-Fragmente beobachtet. Das Fragment mit der Größe von ungefähr 684 bp enthielt die Exons 1-5. Die Tatsache, dass bei dieser PCR mehrere Reaktionsprodukte entstanden, weist darauf hin, dass bei PXT1 das alternative Spleißen eine Rolle spielt. In den untersuchten Transkripten zeigten sich bei der Sequenzanalyse verschiedene Kombinationen der einzelnen Exons. Im nächsten Abschnitt (3.2.2) wird auf die genauen Ergebnisse des alternativen Spleißens eingegangen.

Neben den bisher in der DNA-Datenbank bekannten Exons 4 und 5 konnte die Expression von drei zusätzlichen Exons in 5'-Richtung bestätigt werden. Das „neue“ Exon 1 umfasst 355 bp. Die beiden anderen Exons haben eine Größe von 120 bp (Exon 2) und 178 bp (Exon 3). Im Rahmen dieser Arbeit wurden alle Isoformen des humanen PXT1-Gens analysiert.

\subsubsection{Alternatives Spleißen im PXT1-Gen}

\subsubsection{Analyse auf weitere Exons in 5'-Richtung und deren}

\section{Sequenzierung}

Da in der Datenbank bereits ein cDNA-Klon mit drei weiteren Exons in 5'-Richtung zu finden war, deren Expression mithilfe der RT-PCR (2.2.4.2, S.22) bestätigt werden konnte, wurde unter Verwendung der 5'-RACE-PCR (2.2.4.4, S.24) das PXT1-Gen auf weitere Exons in dieser Richtung untersucht. Als Template wurde Testis-RNA, die mittels RT-PCR (2.2.4.2, S.22) in cDNA umgeschrieben wurde, verwendet. Neben den im 5'-RACE-PCR-Kit 
enthaltenen Primern wurde als erster Primer hPXT1RACERP1 verwendet. Für die im Protokoll beschriebene Nested-PCR (2.2.4.4.7, S.28) diente hPXT1RACERP2. Diese beiden Rückwärtsprimer sind für PXT1 spezifisch und im Exon 3 lokalisiert (Abb. 3.3). Der Vorwärtsprimer bindet bei dieser Reaktion an einen der CAP-Struktur komplementären Adapter.

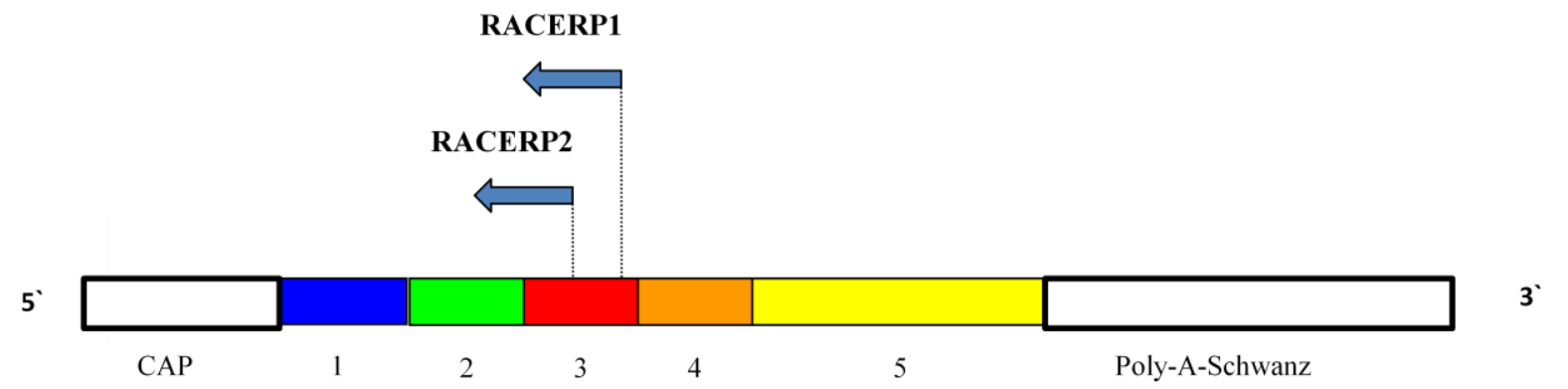

Abb. 3.3: Lokalisation der verwendeten genspezifischen Primer für die 5'-RACE-PCR-Analyse In dieser Abbildung sind die fünf Exons (1-5) der PXT1-cDNA farbig dargestellt. Die Pfeile veranschaulichen die Positionen der verwendeten genspezifischen Primer. Dabei handelt es sich um zwei Rückwärtsprimer (RACERP1/2). Zusätzlich sind in dieser Darstellung am 5'-Ende die CAP-Struktur und am 3'-Ende der Poly-ASchwanz abgebildet.

Das 5'-RACE-PCR-Produkt wurde gelelektrophoretisch (2.2.6, S.32) analysiert und ist in der Abbildung 3.4 veranschaulicht.

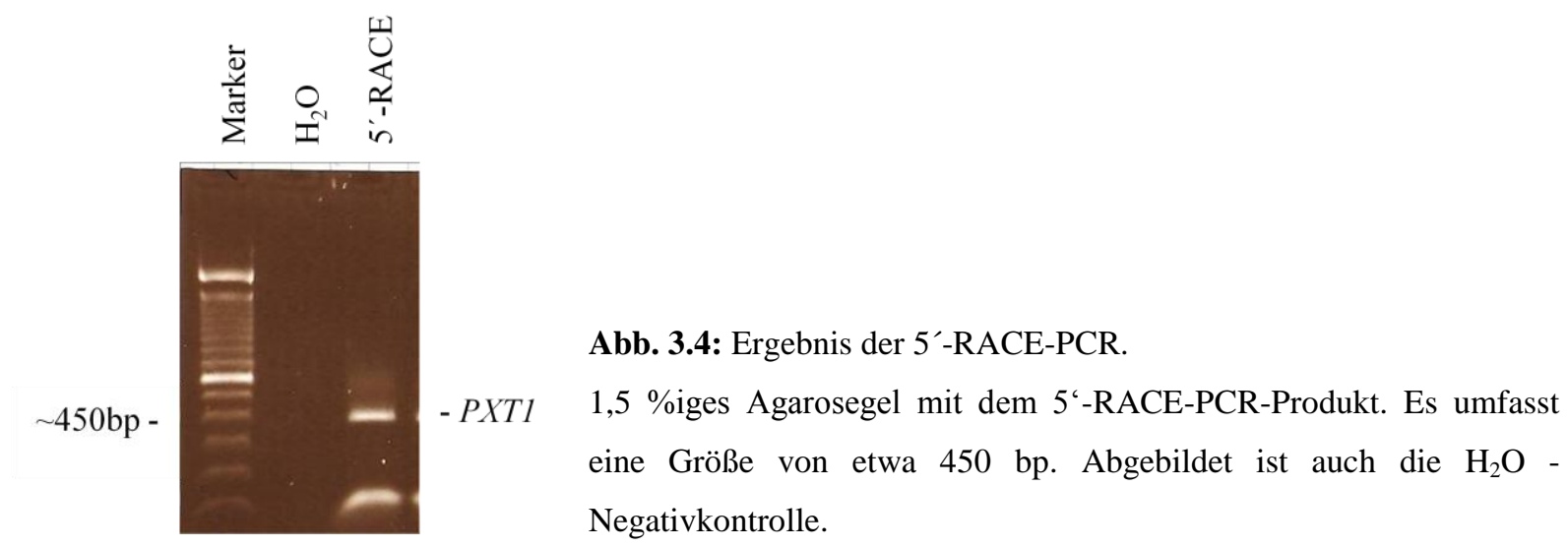

Ein Fragment mit einer Größe von etwa 450 bp konnte identifiziert werden. Unter Berücksichtigung der Gensequenz haben die Exons 1-3 zusammen eine Größe von 653 bp. Der Vergleich der Exongröße mit der dargestellten Bande lässt vermuten, dass in dem Amplifikat die beschriebenen Exons nicht komplett enthalten sind. 
Das 5'-RACE-PCR-Produkt wurde aufgereinigt (2.2.7, S.32) und in den Vektor pGEM Teasy kloniert (2.2.8, S.33). Nach der Mini-Präparation (2.2.10, S.34) wurden die Inserts (2.2.11, S.34) bei einer Restriktionsanalyse mit EcoRI überprüft. Dabei hat sich gezeigt, dass unterschiedlich große Inserts ligiert waren (Abb. 3.5).

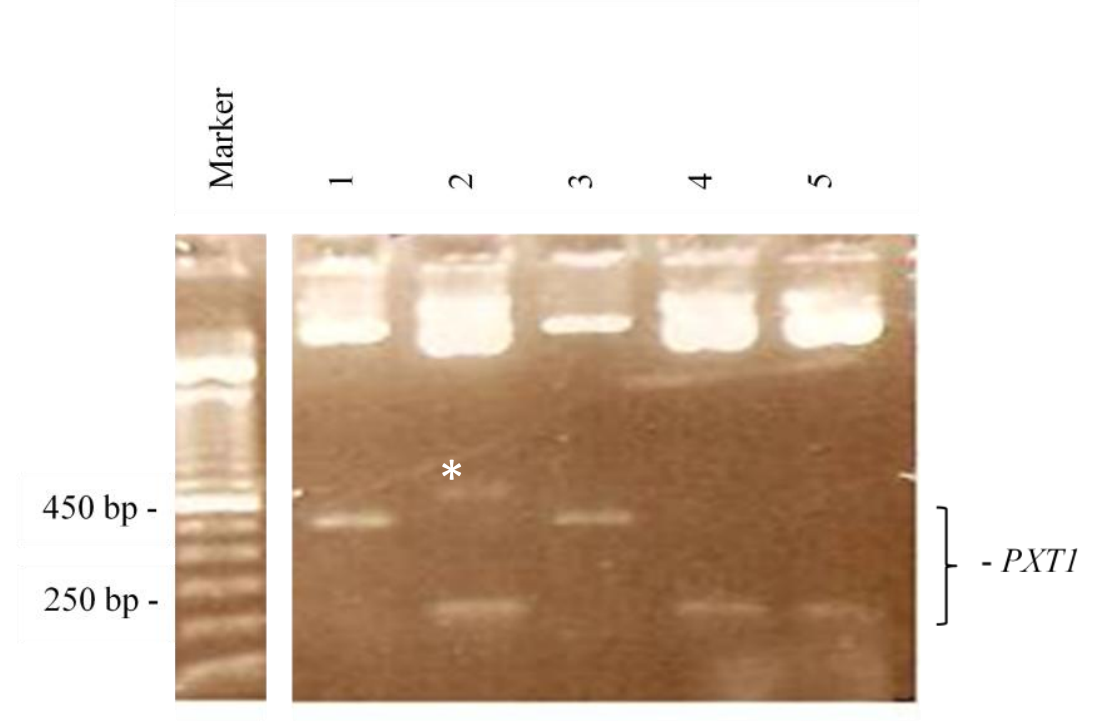

Abb. 3.5: Restriktionsanalyse des 5'-RACE-PCR-Produkts, kloniert in den pGEM T-easy-Vektor

Das 5'-RACE-PCR-Produkt wurde in pGEM T-easy kloniert. Nach der Ligation wurden fünf Klone (1-5) isoliert. Nach der Restriktionsanalyse mit EcoRI konnte man zwei unterschiedlich große Inserts identifizieren. Bei den Klonen 1 und 3 umfasst das Insert eine Größe von etwa 450 bp. In den anderen Klonen war ein Insert mit einer Größe von 250 bp enthalten. Das mit ,*“-markierte Fragment konnte nicht analysiert werden (Spur 2).

Die Abbildung 3.5 zeigt, dass unterschiedlich große Inserts bei der Restriktionsanalyse im Agarosegel nachgewiesen werden konnten. Die Klone 1 und 3 enthalten eine ligierte Sequenz mit einer Größe von etwa 450 bp. Hingegen zeigen die Klone 2, 4 und 5 kleinere Inserts, die lediglich eine Länge von ca. 250 bp besitzen.

Im weiteren Verlauf wurde die Sequenzanalyse durchgeführt. Dabei wurden die Plasmide mit dem klonierten 5'-RACE-PCR-Produkt mit den Primern SP6 und T7 sequenziert (2.2.4.3, S.23) und die Ergebnisse dann mit der DNA-Datenbank abgeglichen. In allen Klonen konnte PXT1 identifiziert werden. Die Resultate der Sequenzanalyse ergaben, dass das erste Exon in drei Exons (1a, 1b und 1c) gliedert ist. In Abbildung 3.6 sind diese schematisch dargestellt. 


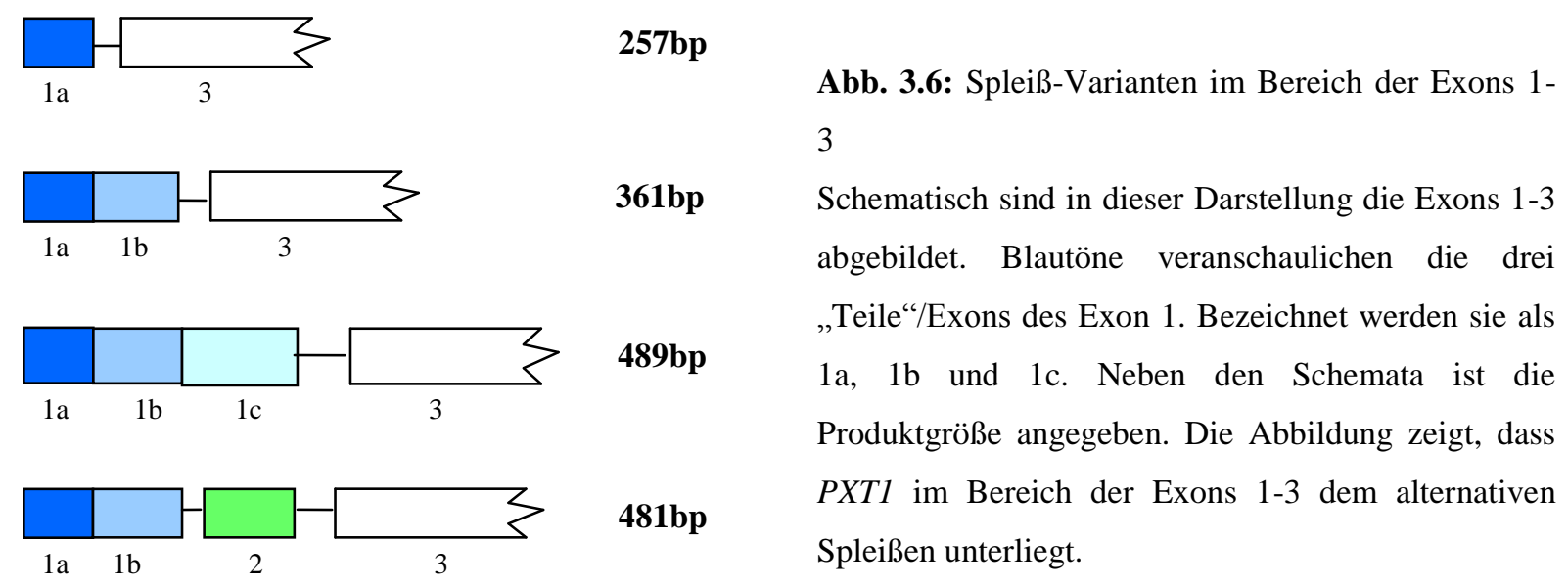

Die Analyse ergab, dass das Reaktionsprodukt der 5'-RACE-PCR aus vier verschiedenen Amplifikaten besteht (Abb. 3.6). Klon 1 (Abb. 3.5) enthält ein Insert mit der Größe von 489 bp. Es beinhaltet die Exons 1a, 1b, 1c und das Exon 3. In den Klonen 2, 4 und 5 war jeweils das gleiche Insert mit einer Größe von 257 bp im Vektor nachzuweisen. Es besteht aus dem Exon 1a und dem Exon 3. Schließlich war in dem Klon 3 ein weiteres, 481 bp großes Insert enthalten. Die Exons 1a und 1b, Exon 2 und Exon 3 waren in diesem Insert nachzuweisen. In der Abbildung 3.6 ist eine weitere Spleißvariante mit einer Größe von 361 bp dargestellt. Dieses Fragment wurde bei der Direktsequenzierung des 5'-RACE-PCR-Produktes identifiziert. Diese Variante setzt sich aus den Exons 1a, 1b und dem Exon 3 zusammen. Das PXT1-Gen unterliegt im Bereich der Exons 1-3 dem alternativen Spleißen. Die Untersuchungen haben ergeben, dass das Exon 1a eine Größe von 123 bp hat, das Exon 1b 104 bp und das Exon 1c - 128 bp. Zwischen den einzelnen Anteilen befindet sich die typische Spleiß-Akzeptor-Sequenz „AG-GA“.

Bei den Analysen der Transkripte ergab sich, dass in allen identifizierten Varianten Exon 1c und Exon 2 nie zusammen im Amplifikat vorkommen. Die dazwischenliegenden Exons (1b, 1c und 2) kommen, wie in Abbildung 3.6 veranschaulicht, in unterschiedlichen Kombinationen miteinander vor.

Mit Hilfe der 5'-RACE-PCR konnten keine weiteren Exons in 5'-Richtung identifiziert werden.

\subsubsection{Ergebnisse der RT-PCR mit der Primerkombination F1/R1}

Um das alternative Spleißen beim PXT1-Gen weiter zu untersuchen, wurden die PCRProdukte (2.2.4.1, S.21) analysiert, die mit der Primerkombination hPXT1RTFP1 und hPXT1RTRP1 (Abb.3.1) amplifiziert worden waren. Wie bereits erwähnt (3.2.1), konnten im 
elektrischen Feld bei der Standardgelelektrophorese (2.2.6, S.32) mit dieser Primerkombination mehrere Produkte mit Größen zwischen 428 bp und 684 bp nachgewiesen werden. Sie sind in der Abbildung 3.7 dargestellt. Das Reaktionsprodukt wurde aufgereinigt (2.2.5, S.32) und in den Vektor pGEM T-easy kloniert (2.2.8, S.33). Die Überprüfung des Inserts wurde mit dem Restriktionsenzym EcoRI (2.2.11, S.34) durchgeführt, und die Fragmente wurden schließlich sequenziert. Anschließend erfolgte der Abgleich der erhaltenen Sequenz mit der DNA-Datenbank.

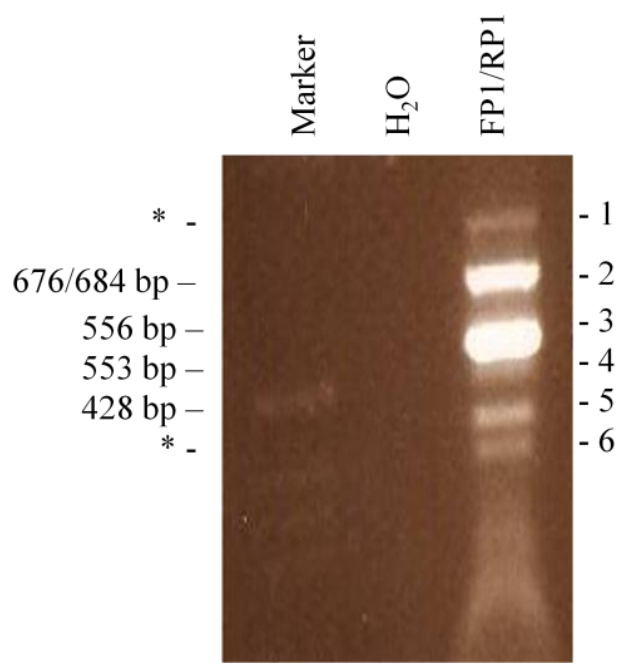

Abb. 3.7: RT-PCR-Ergebnisse der Primerkombination FP1/RP1

1,5 \%iges Agarosegel mit dem Reaktionsprodukt der Primer FP1 (Exon 1b) und RP1 (Exon 5) und einer $\mathrm{H}_{2} \mathrm{O}-$ Negativkontrolle. Die Illustration zeigt 6 Produkte (1-6), mit Größen zwischen 428 bp und 684 bp, die aufgetrennt werden konnten. Die Produkte 1 und 6 konnten nicht identifiziert werden, sie sind mit „*“ gekennzeichnet. Produkt 2 enthält die Exons 1b, 1c, 3, 4 und 5 (684 bp). Ebenso enthält das Produkt ein Amplifikat mit den Exons 1b, 2, 3, 4 und 5 (676 bp). Produkt 3 umfasst die Exons 1b, 3, 4 und 5 (556 bp). Im Produkt 4 konnten die Exons 1b, 1c, 3 und 5 (553 bp) nachgewiesen werden. Schließlich enthält das Produkt 5 die Exons 1b, 3 und 5 (428 bp).

Mit der Sequenzanalyse lässt sich in dem Produkt 2 zum einen ein Amplifikat mit den Exons 1b, 1c, 3, 4 und 5 (684 bp) nachweisen. Zum anderen lässt sich aus diesem Produkt ein Amplifikat isolieren, dass die Exons 1b, 2, 3, 4 und 5 (676 bp) enthält. In dem Produkt 3 sind die Exons 1b, 3, 4 und 5 (556 bp) nachgewiesen worden. Die Exonkombination aus den Exons 1b, 1c, 3 und 5 (553 bp) ist im Produkt 4 identifiziert worden und schließlich sind in dem Produkt 5 die Exons 1b, 3 und 5 (428 bp) nachweisbar. Die Produkte 1 und 6 konnten nicht identifiziert werden. 


\subsubsection{Transkripte vom PXT1-Gen und deren Auswirkungen auf die Proteinstruktur}

In der 5'-RACE-PCR (3.2.2.1) und in der RT-PCR (3.2.2.2) konnte das alternative Spleißen beim PXT1-Gen bereits gezeigt werden. Jedoch ist eine genaue Identifizierung aller möglichen Transkripte nur unter Zusammenfassung der Ergebnisse beider Analysemethoden möglich. Bei der 5'-RACE-PCR wurde lediglich das 5'-Ende bis Exon 3 und bei der RT-PCR der Bereich Exon 1b bis Exon 5 untersucht. In der Abbildung 3.8 sind die möglichen Transkripte schematisch dargestellt.

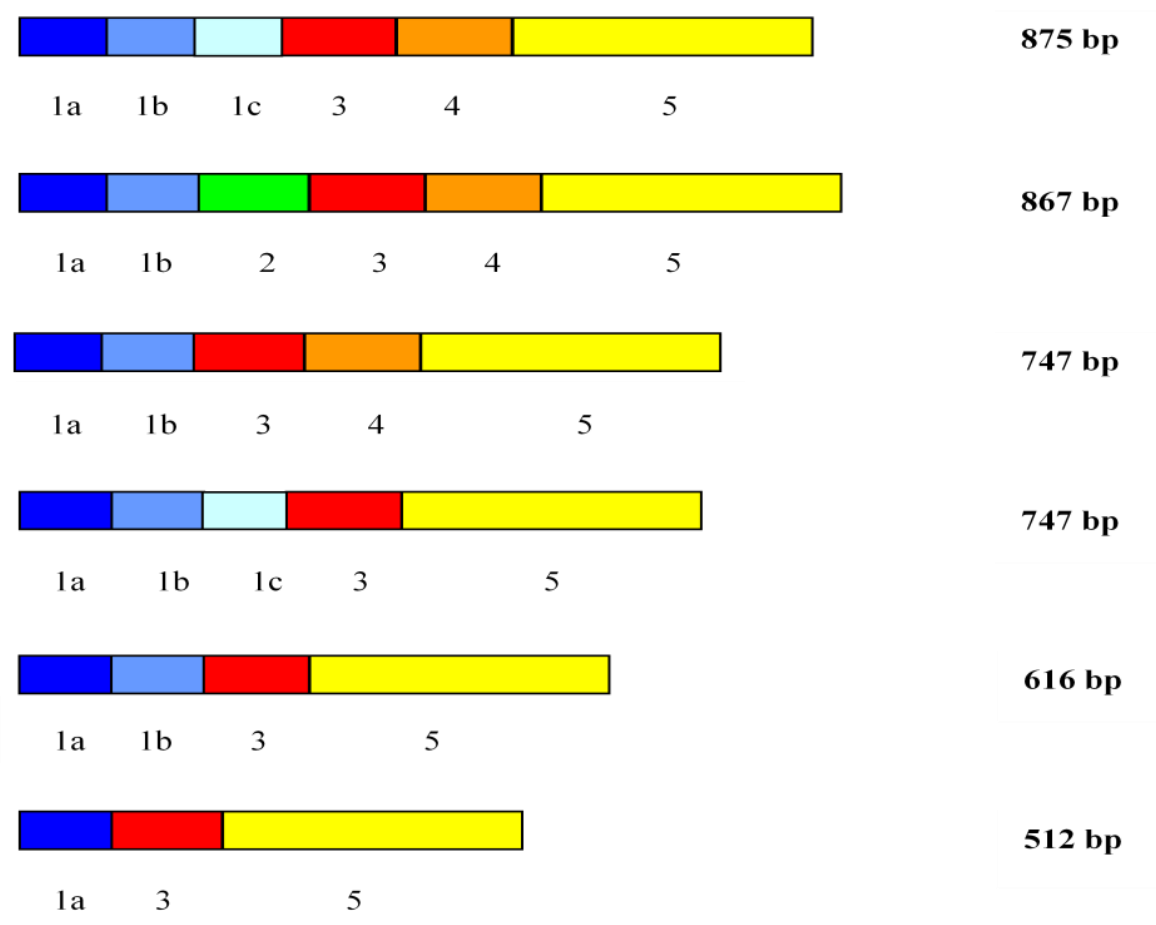

Abb. 3.8: Transkripte des humanen PXT1-Gens aus den RT-PCR- und 5'-RACE-PCR-Ergebnissen

Die Abbildung zeigt schematisch die putativen Transkripte des humanen PXT1-Gens. Die einzelnen Exons sind farbig markiert und mit 1-5 beschriftet. Rechterhand der Schemazeichnung ist die Größe der einzelnen Transkripte dargestellt. Von dem alternativen Spleißen sind die Exons 1b, 1c, 2 und 4 betroffen. In keinem Transkript konnten jedoch die Exons 1c und 2 gleichzeitig nachgewiesen werden.

Die schematisch dargestellten Transkripte (Abb. 3.8) zeigen, dass die Exons 1b, 1c, 2 und 4 dem alternativen Spleißen unterliegen. Es konnte aber kein Transkript nachgewiesen werden, in dem alle Exons enthalten waren. Es ist bemerkenswert, dass das Exon 1c nie gemeinsam mit Exon 2 in einem Transkript vorkommt. Desweiteren existiert ein Transkript, in dem das Exon 4 nicht enthalten ist. Da es sich innerhalb des ORF befindet, ist anzunehmen, dass das alternative Spleißen bei dem PXT1-Gen Auswirkungen auf dessen putative Proteinsequenz 
hat. Aufgrund der Tatsache, dass die mRNA des PXT1-Gens, nicht wie bisher angenommen, aus zwei Exons, sondern aus fünf Exons besteht, haben diese zusätzlichen Exons ebenso einen Einfluss auf die Proteinsequenz.

Die ursprüngliche Nukleotidsequenz der mRNA vom PXTlGen, bestehend aus zwei Exons, kodiert für 51 Aminosäuren. Das Startkodon ist im heutigen Exon 4 lokalisiert. Die Aminosäuresequenz sieht wie folgt aus:

\section{MQLRHIGDNIDHRMVREDLQQDGRDALDHFVFFFFRRVQVLLHFFWNNHLL}

Den Anfang dieser Sequenz repräsentieren die hervorgehobenen Aminosäuren die BH3ähnliche Domäne, die mittels SMART-Software (http://smart.embl-heidelberg.de/) identifiziert wurde. Es ist bekannt, dass solche Domänen eine proapoptotische Funktion besitzen (Du et al. 2011). Die proapoptotische Funktion der homologen Domäne wurde bei dem murinen Pxt1 nachgewiesen (Kaczmarek et al. 2011). In der Aminosäuresequenz wurde zusätzlich die PTS1 (Peroxisome Targeting Signal Type 1)-Domäne markiert.

Durch das Hinzukommen der weiteren Exons verlängert sich der ORF auf 134 Aminosäuren. Die längere Form von PXT1 kodiert für folgendes putatives Protein:

MKKKHDGIVYETKEVLNPSPKVTHCCKSLWLKYSFQKAYMTQLVSSQPVPAMSRNPDHNL LSQPKEHSIVQKHHQEEIIHKLAMQLRHIGDNIDHRMVREDLQQDGRDALDHFVFFFF RRVQVLLHFFWNNHLL

Durch die Sequenzverlängerung entwickelt sich aus der beschriebenen BH3-ähnlichen Domäne die markierte BH3 interacting domain (BID), in welcher die Sequenz der BH3Domäne laut in-silico-Analysen mit Hilfe der Motif-Scan-Software (http://myhits.isbsib.ch/cgi-bin/motif_scan) enthalten ist. Diese besitzt ebenso eine proapoptotische Funktion. Bei der Expressionsanalyse des PXT1-Gens konnte ein Transkript, in dem aufgrund von alternativem Spleißen die Sequenz von Exon 4 nicht enthalten ist, identifiziert werden. Das Transkript enthält einen ORF, der für ein 74 Aminosäure langes putatives Protein kodiert. Im Vergleich zu anderen Transkripten des PXT1-Gens resultiert der Verlust des Exons 4 in diesem Transkript in einer Leserasterverschiebung (Frameshift). Ein vorzeitiges Stopkodon entsteht im Exon 5. Die resultierende Aminosäuresequenz sieht wie folgt aus: 
MKKKHDGIVYETKEVLNPSPKVTHCCKSLWLKYSFQKAYMTQLVSSQPVPAMS RNPGSSTGWQRCTRSFCLLFL

Der hervorgehobene Bereich kennzeichnet den nicht betroffenen Bereich des alternativen Spleißens, d. h. die Aminosäuresequenz, für die Exon 3 kodiert. Der „Frameshift“ löscht die BID Region.

\title{
3.2.3 Überlappung des Exons 1 vom PXT-Gen mit dem Exon 1 vom KCTD20-Gen
}

Beim Sequenzabgleich der Transkripte des PXT1-Gens mit der DNA-Datenbank zeigte sich, dass sich die Sequenz des Exon 1 mit der Sequenz eines anderen Gens überlappt. Dabei handelt es sich um das KCTD20 (potassium channel tetramerisation domain containing 20)Gen, das für ein Kaliumkanalprotein kodiert und ubiquitär exprimiert wird. Im Vergleich zu PXT1 wird es auf dem komplementären DNA-Strang transkribiert (Abb. 3.9).

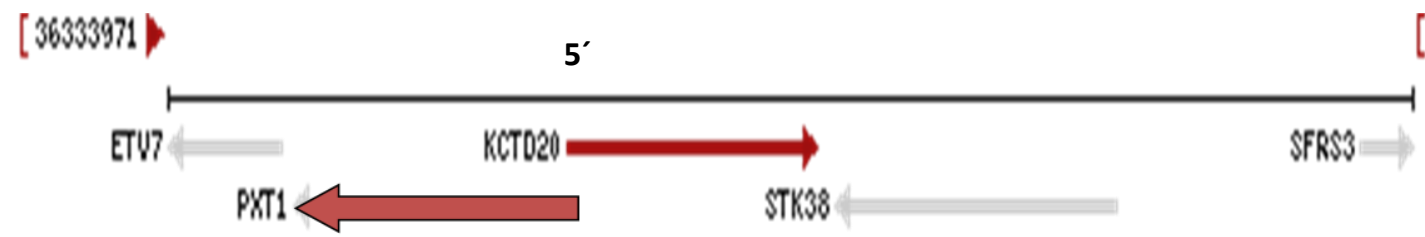

[36572244]

\begin{abstract}
Abb. 3.9: Genomische Lokalisation von PXT1 und KCTD2O
Grafische Darstellung von PXT1 und KCTD20, welche jeweils auf dem komplementären DNA-Strang transkribiert werden. Zusätzlich sind deren benachbarten Genen dargestellt (Reichweite: 36333971-36572244). Die Abkürzungen stehen jeweils für den Namen des Gens (ETV7: ETS Variant 7, SFRS3: Splicing Factor, arginine/Serine-Rich 3, STK38: Serine/Threonine Kinase 38).

Entnommen und modifiziert aus der NCBI-DNA-Datenbank.
\end{abstract}

In der folgenden Abbildung 3.10 sind die überlappenden Bereiche beider Gene in der DNASequenz farblich markiert. 
CGCCCAGCTCAGCCCCGCGGCCTTTCGACTCGGGGGTCCGAACCGCCGCCGCGTCC GGAGGAGACGCCCCCTCGGCCACAAAGGGAAGACTCGGGCCACGCCCGCCGCCACA CTCTCCCTGCCCGGTCTTCGCGCCCGAAACCGTACCGCGCCGCCACTTACTCGTCGCT CCCCGCCGCGCTGTCCCGCTCGGGGCTGGAATCCGCCCGGGAGGCGCGCGCAGGCC GCGCAGCCAGAAGCCGCAGCCGGGACCGGCTGTGCCGCAGCGGCGCGCGCCCCCC GCCCCGGACCGCGCGGCCACGCGGCTGAGTCACCCAGCGCTTCACGTTAAGAGTCCC CTCCGCGCGTGGCACGCCGGGAAGGCCGTGTCTGGGGACCCCGTCCGGGGCCGCAC CGTAAATGGGTGTCGCCTTTCCTCCAGTCCACTCTGCACCCAACCTCAGCGGGCGCAC TTTTCTGAGTTGCGCATACCCTCTCAATTATTAAAGGTTGCAGACGGAAAAGTTAGTAGT TTTCGGAATTGTAGAATACGCTCGTGCAGCGCCAGGACGGCTAATGCTTACCCGAAAAT GTGGAACCCTGATCTCCCCATGCGTGGAGCGAGGTTGGAGGTAGCGTAGTAAGAATAC TGGAGTTGCTTAAACGCATTTGCTCGAAAGTCACTACCCTGGATATACATTCTGGCCAA AAGAAAGGGGGAAAAACTCCACATTTTTCTCAAATACTGAGTTTCATGAAGGTACCTGCT ATTACAAAGGTGTATTACAAATTTTAAATCAACCGGAAGCAAGTTACTGGGAAAACTGTG TTATGAGTAAAAGATTTCAGCATTCAAAAAACATCTATATATGGTCCATGTCCTATGAACC AAATGCTGGAAAACCCAAAAGGAAGTTCTTATTGTCACGGTTTC TAGTGGCTTTTGTACTTTTAAA $3^{\prime}$

Abb. 3.10: Sequenz der beiden Gene mit Darstellung der überlappenden Bereiche In dieser DNA-Sequenz (5'-> 3'-Richtung) ist das Exon 1 der Gene PXT1 und KCTD2O und deren überlappende Sequenz dargestellt. PXT1 ist in $5^{\prime}->3^{\prime}$-Richtung und KCTD20 in $3^{\prime}->5^{\prime}$-Richtung abgebildet. Die farbigen Bereiche sind in der unten stehenden Legende beschrieben. Die nicht farblich hervorgehobenen Sequenzbereiche stellen die Intronsequenz dar.

$\begin{array}{ll}\ldots \ldots \ldots \ldots \ldots & \text { KCTD2O } \\ \ldots \ldots \ldots \ldots . . & \text { Überlappender Bereich von PXT1 und KCTD2O } \\ \ldots \ldots \ldots \ldots . . & \text { PXT1 }\end{array}$

Eine schematische Darstellung dieser sich überschneidenden Bereiche des Exons 1 beider Gene ist in Abbildung 3.11 veranschaulicht. 


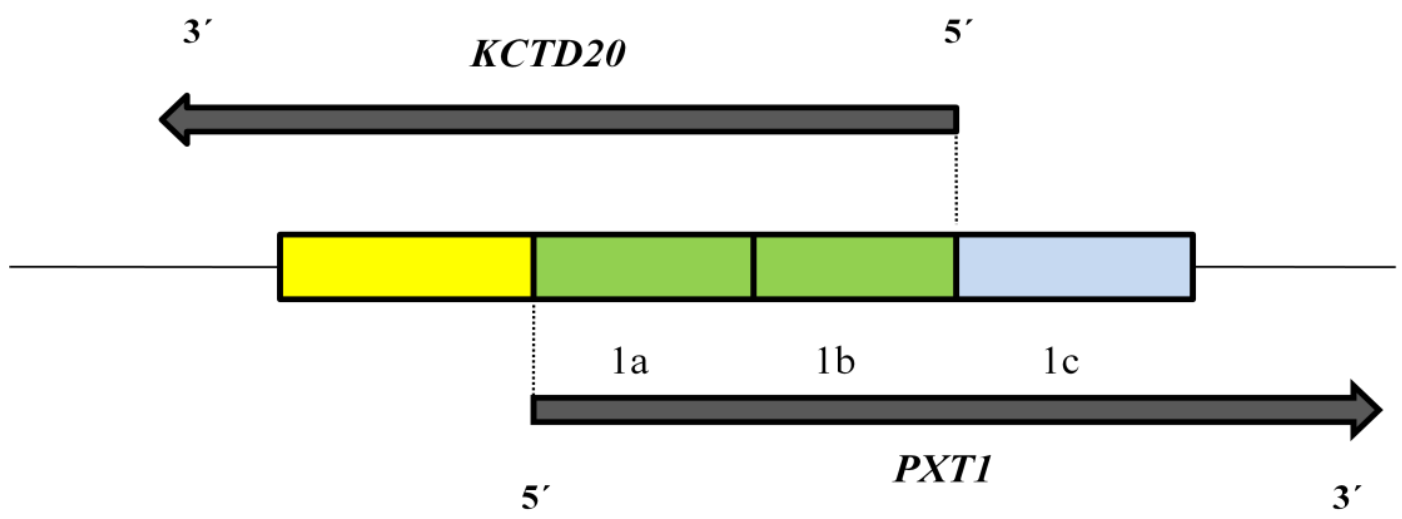

Abb. 3.11: Schematische Darstellung der überlappenden Bereiche von Exon 1 der Gene PXT1 und KCTD20 Die Darstellung zeigt das sich überlappende Exon 1 von PXT1 und KCTD20. Mit der Nummerierung 1a, 1b und 1c sind die Teile/Exons des Exons 1 von PXT1 gekennzeichnet. Die Abbildung zeigt, dass sich nur die Bereiche 1a und 1b des PXT1-Gens mit KCTD20 überschneiden. Die Sequenz des Bereich 1c befindet sich außerhalb des sich überlappenden Bereichs. Die Pfeile kennzeichnen den Start der jeweiligen Gene (5'). Zusätzlich veranschaulichen sie die Transkriptionsrichtung beider Gene. Sie ist jeweils in $5^{\prime}->3^{\prime}-$ Richtung dargestellt.

In den Abbildungen 3.9, 3.10 und 3.11 sind die gegenläufig transkribierten Gene PXT1 und KCTD20 im Verhältnis zueinander abgebildet. Die Abbildung 3.9 zeigt die Lokalisation beider Gene im Genom. Das dargestellte PXT1-Gen wurde angepasst, sodass es alle bekannten Exons beinhaltet. Neben ihrer Position und Transkriptionsrichtung sind benachbarte Gene abgebildet (Abb. 3.9). In 3'-Richtung von PXT1 befindet sich das Gen ETV7 (ets variant 7 Gene ID: 51513). In Nachbarschaft zu KCTD20, d. h. in 3'-Richtung befinden sich die Gene STK38 (serine/threonine kinase 38 Gene ID: 11329) und SFRS3 (serine/arginine-rich splicing factor 3 Gene ID: 6428). Die Abbildung 3.10 zeigt die DNASequenz des Exons 1 beider Gene und die sich überlappenden Bereiche noch detaillierter. Dieser Überlappungsbereich beider Gene umfasst 227 bp. Bei einer Gesamtlänge von 335 bp überschneiden sich 67,8 \% des Exons 1 von PXT1 mit KCTD20. Hingegen macht die Überlappung bei dem Exon 1 des KCTD20-Gens lediglich einen Anteil von 50,6 \% aus. Schließlich sind in der Abbildung 3.11 die einzelnen Exons 1 (1a, 1b und 1c) dargestellt. Es ist zu erkennen, dass sich genau die Bereiche 1a und 1b des PXT1-Gens mit dem KCTD2OGen überschneiden. Das Exon 1c befindet sich außerhalb des überlappenden Bereichs mit dem KCTD20-Gen.

Recherchen in der DNA-Datenbank haben ergeben, dass das Exon 1 des KCTD20-Gens, ebenso wie das PXT1-Gen, dem alternativen Spleißen unterliegt. Bei beiden analysierten Genen liegt dieser Bereich im 5'-UTR. 


\subsubsection{Expressionsanalyse des humanen $P X T 1$-Gens in verschiedenen Geweben}

\subsubsection{Expressionsanalyse mittels RT-PCR}

Der Ausgangspunkt für die Analysen war die Information aus Mausuntersuchungen, dass Pxt1 testis-/keimzellspezifisch exprimiert wird (Grzmil et al. 2007). Aufgrund der fehlenden Daten über PXT1 beim Menschen wurde die Expression mit cDNA von verschiedenen humanen Geweben untersucht. Das Reaktionsprodukt der verwendeten PCR (2.2.4.1) wurde gelelektrophoretisch (2.2.6) analysiert.

Als erstes wurde die Qualität der cDNA mit Primern für das TBP (TATA box binding protein, GeneID: 6908) untersucht. Ein Produkt von 180 bp Größe konnte in allen Geweben detektiert werden (Abb. 3.12E). Im Anschluss daran erfolgte die Analyse für PXT1 mit folgenden genspezifischen Primern: hPXT1RTFP3 und hPXT1RTRP1 (Abb.3.1). Diese Primerkombination ergibt ein Amplifikat, welches die Exons 4 und 5 enthält. Abbildung 3.12A zeigt, dass in allen getesteten Geweben eine Expression von diesen Exons des PXT1Gens nachzuweisen ist. Obwohl die eingesetzte cDNA-Menge gleich ist, scheint die Expression jedoch in den einzelnen Geweben unterschiedlich stark zu sein.

Es wurden weitere Primer angefertigt, die in den „,neuen“ Exons positioniert sind. So sind die Primer hPXT1RTFP1 im Exon 1, hPXT1RTFP1,5 im Exon 2 und hPXT1RTFP2 im Exon 3 lokalisiert. Als Rückwärtsprimer diente immer hPXT1RTRP1, welches im Exon 5 positioniert ist (Abb. 3.1). 


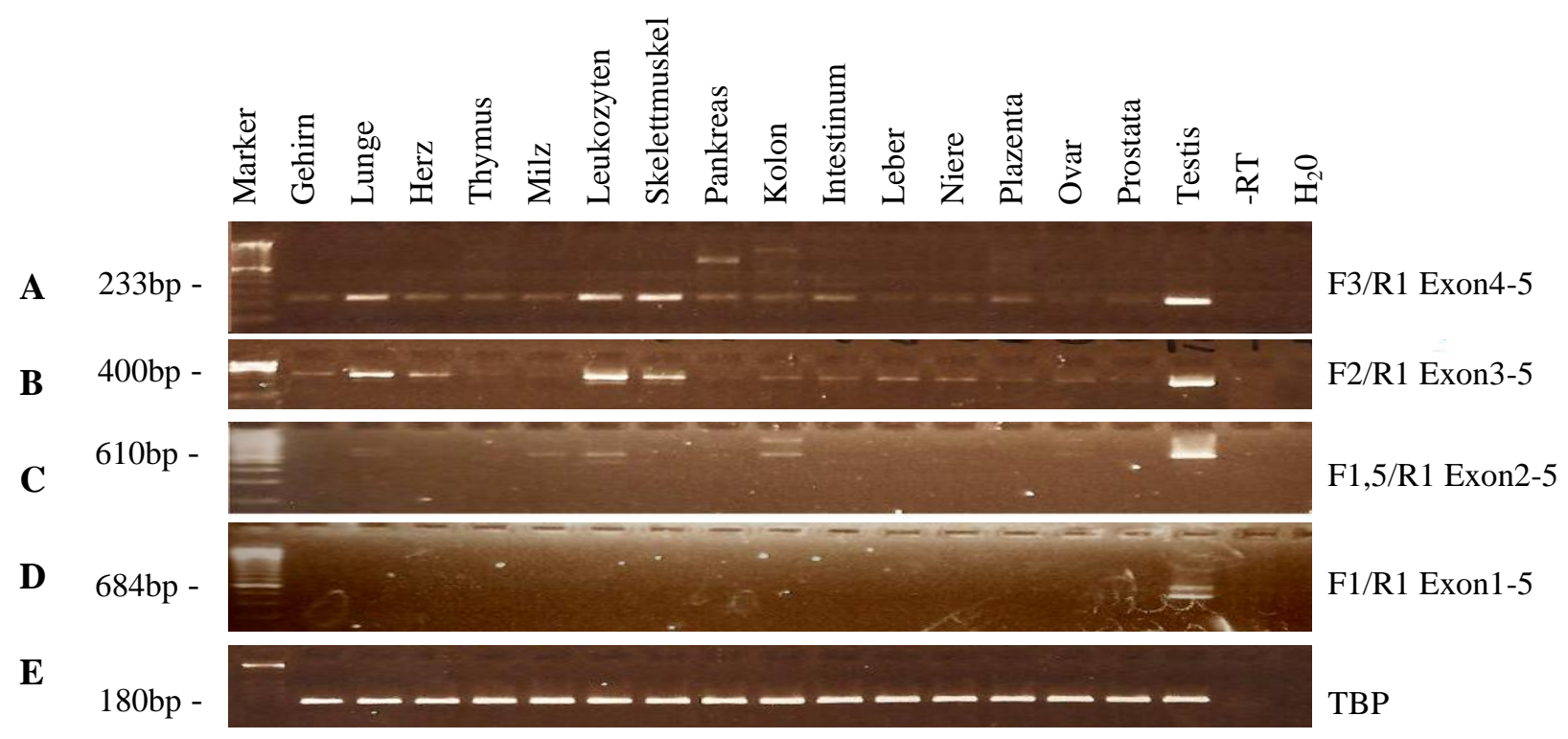

Abb. 3.12: Die PXT1-Expression in verschiedenen Geweben

1,5 \%iges Agarosegel mit den Reaktionsprodukten der PCR. (A) Das Transkript, das die Exons 4-5 umfasst, konnte in allen analysierten Geweben amplifiziert werden. (B) Eine starke Expression der Exons 3-5 ist in den Geweben von Lunge, Herz, Leukozyten, Skelettmuskeln und dem Testis nachzuweisen. (C) Das Amplifikat, das sich aus den Exons 2-5 zusammensetzt, ist in den Geweben von Lunge, Milz, Leukozyten, Kolon und dem Testis nachzuweisen. (D) Das größte Produkt, das die Exons 1-5 umfasst, konnte schließlich nur noch im Testis amplifiziert werden. (E) Die Kontrollreaktion mit dem TBP Primer hat die Qualität der cDNA nachgewiesen.

Das Produkt der Kombination des genspezifischen Primerpaares hPXT1RTFP2/hPXT1RTR1 (Abb. 3.12B) ist neben dem Testis in der Lunge, im Herzen, in den Leukozyten und im Skelettmuskel deutlich zu detektieren. In den übrigen Geweben ist nur noch eine schwache Expression zu erkennen. Im Unterschied dazu zeigt Abbildung 3.12C, dass ein Transkript, das die Exons 2 bis 5 enthält (Primer hPXT1RTFP1,5 und hPXT1RTRP1), nur noch in Geweben von Lunge, Milz, Leukozyten, Kolon und dem Testis vorhanden ist. Im Kolongewebe konnten zwei Produkte amplifiziert werden. Das obere Fragment konnte aber nicht isoliert und sequenziert werden.

Das längste Produkt von hPXT1RTFP1/hPXT1RTRP1, welches die Exons 1-5 umfasst (Abb. 3.12D), ist nur im Testis nachzuweisen. Die zwei stärksten Banden, die unter 3.2.2.2 bereits beschrieben wurden, kann man hier sehen. Da der F1 Primer im Exon 1b lokalisiert ist, kann man vermuten, dass Exon 1 nur im Testis exprimiert ist und in anderen Geweben ein kürzeres Transkript vorhanden ist. Diese Überprüfung ist aber nicht Bestandteil dieser Arbeit. 


\title{
3.2.4.2 Expressionsanalyse mittels Real Time-PCR
}

Um eine quantitative Aussage über die Expressionsstärke machen zu können, wurde die Bildung der Genprodukte mit den Template-cDNAs der unter 3.2.4.1 analysierten Geweben mithilfe der Real Time-PCR (2.2.4.5, S.29) untersucht. Die verwendeten genspezifischen Primer sind hPXT1RTFP3 und hPXT1RTRP1. Zu Beginn wurde mit einer Verdünnungsreihe (1:5-Verdünnungen) die Standardkurve für PXT1 und die „Housekeeper“ angefertigt und miteinander verglichen. Für die PXT1-Expression wurden zwei ubiquitär transkribierte Gene, GAPDH (glyceraldehyde-3-phosphate dehydrogenase, Gene ID: 2597) und PBGD (Synonyme: HMBS, hydroxymethylbilane synthase, Gene ID: 3145), für die Normalisierung verwendet. Die von der Real Time-PCR erhaltenen $\Delta \mathrm{C}_{\mathrm{T}}$-Werte sind willkürliche Werte. Indem man von den jeweiligen PXT1-Werten die „Housekeeping“-Werte (für GAPDH und $P B G D$ ) subtrahiert, werden diese berechnet. Der Mittelwert aus zwei $\Delta \mathrm{C}_{\mathrm{T}}$-Werte für jede Probe stellt den Ausgangswert für die anschließende relative Quantifizierung (2.2.4.5.1, S.30): $2^{(-\Delta \mathrm{CT})}$ dar.

Die als Template dienende cDNA wurde auf ihre Expression von PXT1 untersucht. Für die Analyse wurde das Primerpaar hPXT1qPCRFP1 und hPXT1qPCRRP1 (Abb. 3.13) als genspezifische Primer verwendet.

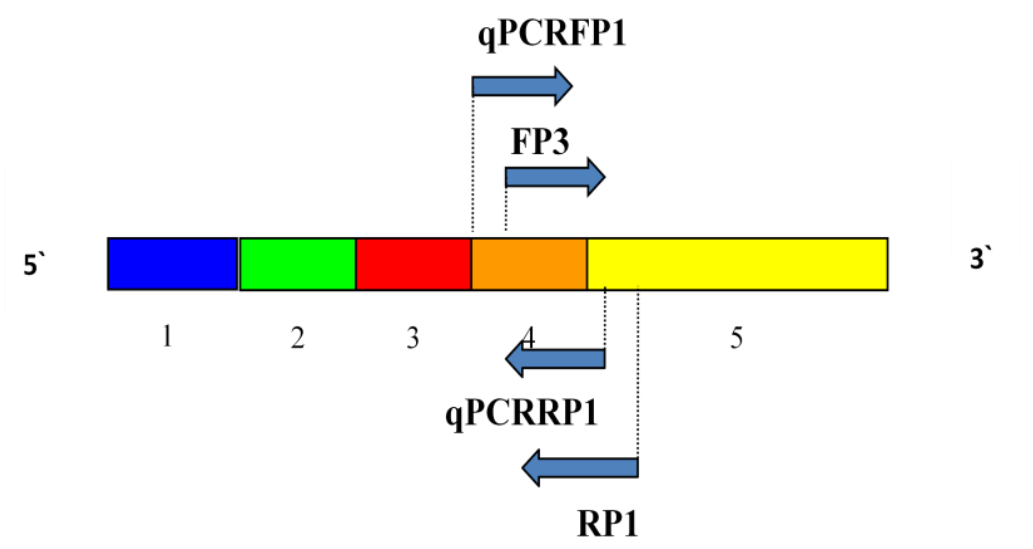

\begin{abstract}
Abb. 3.13: Lokalisation der verwendeten genspezifischen Primer für die Expressionsanalyse In dieser Abbildung sind die fünf Exons (1-5) der PXT1-cDNA farbig dargestellt. Die Pfeile veranschaulichen die Positionen der verwendeten genspezifischen Primer. Neben den Primern für die Expressionsanalyse (qPCRFP1, qPCRRP1) sind auch die Primer FP3 und RP1 für die Standardisierung der Reaktion dargestellt.
\end{abstract}

Die Primer wurden in den Exons 4 und 5 lokalisiert, da für diesen Bereich die PXT1Expression in allen Geweben gezeigt werden konnte (Abb. 3.12A). Die Real Time-PCR Reaktion wurde zweimal durchgeführt. 


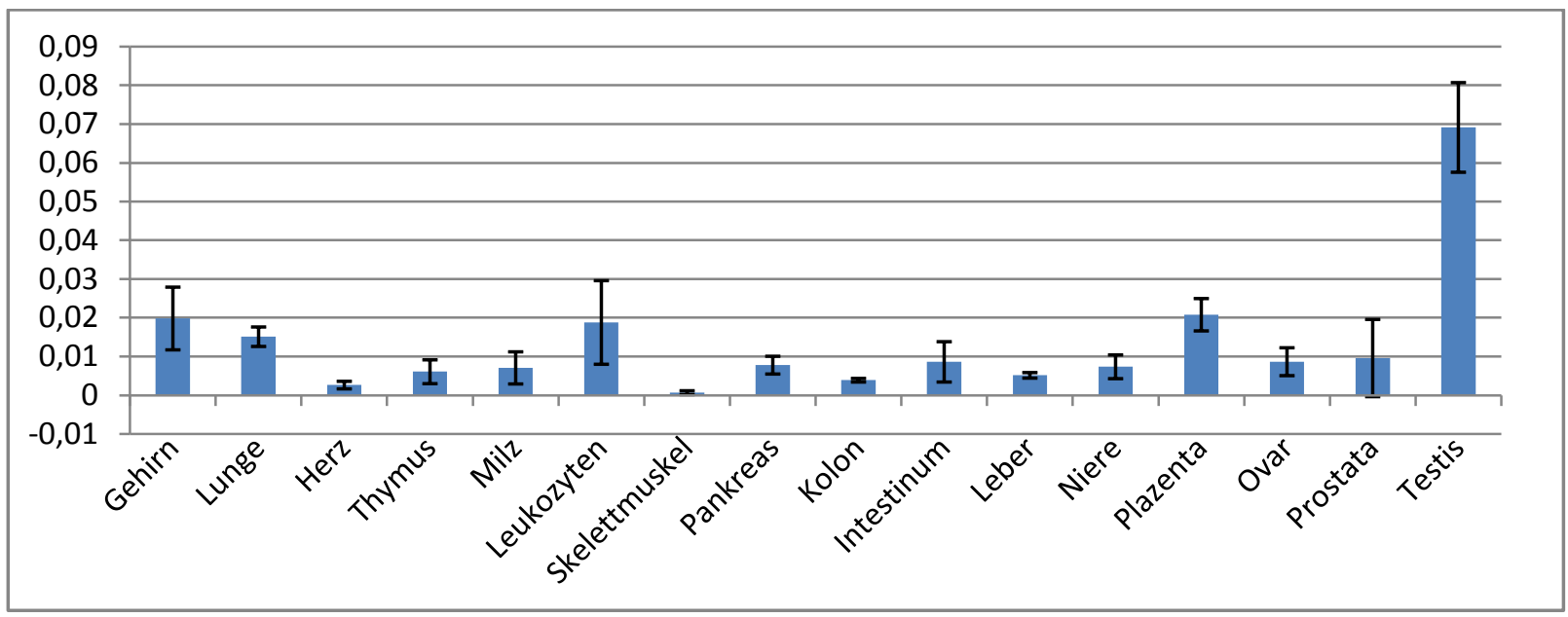

Abb. 3.14: Quantitative Analyse der Expression von $P X T 1$ in verschiedenen Geweben

Die Grafik zeigt, dass PXT1 in allen untersuchten Geweben detektiert werden konnte. Prädominant wird es im Testis exprimiert. In den übrigen Geweben wird es um den Faktor 3-4 schwächer exprimiert. Die Balken repräsentieren die Mittelwerte mit den jeweiligen Standardabweichungen aus zwei Wiederholungen der Real Time-PCR.

In der Abbildung 3.14 sind die untersuchten Gewebe auf der Abszisse angegeben. Auf der Ordinate kann man die relative Stärke der Expression in den einzelnen Geweben ablesen. Es ist zu erkennen, dass PXT1 in allen untersuchten Geweben nachzuweisen ist. Die Analyse zeigt jedoch die stärkste Expression im Testis. Der Wert beträgt in diesem Gewebe 0,07. Im Verhältnis zum Keimzellgewebe ist die Expression in den anderen Geweben um das 3-4 Fache schwächer. Nimmt man die Expression von PXT1 im Testis als $100 \%$ an, beträgt die Expression in den nächst stärker exprimierten Geweben wie Gehirn, Leukozyten und Plazenta (mit einem Wert von etwa 0,02) ca. $29 \%$. In den übrigen Geweben ist PXT1 in einer wesentlich schwächeren Dosis detektierbar. Bei der in-silico-Analyse in der NCBI-UniGeneDatenbank wurde in dem EST-Profil von PXT1 ein cDNA Klon aus der Niere (IMAGE: 3577849) entdeckt, der die Expression von PXT1 in diesem Gewebe bestätigt.

\subsubsection{Nachweis vom PXT1-Gen in HeLa-Zellen und Leukozyten}

Die Ergebnisse der RT-PCR (3.2.4.1) und der Real Time-PCR (3.2.4.2) zeigen, dass das PXT1-Gen in verschiedenen Geweben exprimiert wird. Bei diesen Analysen wurde cDNA der Firma Clontech verwendet. Als Kontrolle wurde cDNA aus der RNA von HeLa-Zellen und Leukozyten hergestellt. Für diesen Versuch wurden zum einen Karzinom/HeLa-Zellen angezüchtet (2.2.2.2.2., S.19). Zum anderen wurden Leukozyten, die von einem anonymen 
Spender mit geprüfter Fertilität stammen, isoliert (2.2.2.2.1, S.19). Die RNA (2.2.2.3, S.20) wurde in cDNA umgeschrieben (2.2.4.2, S.22). Mit den Vorwärtsprimern hPXT1RTFP2 und hPXT1RTFP3 und dem Rückwärtsprimer hPXT1RTRP1 (Abb. 3.1) aus den Versuchen 3.2.1 und 3.2.4.1 wurden neben der cDNA auch eine -RT-Kontrolle der beiden Zelllinien untersucht. Zur Herstellung der -RT-Kontrollen erfolgte die cDNA-Synthese ohne Reverse Transkriptase. In der Abbildung 3.15 sind die Resultate veranschaulicht.

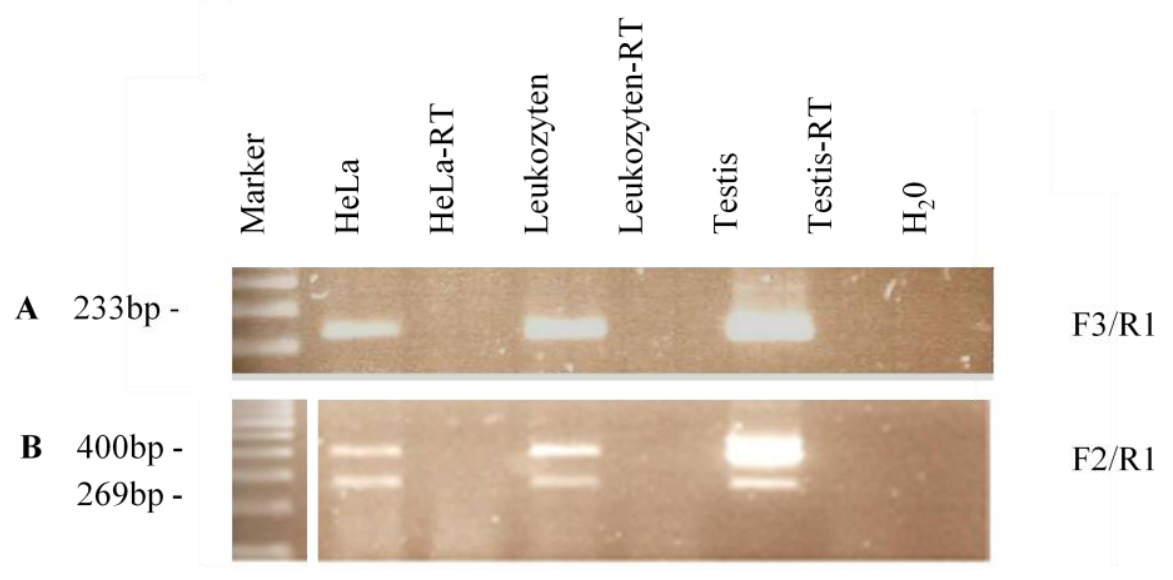

Abb. 3.15: Expression von $P X T 1$ in HeLa-Zellen, Leukozyten und im Testis

1,5 \%iges Agarosegel der PXT1-Amplifikate nach der RT-PCR. Neben den Proben ist die entsprechende -RT als Kontrolle für die Spezifität der cDNA-Synthese aufgetragen. Ebenso gibt es eine Negativkontrolle mit $\mathrm{H}_{2} \mathrm{O}$.

(A) Ein 233 bp großes Produkt, das die Exons 4-5 (F3/R1) von PXT1 enthält, konnte in allen untersuchten Geweben nachgewiesen werden. (B) In allen Geweben sind zwei Spleißprodukte identifizierbar. Die Exons 3-5 sind in dem 400 bp großen Reaktionsprodukt enthalten. In dem Amplifikat mit 269 bp fehlt das Exon 4, d. h. Exon 3 und 5 sind nachweisbar.

Mit dem Amplifikat der Primerkombination hPXT1RTFP3/hPXT1RTRP1 (Abb. 3.15A) wurden die Exons 4 und 5 auf ihre Expression in den untersuchten Zellen überprüft. Testikuläre cDNA diente als Positivkontrolle. Da die HeLa- und die Leukozyten-cDNA dieselben Resultate wie in der PCR von 3.2.4.1 zeigen, wurde als Bestätigung noch die Amplifikation mit den Primern hPXT1RTFP2/hPXT1RTRP1 (Abb. 3.15B) durchgeführt. Wie in Abbildung 3.15B dargestellt, wurden bei dieser Analyse zwei unterschiedliche PXT1Produkte, mit einer Größe von 269 bp und 400 bp, detektiert. In dem kleineren Produkt sind die Exons 3 und 5 enthalten. Nachzuweisen sind in dem größeren 400 bp langen Fragment die Exons 3, 4 und 5. Zur Kontrolle wurden die PCR-Produkte sequenziert. 


\section{3}

Die Untersuchung von DNA-Strangbrüchen in Spermienköpfen

\section{der Pxt1-Knockout-Maus}

\subsubsection{TUNEL-Analysen und das Pxt1-Gen}

Die Maus dient in vielen Bereichen als Modell für die Analyse der Funktion menschlicher Gene. Da die DNA-Sequenz vom murinen Pxt1 zu etwa 74 \% (Grzmil et al. 2007) mit der des Menschen übereinstimmt, kann man annehmen, dass das murine Protein eine ähnliche Funktion wie das humane Protein besitzen könnte.

Kaczmarek et al. (2011) haben gezeigt, dass im Mausmodel die Überexpression des PXT1Proteins Apoptose in Keimzellen induzieren kann. Die Autoren haben die Hypothese aufgestellt, dass die Funktion von Pxtl die Eliminierung von beschädigten Keimzellen ist. Wenn also Pxt1 in homozygoten Pxt1-Knockout-Tieren funktionsunfähig ist, sollte man eine Erhöhung der Anzahl beschädigter Spermien erwarten, da diese nicht komplett eliminiert werden. Um diese Hypothese zu untersuchen, wurden DNA Strangbrüche in Spermien von Pxt1-Knockout-Männchen mittels TUNEL-Assay (2.2.15, S.39) untersucht. Die Spermien wurden aus dem Nebenhodenschwanz von Pxt1-Knockout-Mäusen und als Kontrolle von Wildtyp-Mäusen isoliert (2.2.14, S.39).

Normalerweise sind die Nukleotide über eine 5'-3'-Phosphodiesterbindung miteinander verknüpft. Der Phosphatrest am 5. Kohlenstoff (5’-Ende) einer Desoxyribose ist bei dieser Verbindung mit der 3’-Hydroxygruppe der Desoxyribose eines weiteren Mononukleotides verkettet. Bei DNA-Strangbrüchen sind solche Verbindungen unterbrochen. Es resultieren freie 3'-OH-Gruppen an der Desoxyribose. Das Enzym Terminale Desoxynucleotidyl Transferase kann ein Fluoreszenz-markiertes Nukleotid an solche freien 3'-OH-Gruppen binden. Nach erfolgreicher Bindung wird ein grünes Signal emittiert, das unter dem Fluoreszenzmikroskop (Olympus BX609) detektierbar ist. Um alle Spermien erkennen zu können, werden die Spermienköpfe mit einem blauen Fluoreszenzfarbstoff, DAPI, angefärbt. TUNEL-positive Spermien zeigen in der Überlappung beider Fluoreszenzen ein blaues und ein grünes Signal. Das Ergebnis ist in der Abbildung 3.16 veranschaulicht. 


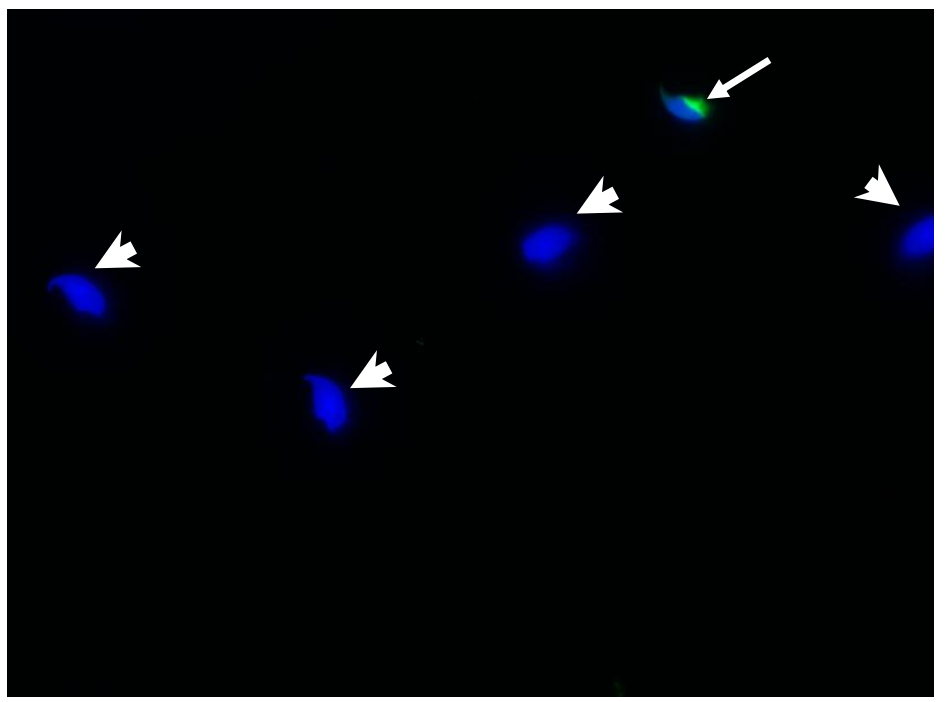

Abb. 3.16: Darstellung eines TUNELpositiven Spermiums

Die Darstellung zeigt eine Überlappung der beiden Fluoreszenzsignale. Das TUNEL-positive Spermium zeigt neben dem blauen Fluoreszenzsignal zusätzlich ein grünes Signal (Pfeil). Die TUNELnegative Spermien sind nur blau gefärbt (Pfeilköpfe).

\subsubsection{Ermittlung der Anzahl der Spermienköpfe mit DNA- Strangbrüchen in der Pxt1-Knockout-Maus}

Als Referenzen zu der Pxt1-Knockout-Maus dienten Mäuse der Mauslinien 129/SvJ und C57BL/6J. Bei der Knockout-Maus handelt es sich um Hybride dieser beiden Linien. Von den Referenzlinien wurden je drei Tiere untersucht, wohingegen bei der Pxt1-Knockout-Maus, aufgrund der hohen Variabilität zwischen den einzelnen Tieren, fünf Individuen analysiert wurden.

Tab. 3.1: Ergebnisse der TUNEL-Analysen

\begin{tabular}{lllll}
\hline & $\begin{array}{l}\text { Mittelwert } \\
(\mathbf{M W})(\mathrm{in} \%)\end{array}$ & St.-Abw. & $\begin{array}{l}\text { p vom WT } \\
\text { (gepoolt) }\end{array}$ & $\begin{array}{l}\text { p von Pxt1-KO } \\
\text { (einzeln) }\end{array}$ \\
\hline C57BL/6J (WT) & 1,05 & 0,15 & -- & $\mathrm{p}<0,05$ \\
129/SvJ (WT) & 1,13 & 0,05 & --- & 0,09 \\
Pxt1-KO & 1,53 & 0,26 & $\mathrm{p}<0,05$ & --- \\
\hline
\end{tabular}

Bei der Auswertung wurden die Tiere der Linien C57BL/6J und 129/SvJ als Wildtypen (WT) bezeichnet. Die Mittelwerte der TUNEL-Analyse zeigen, dass die Spermien der Pxt1-Knockout(KO)- im Vergleich zu den Wildtyp-Tieren eine erhöhte Anzahl an DNA-Schäden aufweisen. Unter Berücksichtigung der erhöhten Standardabweichung im Verhältnis zu den Wildtyp-Tieren zeigt das Resultat des t-Tests für unabhängige Gruppen einen signifikanten Unterschied mit $\mathrm{p}<0,05$ in der Anzahl an DNA-Strangbrüchen. Beim Abgleich mit den einzelnen Wildtyp-Tieren ist die Differenz zwischen den Schäden in den Keimzellen nur im Vergleich zu den C57BL/6J-Tieren signifikant erhöht. 
Nachdem die TUNEL-positiven im Verhältnis zu den TUNEL-negativen Spermien der einzelnen Tiere der verschiedenen Mauslinien ausgezählt waren, wurden für jede Linie der Mittelwert und die Standardabweichung ermittelt. Die Resultate sind in der Tabelle 3.1 dargestellt. Nachdem die Ergebnisse winkeltransformiert worden waren, wurden die Ergebnisse für die statistische Auswertung mit dem t-Test für unabhängige Gruppen (2.1.13, S.18) analysiert.

Wenn man die Werte für die Wildtyp-Tiere poolt, sieht man, dass im Vergleich zu den Wildtyp-Kontrolltieren die Pxt1-Knockout-Tiere signifikant mehr Spermien mit DNAStrangbrüchen aufweisen ( $\mathrm{p}<0,05)$. Bei dem Vergleich der Kontrolltiere mit den Pxt1Knockout-Tieren im einzelnen zeigt sich, dass sich mit einem $\mathrm{p}=0,09$ die Ergebnisse der Pxt1-Knockout-Tiere von denen der 129/SvJ-Mäusen nicht signifikant unterscheiden. Im Gegensatz dazu zeigt das Ergebnis des t-Tests, dass sich die Wildtyp-Tiere C57BL/6J signifikant in ihrer Anzahl an Spermien mit DNA-Schäden von den Pxt1-Knockout-Tieren unterscheiden $(\mathrm{p}<0,05)$.

\subsubsection{Induktion von Strangbrüchen mithilfe von DNase I}

Die isolierten Spermien (2.2.14, S.39) wurden mit dem Enzym DNase I unterschiedlich lang behandelt. Das Enzym induziert DNA-Strangbrüche, indem es die Phosphodiesterbindungen hydrolysiert. Mit dieser Analyse sollte herausgefunden werden, ob die DNA der Pxt1Knockout-Mäuse sensibler auf Noxen reagiert und sich daher leichter Strangbrüche in der DNA induzieren lassen. Als Kontrolle wurden bei dieser Analyse C57BL/6J-Tiere verwendet.

Die Zeitintervalle der DNase-I-Behandlung lagen in einen Abstand von jeweils 2 min zwischen 0 min und maximal 10 min. 
Tab. 3.2: Induktion von Strangbrüchen in Abhängigkeit von der Zeit

\begin{tabular}{llllll}
\hline $\begin{array}{l}\text { Zeit } \\
\text { (in min) }\end{array}$ & $\begin{array}{l}\text { Pxt1-KO } \\
\text { MW (in\%) }\end{array}$ & St.-Abw. & MW (in \%) & St.-Abw. & p-Wert \\
\hline $\mathbf{0}$ & 1,43 & 0,1 & 0,96 & 0,01 & 0,04 \\
$\mathbf{2}$ & 2,35 & 0,48 & 1,55 & 0,49 & 0,12 \\
$\mathbf{4}$ & 3,595 & 0,01 & 2,9 & 0,42 & 0,13 \\
$\mathbf{6}$ & 4,565 & 1,36 & 3,4 & 0,28 & 0,22 \\
$\mathbf{8}$ & 5,465 & 0,71 & 5,53 & 0,89 & 0,47 \\
$\mathbf{1 0}$ & 7,36 & 0,14 & 8 & 1,27 & 0,3 \\
\hline
\end{tabular}

Mit dem t-Test wurde die Anzahl an Spermien mit Chromatinschäden mit der Zunahme der Inkubationsdauer zwischen den Pxt1-Knockout(KO)-Mäusen und den Wildtyp-Tieren C57BL/6J geprüft. Zum Zeitpunkt 0 ist ein signifikanter Unterschied mit $\mathrm{p}<0,05$ zwischen beiden Tiergruppen zu sehen. Im zeitlichen Verlauf (2-10 min) steigen die DNA-Schäden kontinuierlich an, jedoch bleibt die Differenz unter dem Signifikanzlevel.

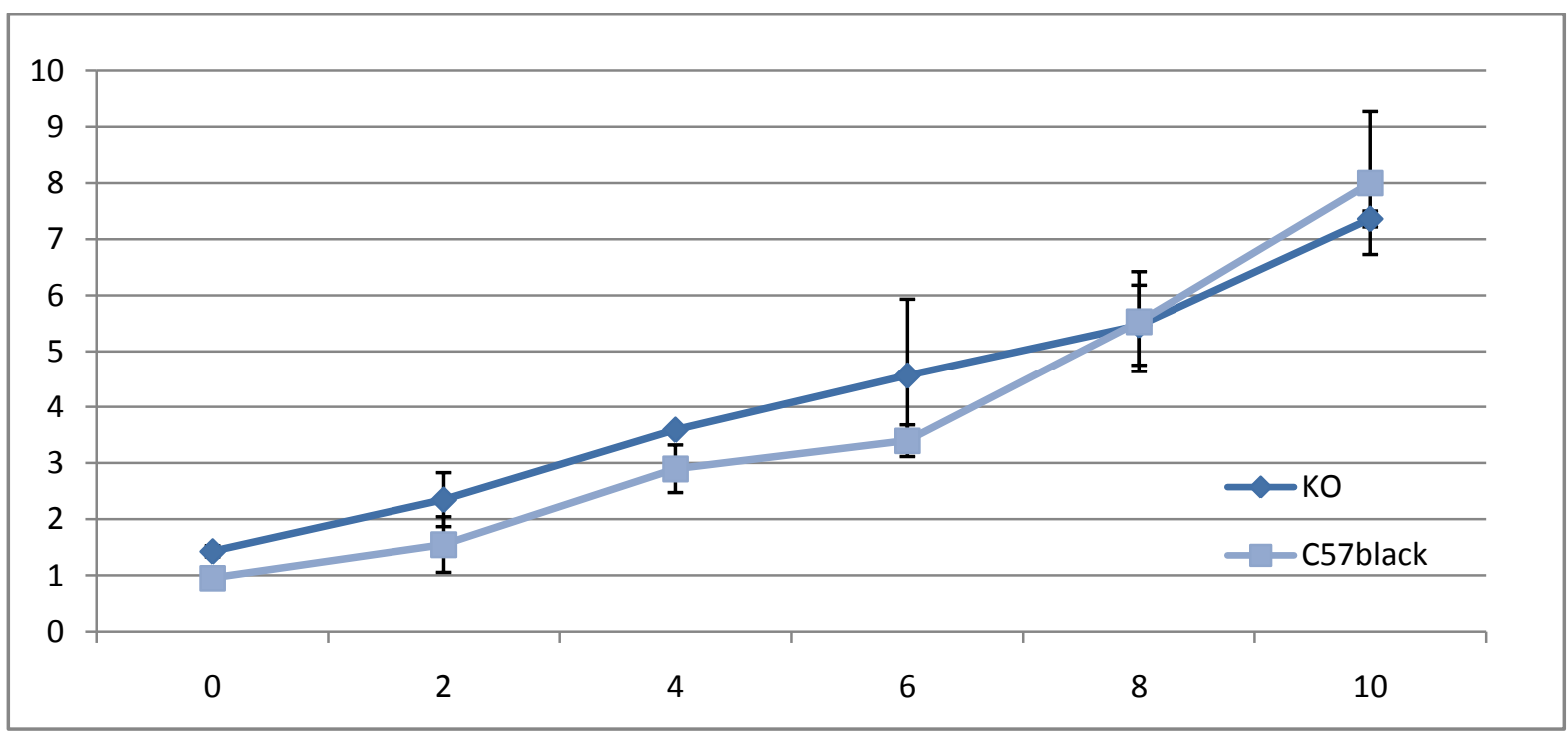

Abb. 3.17: Grafische Darstellung der Anzahl an Strangbrüchen in Abhängigkeit von der Dauer der Inkubation mit DNase I

Auf der Abszisse ist die Inkubationsdauer (in min) und auf der Ordinate die Anzahl an TUNEL-positiven Spermien (in \%) visualisiert. Die Grafik zeigt den kontinuierlichen Anstieg der Anzahl an DNA-Schäden mit zunehmender Inkubationsdauer mit dem Enzym DNase I. Zu Beginn ist eine Differenz in der Anzahl an DNA-Schäden zwischen beiden Mausarten zu erkennen. Im weiteren Verlauf hebt sich dieser Unterschied unter Berücksichtigung der Standardabweichung auf. 
Tabelle 3.2 und Abbildung 3.17 zeigen, dass die Anzahl an Spermienköpfen mit DNAStrangbrüchen linear in Abhängigkeit von der Inkubationsdauer mit dem Enzym DNaseI bei beiden analysierten Mäusearten zunimmt. Wie schon früher demonstriert, sieht man zum Zeitpunkt 0 (nicht induzierte Strangbrüche), dass die Anzahl an DNA-Strangbrüchen beider Arten sich signifikant unterscheidet $\mathrm{p}<0,05$ (3.2.1). Im Verlauf zeigt sich aber, dass unter Berücksichtigung der Standardabweichung die Werte beider Arten parallel verlaufen. Der Anstieg beider Verläufe ist in etwa konstant. Die erhaltenen Werte wurden mit dem t-Test (2.1.3, S.18) für unabhängige Gruppen zu jedem Zeitpunkt überprüft (Tab. 3.2). Im zeitlichen Verlauf der Inkubationsdauer zeigt sich ein p-Wert von 0,12 bei 2 min, von 0,13 nach 4minütiger Inkubation, von 0,22 bei 6 min, von 0,47 bei 8 min und schließlich von 0,3 nach 10-minütiger Inkubationsdauer. Es ist somit kein signifikanter Unterschied zu sehen. Weder die Pxt1-Knockout(KO)-Mäuse, noch die C57BL/6J-Wildtyp-Tiere weisen eine erhöhte Sensibilität für DNase I Behandlung auf.

\subsection{Mutationsuntersuchungen im PXT1-Gen bei infertilen Männern}

\subsubsection{Punktmutationsanalysen}

Bei den untersuchten Mausmodellen zeigte sich, dass die Pxt1-Knockout-Maus eine signifikant erhöhte Anzahl an Spermien mit DNA-Strangbrüchen aufweist. Ebenfalls führt eine Überexpression des PXT1-Proteins zu einer Degeneration der Keimzellen und somit zu einer Azoospermie (Kaczmarek 2009, Kaczmarek et al. 2011).

Beim Menschen sollte untersucht werden, ob Punktmutationen im PXT1-Gen zu Infertilität führen kann. Für diese Analysen wurden DNA-Proben von 55 anonymisierten Patienten aus der DNA-Bank der Infertilen Männer des Instituts für Humangenetik Göttingen untersucht, bei denen schon früher bekannte Ursachen für ihre Unfruchtbarkeit ausgeschlossen worden waren.

Das PXT1-Gen wurde dazu in 7 Amplikons geteilt, die alle Exons mit flankierenden Intronsequenzen beinhalten (Abb. 3.18). Aufgrund der Tatsache, dass das Gen regulatorische Sequenzen enthält, wie z. B. microRNA-Bindungsstellen, wurden außer der kodierenden Sequenz auch die UTRs mitsequenziert. 


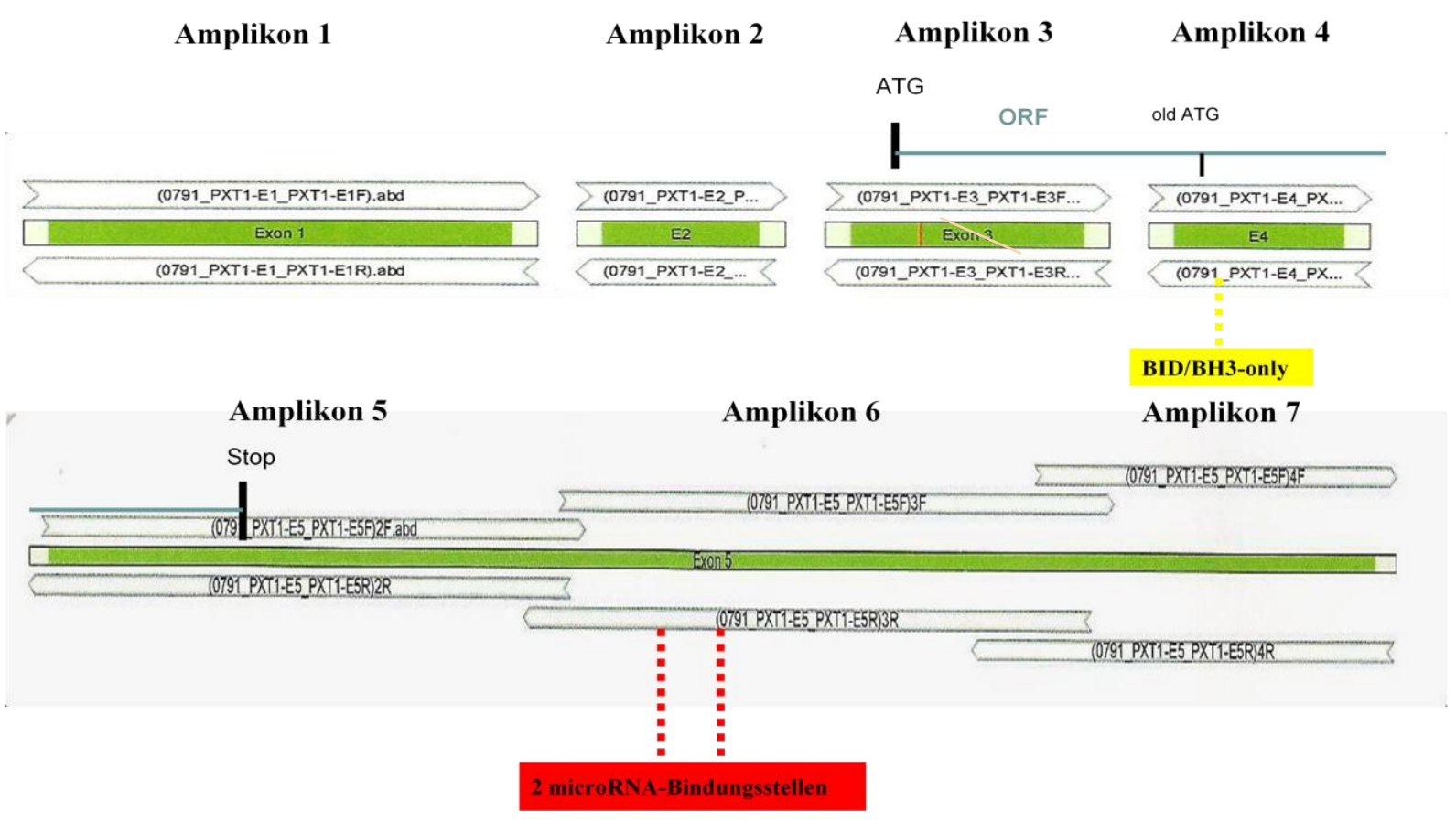

Abb. 3.18: Position der Amplikons im PXT- Gen

Die Darstellung zeigt PXT1, unterteilt in 7 Amplikons und deren jeweilige Positionen zu den Exons. Zusätzlich sind in dieser Darstellung der offene Leserahmen (ORF) sowie das Startkodon (ATG) und Stopkodon (Stop) eingezeichnet. Gelb hervorgehoben ist die proapototische BID bzw. BH3-only Domäne. Die zwei microRNABindungsstellen sind rot markiert.

Mit folgenden Primern (Tab. 3.3) erfolgte die PCR (2.2.4.1, S.21) der Patienten-DNA. Die Abbildung 3.19 zeigte die Position der Primer im PXT1-Gen.

Tab. 3.3: Verwendete Primer per Amplikon

\begin{tabular}{ll}
\hline Amplikon & Primer \\
\hline $\mathbf{1}$ & hPXT1newEx1FP, hPXT1newEx1RP \\
$\mathbf{2}$ & hPXT1newEx2FP, hPXT1newEx1RP \\
$\mathbf{3}$ & PXT1newExFP, Pxt1newExRPc \\
$\mathbf{4}$ & PXT1E1f, PTX1E1r \\
$\mathbf{5}$ & PXT1E2.1f, Pxt1E2FP2new3 (nur Seq-PCR), PXT1E2.3r \\
$\mathbf{6}$ & PXT1E2.4f, PXT1E2.5r \\
$\mathbf{7}$ & PXT1E2.6f, PXT1E2.7r \\
\hline
\end{tabular}




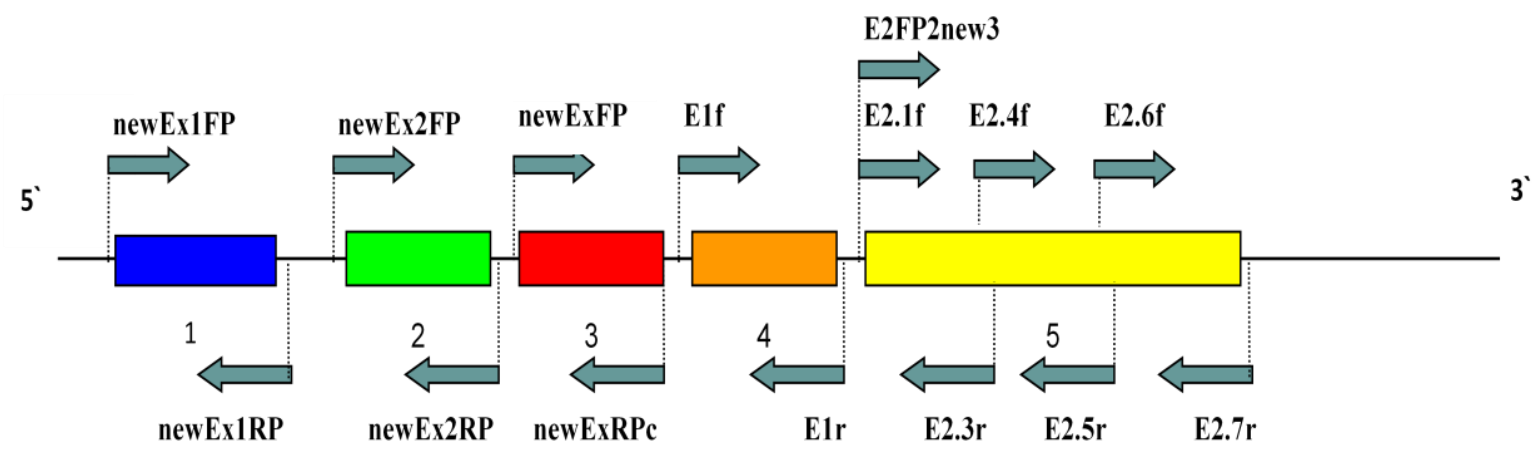

Abb. 3.19: Lokalisation der verwendeten Primer für die Punktmutationsanalyse im PXT1-Gen

In dieser Abbildung sind die fünf Exons (1-5) des PXT1-Gens farbig dargestellt. Die Pfeile veranschaulichen die Position und deren Transkriptionsrichtung der verwendeten genspezifischen Primer. Dabei handelt es sich um acht Vorwärtsprimer (newEx1FP, newEx2FP, newExFP, E1f, E2.1f, E2FP2new3, E2.4f, E2.6f) und sieben Rückwärtsprimer (newEx1RP, newEx1RP, newExRPc, E1r, E2.3r, E2.5r, E2.7r). Da der Startpunkt der Primer E2.1f und E2FP2new3 kurz vor Beginn des Exons 5 liegt und der Intronbereich an dieser Stelle irrelevant ist, sind sie in der Abbildung auf dem gleichen Startpunkt eingezeichnet (Abstand: 168 bp).

Zuerst mussten die PCR-Bedingungen für alle Primer-Paare optimiert werden. Die Ergebnisse der PCRs nach der Optimierung sind in Abbildung 3.20 dargestellt.

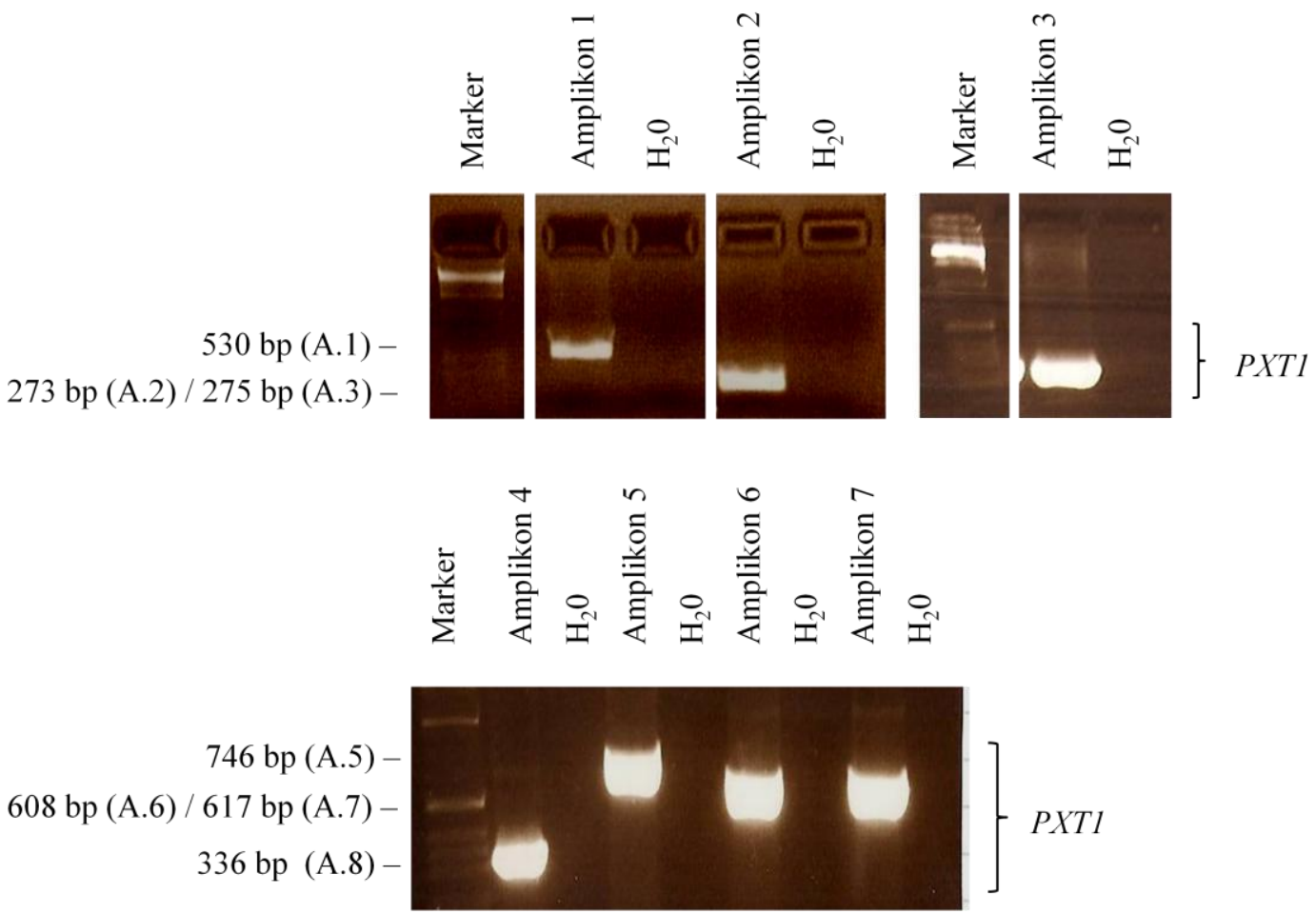

Abb. 3.20: Darstellung der Amplikons von PXT1 im Agarosegel

1,5 \%iges Agarosegel mit den PCR-Reaktionsprodukten der einzelnen Primerkombinationen. Neben den jeweiligen Reaktionsprodukten befindet sich eine Negativkontrolle $\left(\mathrm{H}_{2} \mathrm{O}\right)$.

A. - Amplika 
Die PCR-Produkte wurden aufgereinigt (2.2.5, S.32) und sequenziert (2.2.4.3, S.23). Für die Auswertung der Sequenzen wurde die Software SeqPilot verwendet. Dabei wurden die Sequenzresultate mit einer Referenz-Sequenz von PXT1 (AC_000138) verglichen, die aus der NCBI DNA-Datenbank entnommen und eingefügt wurde.

Um exakte Angaben über Veränderungen in der Basensequenz machen zu können, wurden nur Sequenzen mit ausreichender Qualität berücksichtigt. Beim Amplikon 5, welches sich im Exon 5 von PXT1 befindet, konnte unter Verwendung von PXT1E2.1f keine ausreichende Qualität der Sequenzen erzielt werden. Aus diesem Grund musste für die Sequenz-PCR ein zusätzlicher Primer, Pxt1E2FP2new3, angefertigt werden.

Beim Abgleich der Basensequenz zeigte sich an der Position des Thymins des Startkodons bei vier Patienten neben der besagten Base noch ein Cytosin an dieser Position, dessen Ausprägung so stark war, dass nicht exakt zwischen einem Hintergrund Cytosin und einer heterozygoten Mutation unterschieden werden konnte. Aus diesem Grund wurden diese Proben nochmals amplifiziert (2.2.4.1, S.21) und anstelle mit dem MegaBace 1000 mit dem ABI Prism 7900HT Sequence Detection System (Applied Biosystems) sequenziert (2.2.4.3, S.23). Auf diese Weise konnte eine Mutation ausgeschlossen werden.

Bei den untersuchten Patienten konnten zwei bekannte Single Nucleotid Polymorphisms (SNPs) identifiziert werden. Sie sind in Abbildung 3.21 veranschaulicht:

Der erste SNP (rs664370) liegt im Exon 3. Hier ist Thymin durch Cytosin ersetzt. Dieser Basenaustausch resultiert in einem Aminosäurewechsel Valin zu Alanin an der Position 15 des PXT1-Proteins. 24 von 55 Patienten haben diesen Polymorphismus in heterozygotem und 5 Patienten in homozygotem Zustand.

Im Gegensatz zum ersten identifizierten SNP ist der zweite Polymorphismus (rs62403732) synonym. Er ist im Genom von 7 Patienten nachzuweisen. Dieser SNP ist im Exon 4 lokalisiert und durch den Austausch Guanin zu Adenin charakterisiert. 


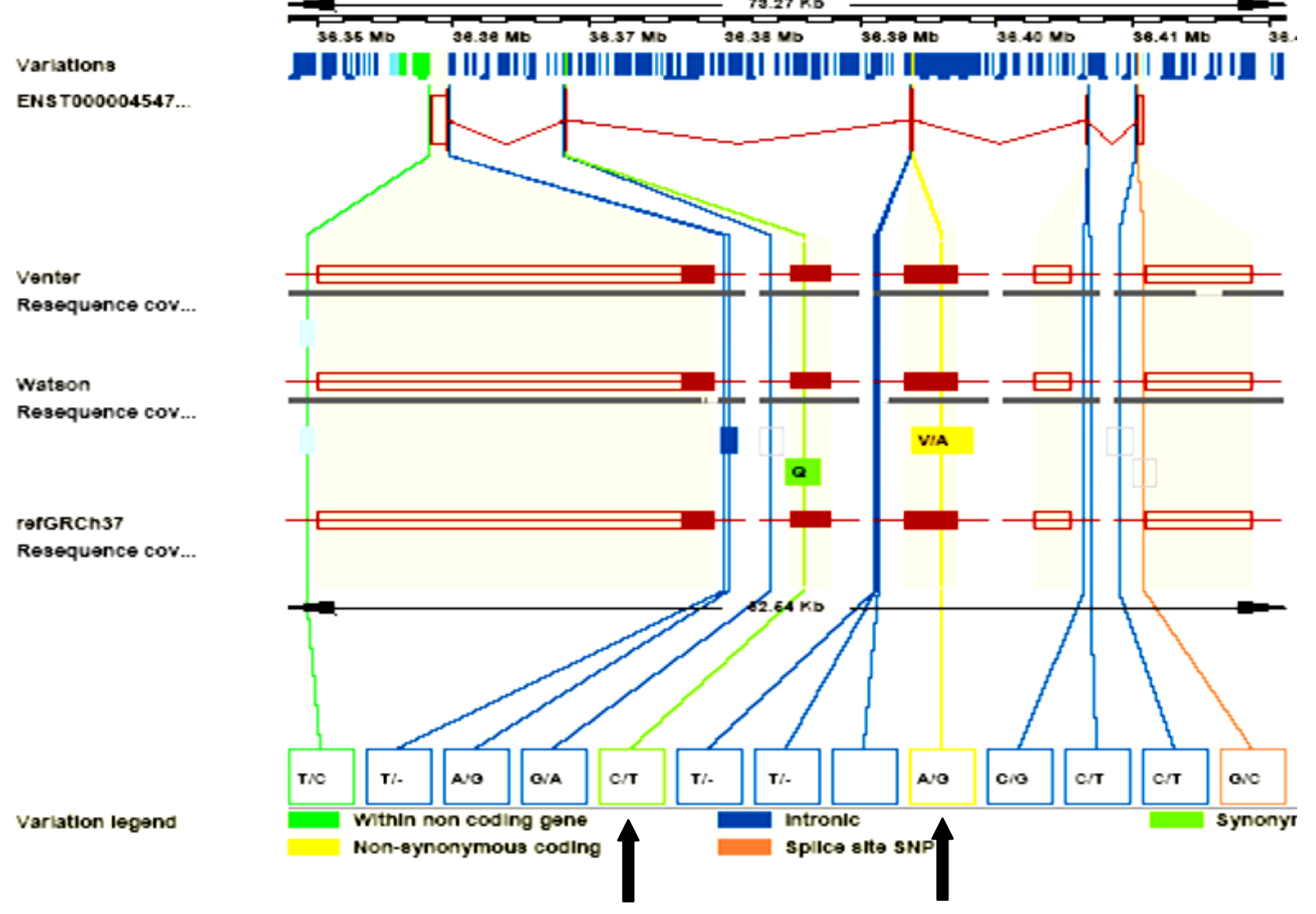

Abb. 3.21: Grafische Darstellung aller bekannten Polymorphismen in PXT1 aus der Ensemble-Datenbank Die Grafik aus der Gendatenbank zeigt die fünf Exons mit den zugehörigen Introns von PXT1. Die Darstellung erfolgt in $3^{\prime}->5^{\prime}-$ Richtung und veranschaulicht die bekannten Polymorphismen des untersuchten Gens. Die in dieser Arbeit identifizierten Polymorphismen sind mit Pfeilen markiert.

Bei allen 55 analysierten Patienten konnten mittels der Sequenzierung keine Mutationen in den Exons und in den Exon-Intron-Übergängen von PXT1 identifiziert werden.

\subsubsection{Ergebnisse der Deletionsanalyse mittels Real Time-PCR}

Eine Punktmutation im PXT1-Gen konnte als Ursache für Infertilität bei den hier untersuchten Patienten nicht identifiziert werden (3.4.1). Deletionen oder Duplikationen in Exons können die Proteinfunktion massiv beeinflussen. Allerdings können solche Deletionen nicht mittels Sequenzierung erfasst werden. Aus diesem Grund wurde eine Auswahl an Patientenproben mithilfe der Real Time-PCR (2.2.4.5, S.29) und der Auswertungsmethode der absoluten Quantifizierung (2.2.4.5.2, S. 31) auf putative Deletionen oder Duplikationen hin untersucht.

Die verwendeten Primer sind in der Tabelle 3.4 aufgelistet und deren Lokalisation ist in der Abbildung 3.22 dargestellt. 
Tab. 3.4: Verwendete Primer per Exon

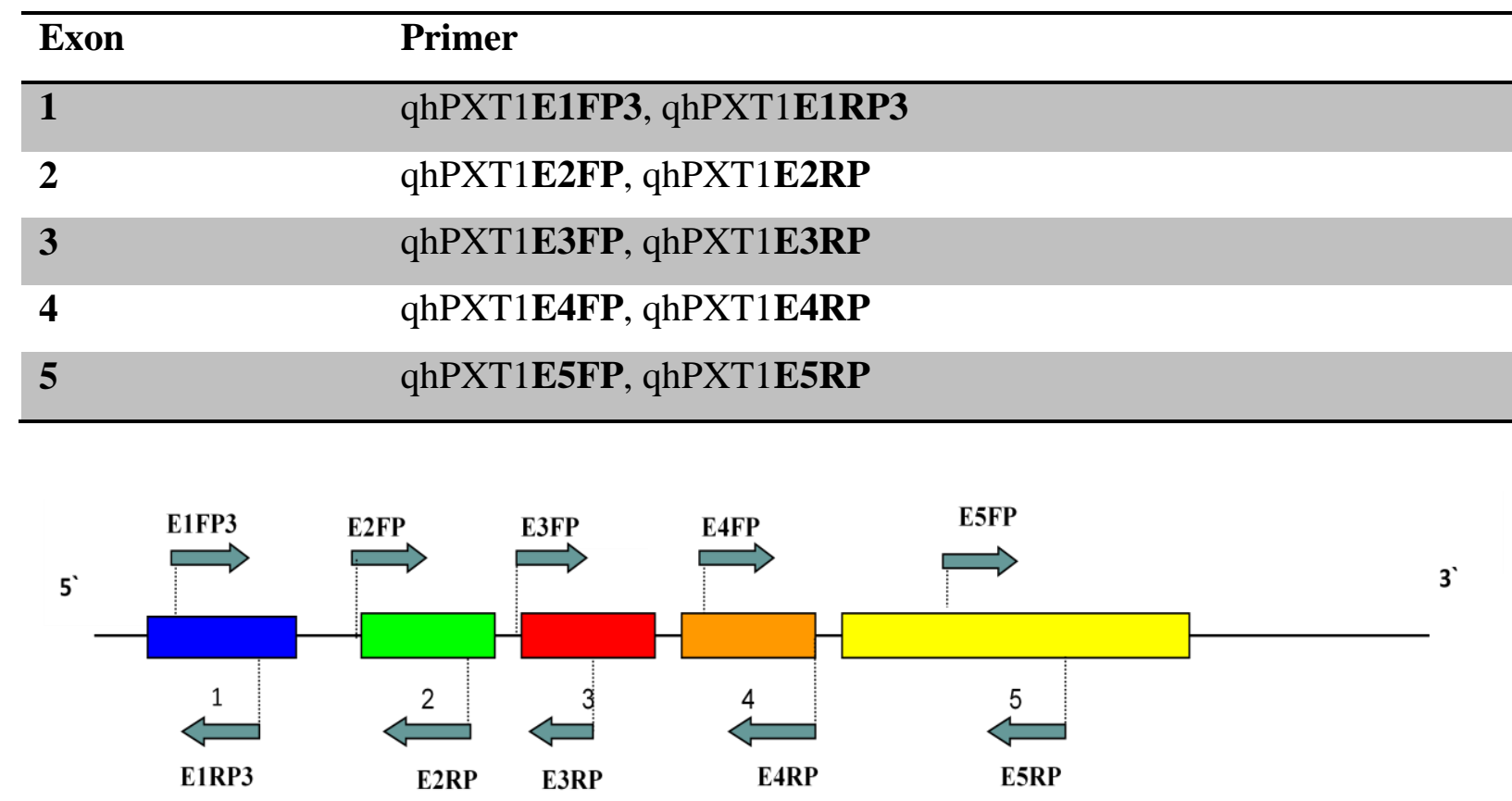

Abb. 3.22: Lokalisation der verwendeten Primer für die Deletionsanalyse

In dieser Abbildung sind die fünf Exons (1-5) des PXT1-Gens farbig dargestellt. Die Pfeile veranschaulichen die Position und die Transkriptionsrichtung der verwendeten genspezifischen Primer. Dabei handelt es sich um fünf Vorwärtsprimer (E1FP3, E2FP, E3FP, E4FP, E5FP) und fünf Rückwärtsprimer (E1RP3, E2RP, E3RP, E4RP, E5RP).

Zusätzlich zu den genspezifischen Primern wurden Referenzprimer verwendet, deren Bindungsstellen als zwei Kopien im Genom vorhanden sind. Für den Standard 1 wurden die Primer 3p2-F und 3p2-R, welche auf dem kurzen Arm des Chromosoms 3 lokalisiert sind, und für den Standard 2 die Primer 1p008-F und 1p008-R verwendet. Sie binden am kurzen Arm des Chromosoms 1.

Von den unter 3.4.1 aufgezeigten Patienten wurden jeweils 10 Patienten mit Oligo- und 10 Patienten mit Azoospermie für diese Analyse per Zufall ausgewählt. In dieser Studie sollten die Patienten auf Copy Number Variations $(C N V)$ hin untersucht werden.

Die Optimierung erfolgte an Wildtyp-DNA, d. h. von anonymen Individuen mit geprüfter Fertilität. Nach Optimierung der Primer und der qPCR-Konditionen wurden für diese Analyse drei verschiedene, anonymisierte Kontrollen verwendet. Die Ergebnisse der einzelnen Proben wurden mit der $\Delta \mathrm{C}_{\mathrm{T}}$-Methode auf die Standards normalisiert. Von den Kontrollen (WT) wurde der Mittelwert berechnet. Das Ergebnis ist als Verhältnis zur Kontrolle dargestellt. Liegt der Wert bei ca. 1, ist keine CNV zu vermuten. Liegt der Wert dagegen nah bei 0,5, ist eine Deletion in heterozygotem Zustand anzunehmen. Wenn der Wert bei ca. 1,5 liegt, könnte man eine Duplikation in heterozygotem oder bei einem Wert von etwa 2,0 in homozygotem 
Zustand vermuten. Bei der Primeroptimierung zeigte sich in einer anonymen Kontrolle (Probe 111) eine Deletion. Die Probe ist in der Tabelle 3.5 verzeichnet. Bei der Analyse diente sie aber nicht mehr als Referenz und wurde durch eine zusätzliche WT Kontrolle ersetzt.

Tab. 3.5: Ergebnisse der Analyse bei Patienten mit Oligozoospermie

\begin{tabular}{|c|c|c|c|c|c|c|}
\hline Patient & Mittelwert & St.-Abw. & Mittelwert & St.-Abw. & Mittelwert & St.-Abw. \\
\hline & Ex1 & Exon1 & Ex2 & Exon2 & Ex3 & Exon3 \\
\hline WT (N=3) & 1 & - & 1 & - & 1 & - \\
\hline 111 & 0,43 & 0,06 & 1,05 & 0,14 & 1 & - \\
\hline 665 & 1,89 & 0,2 & 1,01 & 0,14 & 0,95 & 0,14 \\
\hline 555 & 1,31 & 0,03 & 1,02 & 0,02 & 1,08 & 0,02 \\
\hline 659 & 1,05 & 0,04 & 1,09 & 0,07 & 1,04 & 0,07 \\
\hline 625 & 1,18 & 0,01 & 1,25 & 0,15 & 1,13 & 0,14 \\
\hline 602 & 1,24 & 0,08 & 1,28 & 0,20 & 1,23 & 0,2 \\
\hline 600 & 1,15 & 0,02 & 1,12 & 0,19 & 1,09 & 0,19 \\
\hline 597 & 1,39 & 0,02 & 1,11 & 0,01 & 1,04 & 0,01 \\
\hline 598 & 0,84 & 0,06 & 0,93 & 0,10 & 0,99 & 0,11 \\
\hline 672 & 1,4 & 0,06 & 0,96 & 0,19 & 1,11 & 0,22 \\
\hline 567 & 1,23 & 0,07 & 1,27 & 0,08 & 1,23 & 0,08 \\
\hline
\end{tabular}

\begin{tabular}{lllll}
\hline Patient & Mittelwert & St.-Abw. & Mittelwert & St.-Abw. \\
\hline & Ex4 & Exon4 & Ex5 & Exon5 \\
WT $(\mathbf{N = 3})$ & 1 & - & 1 & - \\
$\mathbf{1 1 1}$ & 1 & - & 1 & - \\
$\mathbf{6 6 5}$ & 0,70 & 0,21 & 1,04 & 0,15 \\
$\mathbf{5 5 5}$ & 1,01 & 0,33 & 1,12 & 0,02 \\
$\mathbf{6 5 9}$ & 0,85 & 0,27 & 1,11 & 0,08 \\
$\mathbf{6 2 5}$ & 1,07 & 0,32 & 1,26 & 0,16 \\
$\mathbf{6 0 2}$ & 1,21 & 0,42 & 1,2 & 0,19 \\
$\mathbf{6 0 0}$ & 0,81 & 0,07 & 1,17 & 0,2 \\
$\mathbf{5 9 7}$ & 0,92 & 0,2 & 1,14 & 0,01 \\
$\mathbf{5 9 8}$ & 0,73 & 0,23 & 1 & 0,11 \\
$\mathbf{6 7 2}$ & 0,86 & 0,27 & 1,09 & 0,21 \\
$\mathbf{5 6 7}$ & 0,91 & 0,19 & 1,2 & 0,08 \\
\hline
\end{tabular}

Die Tabelle zeigt die Ergebnisse der Real TimePCR (Mittelwert und Standardabweichung) für die jeweiligen Exons. Abweichung der Mittelwerte in Richtung einer Deletion $(<0,5 \pm 0,1)$ oder Duplikation $(\geq 1,36)$ sind ,fett" schwarz hervorgehoben. 


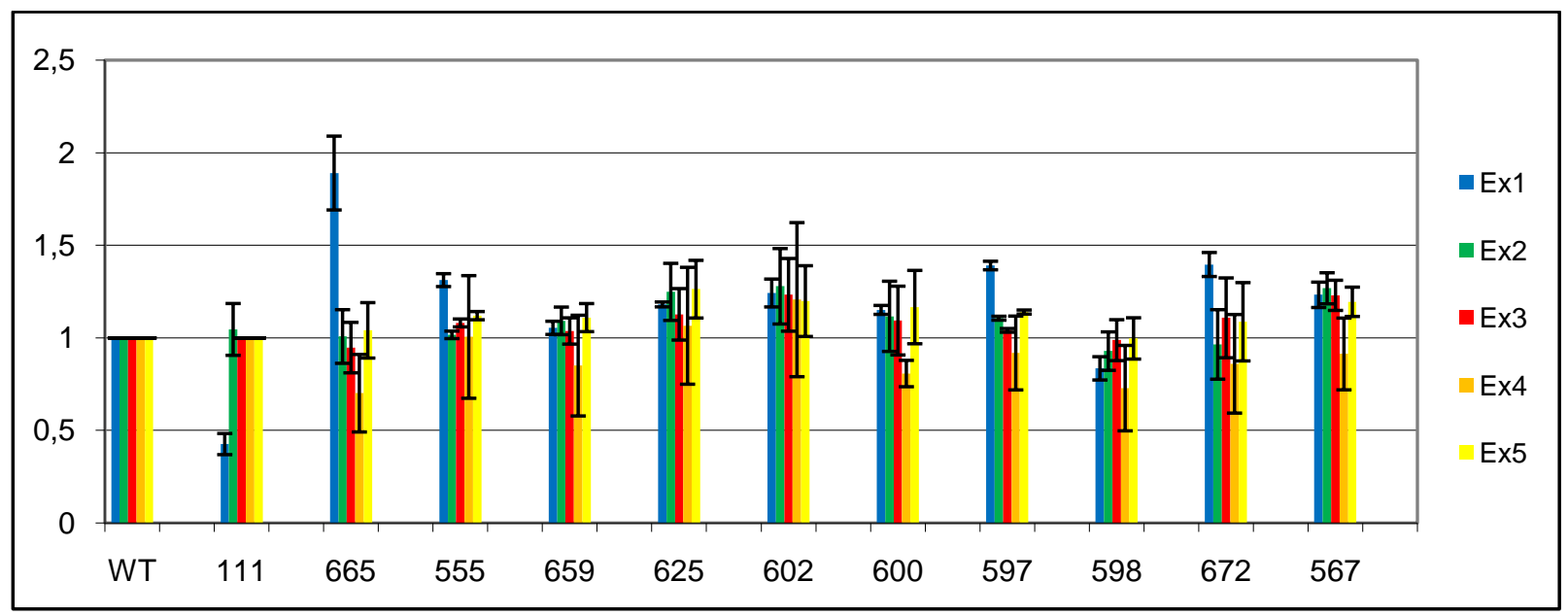

Abb. 3.23: Grafische Darstellung der Oligozoospermieergebnisse

Quantifizierung der Kopienzahl der fünf Exons (Ex1-5) des PXT1-Gens. Auf der Abszisse ist die Probennummer des Patienten und auf der Ordinate die Kopienzahl dargestellt. Die Balken stellen den jeweiligen Mittelwert dar. Innerhalb der Balken ist die Standardabweichung schwarz hervorgehoben. WT repräsentiert den Mittelwert von drei Kontrollspendern. Dieser Wert wurde als 1 festgelegt.

In Tabelle 3.5 sind die Ergebnisse der Quantifizierung dargestellt, die in Abbildung 3.23 grafisch veranschaulicht sind. Der Wert 1,0 ist mit zwei Kopien im Genom definiert. Bei der Probe 111, die eigentlich einen Wildtyp darstellt, ist im Bereich des Exon 1 eine Deletion von PXT1 zu sehen. Da die Nummer 111 nur etwa 0,5 bzw. $50 \%$ dieses Wertes erreicht, ist somit anzunehmen, dass dieser Patient nur eine Kopie von PXT1 im Genom besitzt. In Abbildung 3.18 ist $\mathrm{zu}$ sehen, dass das Exon 1 bei den untersuchten Patienten noch eine andere Abweichung von der Norm zeigt. Der Patient 665 scheint in diesem Bereich eine homozygote Duplikation zu haben, da sich der Wert 1,89 ziemlich der 2,0-Marke nähert. Demzufolge müsste er zwei Genkopien (vier Allele) besitzen. Im Gegensatz dazu scheinen die Patienten mit der Nummer $597(1,39)$ und $672(1,4)$ eine heterozygote Duplikation aufzuweisen. Drei genomische PXT1-Exon-1-Kopien sind hier wahrscheinlich.

Die restlichen Ergebnisse befinden sich unter Berücksichtigung der Standardabweichung im Bereich der Norm, d. h. um den Wert 1,0. 
Tab. 3.6: Ergebnisse der Analyse bei Patienten mit Azoospermie

\begin{tabular}{lllllll}
\hline Patient & Mittelwert & St.-Abw. & Mittelwert & St.-Abw. & Mittelwert & St.-Abw. \\
\hline & Ex1 & Ex1 & $\mathbf{E x 2}$ & $\mathbf{E x 2}$ & $\mathbf{E x 3}$ & Ex3 \\
$\mathbf{W T}(\mathbf{N = 3})$ & 1 & - & 1 & - & 1 & - \\
$\mathbf{7 8 6}$ & 1,04 & 0,05 & $\mathbf{1 , 4 2}$ & 0,2 & 1,08 & 0,02 \\
$\mathbf{6 5 7}$ & $\mathbf{1 , 4 1}$ & 0,01 & 1,20 & 0,07 & 1,15 & 0,05 \\
$\mathbf{6 1 2}$ & 1,18 & 0,31 & $\mathbf{1 , 3 6}$ & 0,18 & $\mathbf{1 , 5 7}$ & 0,23 \\
$\mathbf{6 3 9}$ & $\mathbf{1 , 5 2}$ & 0,30 & $\mathbf{1 , 6 1}$ & 0,35 & 1,22 & 0,13 \\
$\mathbf{6 2 7}$ & 1,17 & 0,06 & 1,34 & 0,2 & 1,33 & 0,22 \\
$\mathbf{6 7 5}$ & $\mathbf{1 , 5 1}$ & 0,09 & 1,2 & 0,07 & 0,98 & 0,14 \\
$\mathbf{6 6 3}$ & 1,28 & 0,01 & $\mathbf{1 , 4 4}$ & 0,1 & $\mathbf{1 , 4 5}$ & 0,21 \\
$\mathbf{6 6 2}$ & 1,01 & 0,03 & 1,16 & 0,06 & 0,87 & 0,16 \\
$\mathbf{8 0 4}$ & $\mathbf{0 , 4 4}$ & 0 & 0,92 & 0,02 & 0,73 & 0,07 \\
$\mathbf{6 2 1}$ & 0,90 & 0,15 & $\mathbf{1 , 8 2}$ & 0,53 & 1,28 & 0,34 \\
\hline
\end{tabular}

\begin{tabular}{lllll}
\hline Patient & Mittelwert & St.-Abw. & Mittelwert & St.-Abw. \\
\hline & Ex4 & Ex4 & Ex5 & Ex5 \\
$\mathbf{W T}$ & 1 & - & 1 & - \\
$\mathbf{7 8 6}$ & 1 & 0,15 & 1,06 & 0,02 \\
$\mathbf{6 5 7}$ & 1,02 & 0,06 & 1,04 & 0,02 \\
$\mathbf{6 1 2}$ & 1,32 & 0,18 & 1,26 & 0,08 \\
$\mathbf{6 3 9}$ & $\mathbf{1 , 3 6}$ & 0,05 & 1,28 & 0,05 \\
$\mathbf{6 2 7}$ & 1,16 & 0,08 & 1,32 & 0,2 \\
$\mathbf{6 7 5}$ & 0,9 & 0,05 & 0,97 & 0,02 \\
$\mathbf{6 6 3}$ & 1,22 & 0,09 & 1,32 & 0,2 \\
$\mathbf{6 6 2}$ & 0,9 & 0,15 & 1 & 0,12 \\
$\mathbf{8 0 4}$ & 0,76 & 0,1 & 0,71 & 0,08 \\
$\mathbf{6 2 1}$ & 1 & 0,03 & 1,18 & 0,12 \\
\hline
\end{tabular}

Die Tabelle zeigt die Ergebnisse der RealTimePCR (Mittelwert und Standardabweichung) für die einzelnen Exons von PXT1. Mittelwerte, die sich in Richtung einer Deletion $(<0,5 \pm 0,1)$ oder Duplikation $(\geq 1,36)$ orientieren, sind ,fett" schwarz hervorgehoben. 


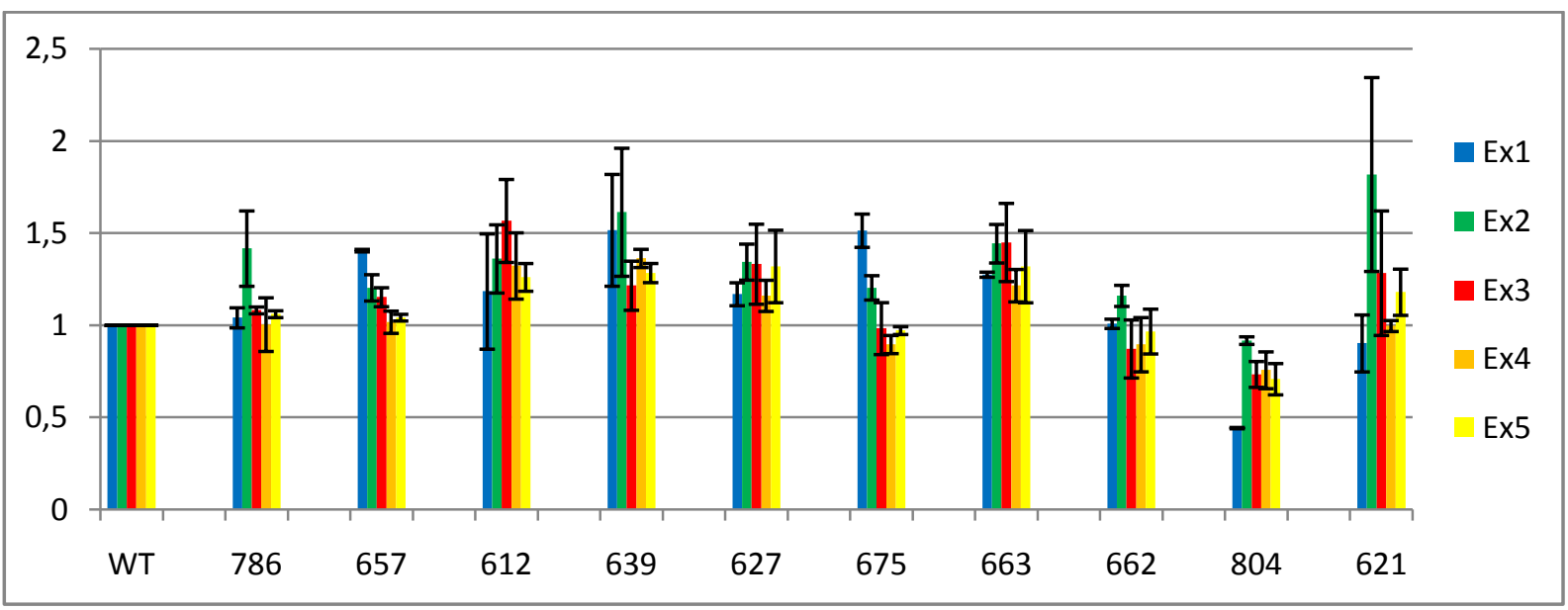

Abb. 3.24: Grafische Darstellung der Azoospermieergebnisse

Die Quantifizierung der Kopienzahl der fünf Exons (Ex1-5) des PXT1-Gens. Auf der Abszisse ist die Patientennummer und auf der Ordinate die Kopienanzahl abgebildet. Die Balken stellen den jeweiligen Mittelwert dar. Innerhalb der Balken ist die Standardabweichung schwarz hervorgehoben. WT repräsentiert den Mittelwert von drei Kontrollspendern. Dieser Vergleichswert wurde als 1 festgelegt.

Ebenso wie die untersuchten Oligozoospermiepatienten zeigen Azoospermiker auch Auffälligkeiten im Exon 1 (Tab. 3.6 und Abb. 3.24). Bei den Patienten 675 (1,51) und 657 $(1,41)$ konnte man in diesem Exon jeweils eine Duplikation in heterozygoter Ausprägung nachweisen. Es konnte auch ein Patient mit einer Deletion im Exon 1 identifiziert werden. Der Patient Nummer 804 zeigt einen Wert von 0,44 im Bereich des Exon 1. Nur eine Kopie des $P X T 1$ Gens ist hier vorhanden.

Ebenso sind in diesem Patientenkollektiv auch Abweichungen von der Norm in den Exons 2, 3 und 4 zu finden. Bei den Männern 621 und 786 ist jeweils eine Duplikation im Exon 2 nachzuweisen. Bei dem Patient $786(1,42)$ ist von einer heterozygoten Duplikation auszugegehen. Im Gegensatz dazu ergab die Analyse bei dem Patient 621 einen Wert von 1,82. Bei einem Wert zwischen 1,5 und 2,0 und einer Standardabweichung von 0,5 sind hier 3-4 genomische Kopien von PXT1 möglich, d. h. es könnte eine heterozygote oder homozygote Duplikation vorliegen. Bei drei weiteren Patienten waren sogar in mehren Exons heterozygote Duplikationen zu identifizieren. Der Patient 612 besitzt im Exon $2(1,36)$ und im Exon 3 (1,57) eine solche Duplikation. Ebenso zeigt der Patient 663 in diesen Exons (Exon 2 1,44 und Exon 3 1,45) diese Duplikationen. In drei Exons konnte bei dem Patient 639 eine Duplikation nachgewiesen werden: Exon $1(1,52)$, Exon $2(1,61)$ und Exon $4(1,36)$. Da aber Exon 3 nicht dupliziert ist und im Exon 4 die Standardabweichung 0,05 beträgt, ist eher davon auszugehen, dass in Exon 4 auch keine Duplikation vorliegt. Bei den übrigen Patienten ging 
man bei Werten von $<1,36$ aus diesem Grund von einem normalen Allelsatz mit zwei Kopien aus.

\subsubsection{Ergebnisse der arraybasierten Comparativen Genomischen Hybridisierung (aCGH)}

Mithilfe der aCGH (2.2.13, S.35) sollten die markanten Ergebnisse der Deletions/Duplikationsuntersuchung bestätigt werden. Der Patient 804 und die ursprüngliche Referenz, Probe 111, sollten auf ihre Deletion mit dieser Methode überprüft werden. Bei den Patienten 672, 597, 665, 639 und 675 sollten im Exon 1 bzw. in den Exons 1 und 2 die Duplikationen überprüft werden.

Da die DNA schon sehr alt ist, hatten nicht alle Proben eine ausreichend gute Qualität, um mittels einer aCGH analysiert zu werden. Aufgrund des Qualitätsproblems war nur eine Überprüfung der Probe 665 möglich. Die Auswertung des Arrays erfolgte mit der Software DNA Analytics 4.0.85. Die Duplikationen im Exon 1 konnten mit der Sonde chr6: 36,538,526-36,538,585 (gtattctacaattccgaaaactactaacttttccgtctgcaacctttaataattgagagg, rev. compl: cctctcaattattaaaggttgcagacggaaaagttagtagttttcggaattgtagaatacbestätigen) für der Probe 665 bestätigt werden.

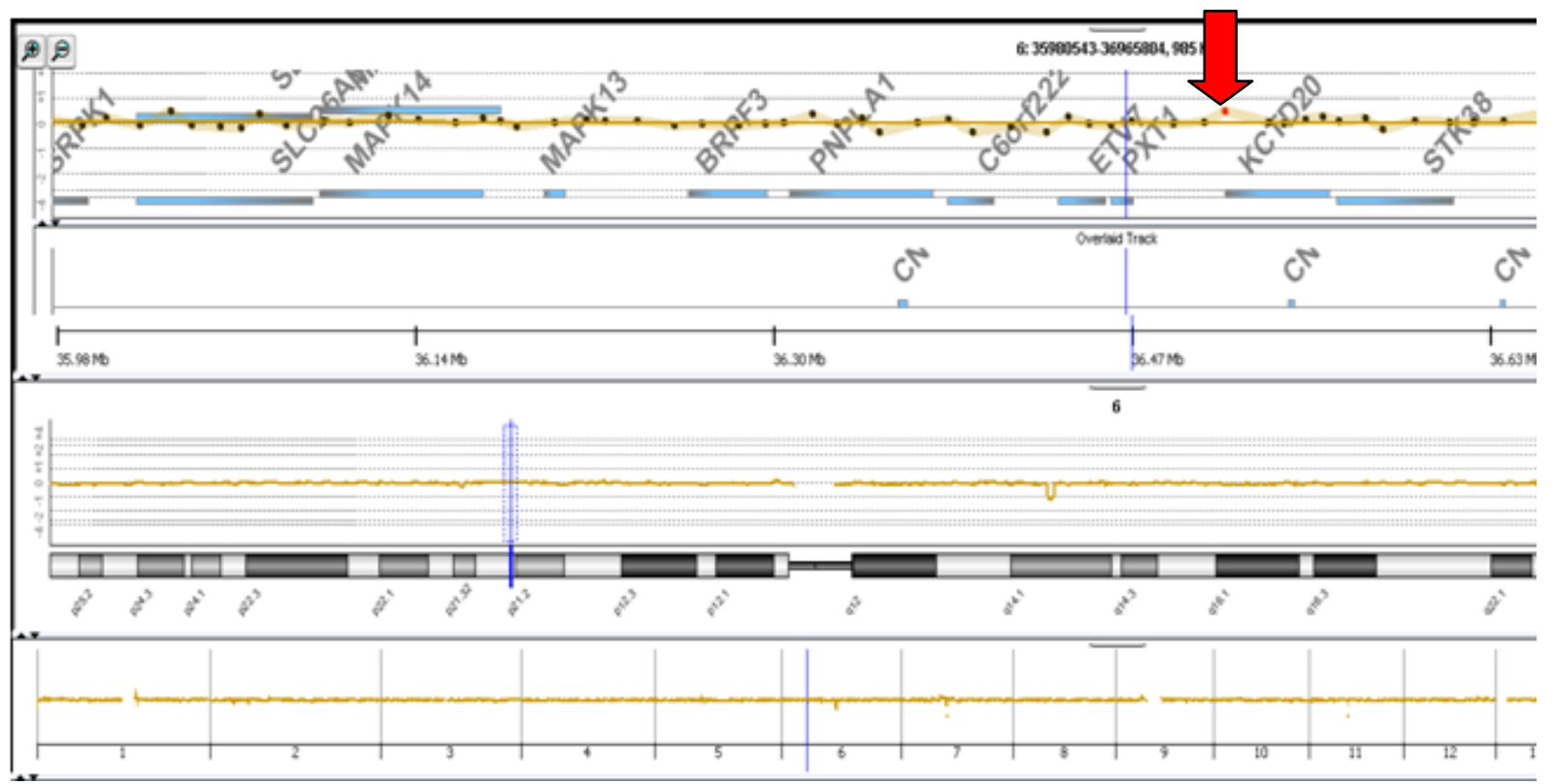

Abb. 3.25: Auszug aus der Analysesoftware des aCGHs

Die Grafik zeigt das Ergebnis für den Patienten 665. Das Ergebnis der verwendeten Sonde ist im oberen Anteil rot-markiert (Pfeil). In diesem Bereich ist die Gendosis dargestellt, wie sie sich in dem abgebildeten Bereich des Genoms verhält. Sie bewegt sich zwischen (0) und (1). Ab einen Wert von 0,5 wird von einer Duplikation in heterozygoter Form ausgegangen. 
Die Abbildung 3.25 zeigt, dass im Bereich des PXT1-Gens eine Abweichung von der Norm besteht. Die Kurve befindet sich an dieser Stelle zwischen (0) und (1). Die (0) steht bei dieser Auswertung für einen normalen Allelsatz, d. h. zwei Kopien sind vorhanden. Im Verhältnis dazu beschreibt der Wert (1) eine homozygote Duplikation. In diesem Fall wären 4 Allele vorhanden. Da sich bei der Probe 665 das Ergebnis zwischen diesen beschriebenen Extremen befindet, ist hier von einer heterozygoten Duplikation auszugehen. Drei Kopien liegen hier vor. Das Ergebnis entspricht dem qPCR-Befund (3.4.2).

In der Database of Genomic Variations (http://projects.tcag.ca/cgibin/variation/tbrowse? source=hg18\&table=Locus\&rnum=0) wurde überprüft, ob bereits genomische Variationen in diesem Genabschnitt bekannt sind. Am 3'-Ende von PXT1 ist eine InDel im Bereich chr6:36,505,040-36,505,040 (Variation_28292) beschrieben. Im 5'-Bereich des KCTD20-Gens, welches teils mit PXT1 überlappt, ist eine Duplikation an der Position chr6:36,551,214-36,553,849 (Variation_6488) bekannt. Die Datenbank zeigt keine Variation in dem analysierten Bereich. Aus diesem Grund wurden 100 Kontrollen auf diese Mutation hin untersucht. Dabei zeigte sich, dass $41 \%$ des Kontrollkollektivs eine Duplikation in heterozygoter Form besitzen. Weitere $10 \%$ weisen diese Duplikation in homozygoter Form auf. Eine Kontrolle besitzt eine heterozygote Deletion an dieser Position. Diese Variation ist in der allgemeinen Population nachzuweisen und hat somit keinen Krankheitswert. 


\subsection{Homologie und evolutionäre Konservierung des Pxt1/PXT1- Gens}

In dieser Arbeit wurde das humane Homolog $\mathrm{zu}$ dem bereits von der Arbeitsgruppe beschriebenen Pxtl-Gen der Maus (Burfeind 1999, Preuss 2002 Grzmil et al. 2007, Kaczmarek et al. 2011) identifiziert und charakterisiert. Beim Menschen wurden zunächst zwei Exons und ein Intron angenommen (,altes“ humanes PXT1-Gen). Aufgrund der durchgeführten Arbeiten konnten fünf Exons und vier Intron im humanen PXT1-Gen festgelegt werden. Die Gemeinsamkeiten und Unterschiede beider humaner Genformen (alt/neu) sowie des murinen Pxt1 sind in der Tabelle 4.1 aufgelistet.

Tab. 4.1: Vergleich des humanen mit dem murinen PXT1/Pxtl-Gen (entnommen und modifiziert aus Kaczmarek 2009, S. 8)

\begin{tabular}{llll}
\hline & Humanes PXT1 & $\begin{array}{l}\text {,altes“6 } \\
\text { humanes } \\
\end{array}$ & $\begin{array}{l}\text { Murines } \\
\text { Pxt1 }\end{array}$ \\
\hline GeneID & 222659 & 222659 & 69307 \\
Genomische Lokalisation & $6 \mathrm{p} 21.31$ & $6 \mathrm{p} 21.31$ & $17 \mathrm{~A} 3.3$ \\
Genomische DNA-Größe (bp) & 62.388 & 9.984 & 8.277 \\
Genomische Organisation & $5 / 4$ & $2 / 1$ & $3 / 2$ \\
(Exon/Intron) & & & \\
cDNA-Länge (bp) & 2.105 & 1.405 & 1.015 \\
\hline 5'-UTR (bp) & 484 & 30 & 143 \\
\hline 3'-UTR (bp) & 1.219 & 1.219 & 716 \\
\hline ORF-Länge (bp) & 402 & 153 & 153 \\
\hline Proteinlänge (AmS) & 134 & 51 & 51 \\
\hline PTS1 Motif & $\mathrm{NHL}$ & $\mathrm{NHL}$ & $\mathrm{NHL}$ \\
\hline
\end{tabular}

Die Tabelle zeigt neben den aktuellen Daten über die humanen und murinen PXT1/Pxt1-Gene auch die Geninformation über PXT1(,,altes“) vor der Identifizierung der drei weiteren Exons in 5'-Richtung.

Das murine Pxt1-Gen ist auf Chromosom 17A3.3 lokalisiert, das humane PXT1-Gen befindet sich in der synthänen Region 6p21.31. Gene, die in diesem chromosomalen Bereich lokalisiert sind, sind bei Maus und Mensch in die Spermatogenese involviert. So ist z. B. das Human-T- 
Complex-Protein-11 (TCP11)-Gen in die Kontrolle der Spermienmorphologie involviert (Liu et al. 2011). Mutationen im T-Complex (Bennett 1975) als auch im Quaking (Qk)-Gen, das ebenfalls im Bereich 17A liegt (Bennett et al. 1971), führen zu einem Spermatogenesearrest. Die Lokalisierung von PXT1 innerhalb dieser Region weist ebenfalls auf eine Rolle in der Spermatogenese hin.

Der Vergleich der genomischen Sequenz im Bereich der kodierenden Region als auch auf dem Proteinlevel zeigte zwischen dem ,alten“ humanen und dem murinen PXT1/Pxt1 eine Homologie von $74 \%$ (Grzmil et al. 2007). Durch die zusätzlichen Exons im 5'-Bereich beträgt jetzt die Homologie zwischen PXT1/Pxt1 von Mensch und Maus nur noch $61 \%$.

Ursprünglich war die Länge der DNA-Sequenz (Mensch: 9.984 bp, Maus: 8.277 bp) als auch die des kodierenden Bereichs mit 153 bp in etwa gleich groß. Im Unterschied zu der aus drei Exons bestehenden murinen Pxtl-mRNA besteht das humane Homolog durch die Identifizierung der drei weiteren Exons am 5'-Ende aus fünf Exons. Zwischen Exon 2 und 3, aber auch zwischen 3 und 4 liegen zwei große Introns, sodass die DNA-Sequenz des humanen Gens 62.388 bp lang ist. Das humane und murine PXT1/Pxt1-Gen zeichnen sich durch einen sehr langen 3'-UTR aus. Diesem Bereich werden regulatorische Funktionen nachgesagt (Grzybowska et al. 2001). Häufig sind hier miRNA-Bindungsstellen (Barthel 2009) lokalisiert, die die Translation beeinflussen können (de Moor et al. 2005, Vasudevan 2011, Wang et al. 2011). Mithilfe eines miRNA-Bindungsscanners (http://microrna.org) konnten zwei solcher putativen miRNA-Bindungsstellen im humanen PXT1 identifiziert werden.

In der Abbildung 4.1 ist die Aminosäuresequenz des humanen und des murinen PXT1 dargestellt. 


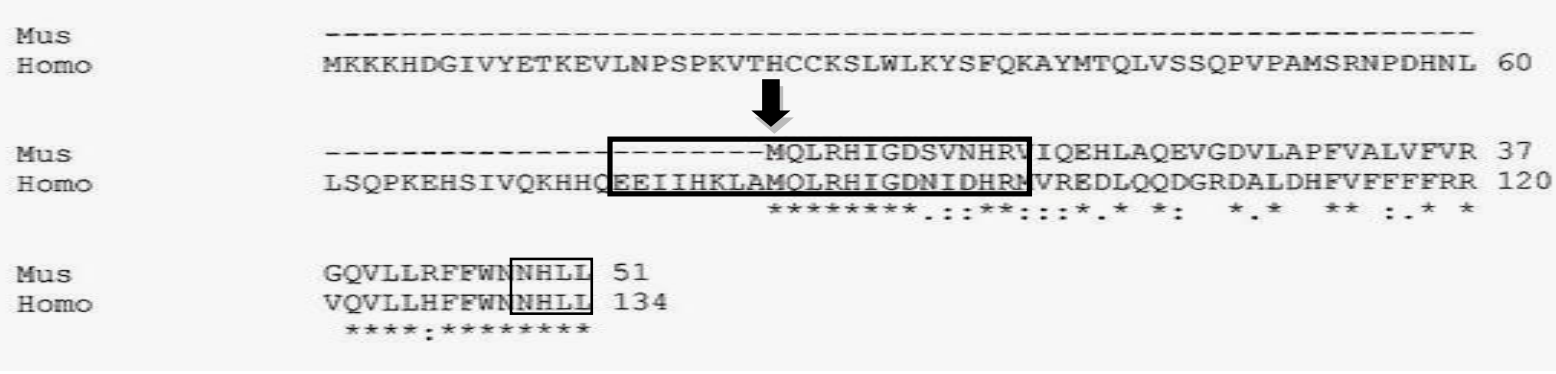

Abb. 4.1: Sequenzvergleich zwischen dem humanen und dem murinen PXT1-Protein

Die Abbildung zeigt die Aminosäuresequenz des humanen (Homo) PXT1s mit einer Größe von 134 Aminosäuren (AmS) und die Sequenz des murinen (Mus) Proteins (51 AmS). Am C-terminalen Ende weisen beide Sequenzen große Homologien auf:

* - Identische Aminosäure

:- AmS einer Gruppe (z. B. V und I = aliphatische AmS)

- keine Übereinstimmung der AmS

. - ähnliche AmS

Mit einem Pfeil $(\boldsymbol{)})$ ist der überlappender Sequenzbeginn gekennzeichnet. Die funktionellen Domänen sind umrahmt:

proapoptotische Domäne

NHL-Motif

Die Darstellung zeigt, dass beide Proteinsequenzen im überlappenden Bereich (ab der humanen AmS-Position 84 und der murinen Position 1; ) große Homologien aufweisen. Für das PXT1 befinden sich in diesen Bereichen charakteristische Domänen. Am 5'-Ende kodiert sowohl die murine als auch die humane Proteinsequenz für eine Domäne mit proapoptotischer Funktion (Kaczmarek et al. 2011). Eine ebenso charakteristische Eigenschaft wird durch die Aminosäuresequenz NHL am 3'-Ende kodiert. Diese Domäne gehört zum Peroxisomal Targeting Sequence typ 1 (PTS1), das für die peroxisomale Lokalisation verantwortlich ist (Gould et al. 1988).

Aufgrund großer Homologien zwischen PXT1 von Maus und Mensch wurde die evolutionäre Konservierung des PXT1-Proteins untersucht. Mithilfe der BLAST Software und der murinen Aminosäuresequenz (Mus musculus: Hausmaus, NP_700439.1) aus der NCBI-Datenbank konnten von folgenden Spezies Proteine mit großer Homologie identifiziert werden: Homo sapiens (Mensch, NP_694535.2), Pan troglodytes (Gemeiner Schimpanse, XP_001173038.2), Pongo abelii (Sumatra-Orang-Utan, XP_002816858.1), Nomascus leucogenys (Nördlicher Weißwangen-Schopfgibbon, XP_003276943.1), Macaca mulatta (Rhesusaffe, XP_002803775.1), Macaca fascicularis (Javaneraffe, EHH52988.1), Loxodonta africana (Afrikanischer Elefant, XP_003404268.1), Callithrix jacchus (Weißbüschelaffe, XP_002746522.1), Sus scrofa (Wildschwein, XP_003128413.1), Bos taurus (Hausrind, XP_002697263.1), Canis lupus familiaris (Haushund, XP_003431765.1), Equus caballus 
(Hauspferd, XP_003363820.1), Ailuropoda melanoleuca (Großer Panda, XP_002914337.1) und Rattus norvegicus (Wanderratte, XP_002725892.1). Mit dem Programm ClustalW2 (http://ebi.ac.uk/Tools/msa/clustalw2/) konnten die Homologien zwischen den Proteinsequenzen der verschiedenen Spezies bestimmt und ein Phylogramm (Abb. 4.2) angefertigt werden.

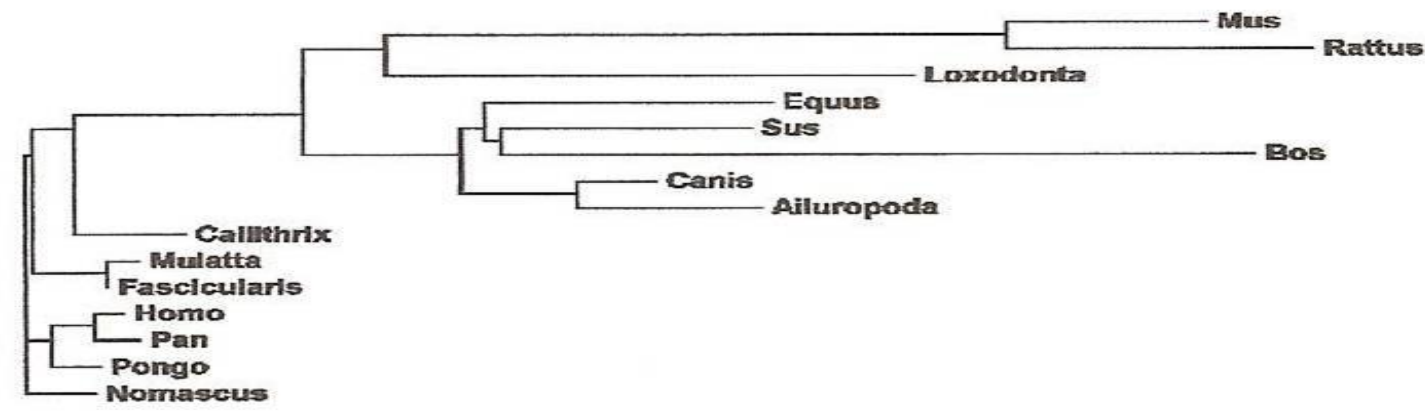

Abb. 4.2: Phylogramm von PXT1 der einzelnen Spezies auf Proteinebene

Das Phylogramm zeigt die Homologie des PXT1 Proteins zwischen den untersuchten Arten. Es handelt sich um einen gewurzelten Stammbaum. Je weiter die einzelnen Arten in diesem Phylogramm von einander entfernt sind, desto größer sind die Unterschiede in der Proteinsequenz. Anhand der Abzweigungen ist eine Einteilung in monophyletische Gruppen möglich.

Die Kurzformen stehen für folgende Spezies:

Ailuropoda: Ailuropoda melanoleuca

Callithrix: Callithrix jacchus

Equus: Equus caballus

Homo: Homo sapiens

Mulatta: Macaca mulatta

Nomascus: Nomascus leucogenys

Pongo: Pongo abelii

Sus: Sus scrofa
Bos: Bos taurus

Canis: Canis lupus familiaris

Fascicularis: Macaca fascicularis

Loxodonta: Loxodonta africana

Mus: Mus musculus

Pan: Pan troglodytes

Rattus: Rattus norvegicus

Phylogramme sind Schemata, mithilfe derer die Ähnlichkeiten bzw. die verwandtschaftlichen Beziehungen in einem Baumdiagramm dargestellt werden können. In dem Phylogramm aus der Abbildung 4.2 ist die Ähnlichkeit des PXT1-Proteins zwischen den einzelnen Spezies, die in die Klasse der Mammalia (Säugetiere) einzuordnen sind, veranschaulicht. Es ist zu erkennen, dass PXT1 von Homo sapiens und Pan troglodytes sehr ähnlich ist. Die Homologie auf Proteinebene beträgt 98\%. Sie bilden eine monophyletische Gruppe, d. h. sie gehen auf den gleichen Ursprung zurück. Als nächster Verwandter ist im Phylogramm der Pongo abelii, ebenfalls ein Mitglied der Hominidae (Menschenaffen)-Familie, dargestellt. Zusammen mit Homo sapiens und Pan troglodytes bilden auch die anderen Catarrhini (Altweltaffen) eine 
Gruppe. Nah mit den Altweltaffen ist die PXT1-Sequenz von Callithrix jacchus (Platyrrhini: Neuweltaffen) auf dem Phylogramm lokalisiert. Die zu $91 \%$ homologen Canoidea (Canis lupus familiaris und Ailuropoda melanoleuca) bilden ebenfalls eine Gruppe. Bei den Ungulata ist die Aufteilung in Artiodactyla, Paarhufer, (Sus scrofa und Bos taurus) und Perissodactyla, Unpaarhufer, (Equus caballus) anhand der Proteinsequenz von PXT1 sichtbar. Eine Überraschung stellt die Ähnlichkeit des PXT1-Proteins von Loxodonta africana mit dem der Muridae (Mus musculus und Rattus norvegicus) dar, obwohl diese Gattung phylogenetisch den Huftieren näher steht (Nowak 1999, McKenna und Bell 2000).

Die Analyse hat gezeigt, dass es ähnlich der stammesgeschichtlichen Verwandtschaft der einzelnen Arten miteinander auch entsprechende Übereinstimmungen in der Proteinsequenz von PXT1 gibt, besonders im Bereich funktioneller Domänen. Da Unterschiede in der genomischen Organisation beider PXT1/Pxt1-Gene bekannt sind und es für das murine Pxt1Gen keinen Anhalt für weitere Exons in 5'-Richtung gibt (Preuss 2002), wurde die genomische Organisation bei den artverwandten Spezies untersucht. Die Sequenz der humanen mRNA wurde mittels BLAST Software mit der NCBI-Datenbank verglichen. Die Anzahl der Exons in den Genen der bereits analysierten Arten konnten wie folgt identifiziert werden:

Tab. 4.2: Unterschiedliche Anzahl von Exons des Pxt1 Gens in verschiedenen Spezies

\begin{tabular}{llll}
\hline Art & GeneID & Familie & Exonanzahl \\
\hline Homo sapiens (Mensch) & 222659 & Hominidae & 5 \\
Pan troglodytes (Gemeiner & 747882 & Hominidae & 5 \\
Schimpanse) & & & \\
Pongo abelii (Sumatra-Orang-Utan) & 100452707 & Hominidae & 5 \\
Nomascus leucogenys (Nördlicher & 100597275 & Hylobatidae & 5 \\
Weißwangen-Schopfgibbon) & & & \\
Macaca mulatta (Rhesusaffe) & 100426726 & Cercopithecidae & 4 \\
Macaca fascicularis (Javaneraffe) & & Cercopithecidae & 4 \\
Equus caballus (Hauspferd) & 100629614 & Equidae & 4 \\
Loxodonta africana (Afrikanische & 100655507 & Elephantidae & 4 \\
Elefant) & & & 3 \\
Callithrix jacchus (Weißbüschelaffe) & 100406195 & Callitrichidae & 3 \\
Sus scrofa (Wildschwein) & 100523258 & Suidae & 3 \\
Bos taurus (Hausrind) & 100335790 & Bovidae & 3 \\
\hline
\end{tabular}




\begin{tabular}{llll}
\hline Canis lupus familiaris (Haushund) & 100682957 & Canidae & 3 \\
Ailuropoda melanoleuca (Große & 100464473 & Ursidae & 3 \\
Panda) & & & \\
Mus musculus (Hausmaus) & 69307 & Muridae & 3 \\
Rattus norvegicus (Wanderratte) & 100360640 & Muridae & 2 \\
\hline
\end{tabular}

In der Tabelle 4.2 sind die Pxt1-Gene der verschiedenen Spezies, ihre zugehörige Speziesfamilie und ihre Exonanzahl aufgelistet. Die Anzahl der Exons variiert zwischen den einzelnen Spezies zwischen 5 und 2 Exons. Die Hominoidea, Menschenartige, besitzen fünf Exons (Hominidae: Homo sapiens, Pan troglodytes und Pongo abelii; Hylobatidae: Nomascus leucogenys). Bei den übrigen Primaten ist eine geringere Anzahl an Exons zu identifizieren. Die Macacae besitzen vier Exons und Callithrix jacchus sogar nur drei. Weitere Arten mit vier Exons sind Equus caballus und Loxodonta africana. Dabei ist bemerkenswert, dass bei der Differenzierung in Artiodactyla, Paarhufer (Equus caballus), und Perissodactyla, Unpaarhufer (Sus scrofa und Bos taurus), ein Exon verloren gegangen ist. Die Canoidea, Canis lupus familiaris und Ailuropoda melanoleuca besitzen wie die Perissodactyla drei Exons. Innerhalb einer Unterfamilie ist bei den Muridae ein weiteres Exon verloren gegangen. Im Pxt1 von Mus musculus sind drei Exons vorhanden, wohingegen im Pxt1 von Rattus norvegicus nur noch zwei Exons identifizierbar sind.

Schlussfolgernd kann man sagen, dass das Pxtl-Gen hochkonserviert ist. Lediglich im Bereich der genomischen Organisation sind Unterschiede zu finden, die eine regulatorische Bedeutung besitzen könnten. Neben dem Pxtl-Gen sind auch bei anderen Genen solche Unterschiede identifiziert, z. B. das DNMT3L (DNA (cytosine-5-)-methyltransferase 3-like)Gen, welches eine Rolle in der Spermatogenese spielt (Hata et al. 2006) und dessen Knockout zu Störungen beim Ablauf der Meiose mit Apoptose der Keimzellen (Webster et al. 2005, Western et al. 2011) und zu großen Methylierungsdefekten (La Salle et al. 2007) führt. Bei diesem Gen kann man Unterschiede in der Exonanzahl bei verschiedenen Spezies finden, die je nach Art zwischen 10 und 14 Exons schwankt. Der Vergleich zeigt, dass bei hochkonservierten Genen speziesspezifische Unterschiede in der genomischen Organisation möglich sind und es sich bei dem Pxtl-Gen um keine Rarität handelt. 


\subsection{Expressionsmuster und alternatives Spleißen des PXT1-Gens}

Die Spermatogenese ist ein komplexregulierter, biologischer Prozess. Zahlreiche Gene sind in die Entwicklung und Differenzierung der Keimzellen involviert. Eine Vielzahl der in die Spermatogenese involvierten Gene zeigt eine testisspezifische Expression (White-Cooper und Bausek 2010). Das Maus Pxt1-Gen ist durch solch ein testisspezifisches Expressionsmuster gekennzeichnet (Burfeind 1999, Grzmil et al. 2007). Ein weiterer Kandidat ist das humane Testis-Developmental-Related-Gene-1 (TDRG1)-Gen. Seine testikuläre Expression lässt sich sogar konkretisieren und zeigt während der Spermatogenese sein höchstes Expressionslevel im postpubertären Testis (Jiang et al. 2011). Weitere Gene mit einer testisspezifischen Expression werden zunehmend, ähnlich dem Pxtl-Gen, mithilfe des Differential Displays identifiziert. Bei der Maus beträgt der Anteil an proteinkodierenden Genen mit testisspezifischem/testisangereichertem Expressionsmuster $11 \%$ (Choi et al. 2007). Vergleichbare Zahlen sind auch bei D. melanogaster bekannt. Bei ihnen handelt es sich um $10 \%$ der in männlichen Keimzellen exprimierten Gene (Chintapalli et al. 2007). Zusätzlich zeigen Berichte von Drosophila melanogaster, dass sich neue testisspezifische Gene aus nicht-transkribierten genomischen Sequenzen entwickelt haben (Levine et al. 2006, Begun et al. 2007). Für solche testisspezifischen Gene sind kurze Promotoren charakteristisch, die dazu dienen, den de novo Erwerb ihrer transkriptionellen Aktivität in einer bestimmten genomischen Region zu erleichtern (White-Cooper und Bausek 2010).

Von in die Spermatogenese involvierten Genen mit reinem testisspezifischen Expressionsmuster muss man jedoch auch Gene abgrenzen, von denen man Transkripte auch in anderen Geweben nachweisen kann (White-Cooper und Bausek 2010). Die Expressionsuntersuchungen für das humane PXT1-Gen haben mithilfe von RT-PCRs und Real Time-PCRs im Unterschied zum murinen Pxt1-Gen ergeben, dass das Gen nicht nur im Testis sondern auch in anderen Geweben exprimiert wird. Von dem im Testis prädominat exprimierten PXT1-Gen waren Transkripte um den Faktor 3-4 in Lunge, Leukozyten, Milz, Kolon und Ovar schwächer nachweisbar. Diese verschiedenen Expressionsmuster zwischen Mensch und Maus sind kein Phänomen des PXT1/Pxt1-Gens. Solche Speziesunterschiede bei der Genexpression sind beispielsweise auch bei dem Bromodomain,-testis-specific (Brdt)-Gen bekannt. Es ist ein Mitglied der BET-Familie, die durch zwei N-terminale hochkonservierte Bromodomänen (Haynes et al. 1992) und einer am C-Terminus gelegenen extraterminalen (ET) Domäne gekennzeichnet ist (Florence und Faller 2001). Die Expression vom humanen und murinen BRDT-Gen ist auf die Keimzellen begrenzt. Jedoch sind im Unterschied zum humanen BRDT-Gen, das in testikülären Keimzellen exprimiert wird (Barda et al. 2012), 
Transkripte des murinen Homologs zusätzlich in Ovarien nachweisbar (Paillisson et al. 2007). Zusätzlich zeigen Untersuchungen am Brdt-Gen, dass normalerweise Mitglieder der BETFamilie (BRD2, 3 und 4) durch eine ubiquitäre Expression charakterisiert sind (Paillisson et al. 2007). Auch in anderen Arbeiten sind speziesspezifische Expressionsmuster beschrieben. Dabei wurden in der Arbeit von Fougerousse et al. (2000) besonders Gene der frühen Embryogenese mit solchen Charakteristika gezeigt. Dabei fielen besonders das Wnt7a (Wingless-related MMTV integration site 7a)-Gen und das CAPN3 (Calpain3)-Gen auf.

Typisch für in die Spermatogenese involvierten Gene ist neben einer oftmals keimzellspezifischen Expression ein zusätzliches stadienspezifisches Expressionsmuster. 2058 Gene, die im Zusammenhang mit der Spermatogenese stehen, wurden in der Arbeit von Xiao et al. (2008) beschrieben. Die Expression zahlreicher Gene ist erst ab einem bestimmten Stadium der Spermatogenese nachweisbar bzw. zu verschiedenen Zeitpunkten unterschiedlich reguliert. Beispielsweise sind in Bezug auf murine spermatogoniale Stamm-/Progenitorzellen Gpr107 (G protein-coupled receptor 107) und Smad4 (SMAD familiy member 4) herunter reguliert, während Gprl16 und Gprl46 hinauf reguliert sind (Kokkinaki et al. 2010). Insgesamt zeigt sich, dass im Verlauf der Spermatogenese, d. h. in späteren Stadien, mehr Gene aktiviert werden (Xiao et al. 2008). Vom murinen Pxtl-Gen ist bekannt, dass sein Transkript erst ab dem 15. dpp, dem Stadium der pachytänen Spermatozyten, nachgewiesen werden kann (Burfeind 1999, Grzmil et al. 2007). Der Nachweis von Genprodukten in diesem Stadium ist u. a. auch vom HGF-regulated tyrosine kinase substrate (Hgs)-Gen (Itman et al. 2011), dem Maushomolog Ovol2/MOVO-Gen (Mével-Ninio et al. 1995, Chizaki et al. 2011), dem Proacrosin (Acr) Gen (Raab et al. 1994) und dem Phosphoglyceratkinase2 (Pgk2) Gen (Robinson et al. 1989) bekannt.

Neben den unterschiedlichen Expressionsmustern des humanen und des murinen PXT1/Pxt1Gens konnte in dieser Arbeit auch gezeigt werden, dass das humane PXT1-Gen dem alternativen Spleißen unterliegt. Das Spleißen (Syn. Splicing) ist ein Prozess, bei dem Introns an spezifischen Sequenzen (Konsensussequenzen: 5'-Ende der Introns -GU- und am 3'-Ende AG-) durch zwei Umesterungen aus der hnRNA herausgeschnitten und auf diese Weise die Exons zusammengefügt werden. Dieser Vorgang erfolgt u. a. mithilfe von snRNAs und zahlreichen Proteinen unter der Bildung von Spleißosomen (Ritschie et al. 2009, Wahl et al. 2009, Fischer et al. 2011). Der Prozess kann durch Transkriptionsfaktoren wie das Tra2 $\beta$ getriggert werden (Grellscheid et al. 2011). Von dem „normalen“ Spleißvorgang unterscheidet sich das alternative Spleißen durch das zusätzliche Entfernen von Exons. Auf 
diese Weise ist eine Erhöhung der Anzahl an verschiedenen Genprodukten eines Gens möglich (Black 2003, Clancy 2008).

Bei dem humanen PXT1-Gen konnten insgesamt sechs Transkripte identifiziert werden. Von den fünf bekannten Exons unterliegen Exon 1b, 1c, 2 und Exon 4 dem alternativen Spleißen. Von den vier betroffenen Exons liegen Exon 1b, 1c und Exon 2 im 5'-UTR. Es ist bekannt, dass sich in einem solchen Bereich regulatorische Domänen für die Genexpression befinden können (Lukowski et al. 2011). Eine Besonderheit der Exons 1a und 1b des PXT1s konnte mithilfe der in-silico-Analyse des PXT1-Gens in der Gendatenbank gezeigt werden. Die Sequenz dieser beiden Exons überlappt sich mit dem Potassium Channel Tetramerisation Domain containing 20 (KCTD20), welches für einen Kaliumkanal kodiert und dessen mRNA ubiquitär exprimiert wird. Das zu den 1.557 identifizierten Genen des Chromosoms 6 (Mungall et al. 2003) gehörige Gen besteht aus acht Exons. Wie PXT1 unterliegt es dem alternativen Spleißen (Watahiki et al. 2004). Insgesamt gibt es aber keine weiteren Informationen über die Organisation, Expression und Funktion dieses Gens. Eventuell spielt es eine Rolle in der Präimplantationsphase, wo es u. a. nachgewiesen werden konnte (Ko et al. 2000). Insgesamt ist das alternative Spleißen ein häufig vorkommendes Phänomen für testisspezifische Transkripte (Gan et al. 2011). Bei zahlreichen Genen, die mit der Spermatogenese assoziiert sind, konnte dieser Vorgang nachgewiesen werden. Zu ihnen zählen u. a. das humane T-Complex Protein 11 (TCP11) (Ma et al. 2003), das für die Akrosomenreaktion und die Kapazitation notwendiges Fertilization promoting peptid (FPP) kodiert (Liu et al. 2011) und das Amyotrophic lateral sclerosis 2 chromosome region candidate 12 (Als2cr12), welches mit der fibrösen Scheide des Spermienschwanzes assoziiert ist (Choi und Cho 2011).

In dieser Arbeit konnte gezeigt werden, dass unterschiedliche Spleiß-Produkte des PXT1Gens unterschiedliche Expressionsmuster aufweisen. Dabei fällt auf, dass lange Transkripte, die Exon $1 \mathrm{~b}$ beinhalten, testisspezifisch exprimiert werden. Kürzere Transkripte konnten auch in anderen Geweben nachgewiesen werden. Dieses „,transkriptabhängige“ Expressionsmuster ist auch von dem humanen Novel Retinal Pigment Epithelial Gene (NORPEG) bekannt. Ähnlich dem PXT1-Gen existiert ein kürzeres, ubiquitär exprimiertes Transkript (Yuan et al. 2005). Zusätzlich konnten aber zwei längere Transkripte in Plazenta, Testis und abgeschwächte in humanen Krebszelllinien nachgewiesen werden (Kutty et al. 2000). Aufgrund der Tatsache, dass vor allem die längeren Transkripte eine spezifische (keimzellspezifische) Expression aufweisen, ist anzunehmen, dass sie im 5'-UTR (keimzell)spezifische Translationspotentiale besitzen. Auf diese Weise zeigt ein Transkript 
des DEAD-box-Y-(DBY)-RNA-helicase (aka DDX3Y)-Gens mit einem verlängerten 5'-UTR im Vergleich zu seinen anderen Transkripten dieselbe Testisspezifität wie PXT1. Es unterliegt dem alternativen Spleißen im Exon 1, und durch Schleifenbildung der mRNA kann es die Translation in anderen Geweben unterdrücken (Jaroszynski et al. 2010). Eine repressorische Funktion im 5'-UTR wird in der verlängerten, testisspezifischen Form $\left(\mathrm{T}_{\mathrm{SOD}-1}\right)$ der beiden Transkripte des Superoxid-Dismutase (SOD-1) Gens der Maus vermutet. Sie unterscheidet sich von der ubiquitären, kürzeren Form $\left(\mathrm{S}_{\mathrm{SOD}-1}\right)$ durch einen um 114 Nukleotide verlängerten 5'-UTR (Gu und Hecht 1996). Die durch alternatives Spleißen beeinflusste 5'-UTR soll Auswirkungen auf die posttranskriptionelle Regulation der Genexpression haben, womit sie einen hohen Stellenwert in der Kontrolle der Einleitung der Translation einnimmt (Hughes 2006). In der Arbeit von Denoeud et al. (2007) wurden weitere zahlreiche Gene mit elongierten 5'-UTRs im Testis identifiziert, die in die Spermatogenese involviert sind.

Neben Veränderungen der 5'-UTRs wurden auch die Auswirkungen von regulatorischen Sequenzen im 3'-UTR beschrieben. Das Beispiel der murinen Adenylat Kinase 1 (Akl) zeigt, dass eine verkürzte $3^{\prime}$-UTR und ein Unterschied in der Nukleotidsequenz des 5'-UTR die keimzellspezifische mRNA der $A k l$ von der somatischen unterscheidet (Cao et al. 2006). Aufgrund der Sequenzveränderungen im 5'-UTR ist bei diesem Beispiel nicht eindeutig gezeigt, dass die verkürzte 3'-UTR die Expression beeinflusst. Es ist aber bekannt, dass im 3'UTR regulatorische Sequenzen, wie miRNA-Bindungsstellen, lokalisiert sind. Von diesen Bindungsstellen ist bekannt, dass sie die Genexpression posttranskriptionell hochregulieren können (Vasudevan 2011). Insgesamt ist aber eine Herunterregulation am häufigsten zu beobachten (Moncini et al. 2011). Die Auswirkungen dieser Bindungen hängen jedoch vom jeweiligen Interaktionspartner ab (Shibata $M$ et al. 2011). Im humanen PXT1-Gen ist die Existenz von zwei putativen miRNA-Bindungsstellen im 3'-UTR bekannt. Untersuchungen am DAZ-Associated-Protein-1 (DAZAP1)-Gen, das zahlreiche miRNA-Bindungsstellen im 3'-UTR besitzt und ebenfalls in die Spermatogenese involviert ist, haben gezeigt, dass seine Translation durch die miRNA-Bindungsstellen beeinflusst werden kann (Smith et al. 2011).

Für das humane PXT1-Gen wird vermutet, dass die alternativ gespleißte 5'-UTR wie auch die miRNA-Bindungsstellen in der 3'UTR die Genexpression unterdrücken und somit das proapoptotische Potential seines Proteins dämpfen. Bei Patienten mit Fertilitätsstörungen könnten diese regulatorischen Sequenzen mutiert sein. Eine Mutation im heterozygoten Zustand würde eine ausreichende Dominanz besitzen, um einen Phänotyp zu verursachen (Bannister et al. 2007), da im Mausmodell alle heterozygoten, transgenen Tiere Fertilitätsstörungen aufweisen (Kaczmarek 2009, Kaczmarek et al. 2011). Mithilfe der 
transgenen Mutanten konnte gezeigt werden, dass bereits ein doppeltes Expressionsniveau zur Apoptose der Keimzellen führt (Morich 2012). Bei dem Mutationsscreening der infertilen 55 Patienten mit den Phänotypen einer Azoo- oder Oligozoospermie konnte in Bereich der beiden miRNA-Bindungsstellen jedoch keine Mutation nachgewiesen werden.

\subsection{Funktion und putative Rolle des Pxt1/PXT1-Gens in der Spermatogenese}

In vorangegangenen Arbeiten konnte mithilfe von Mausmodellen das proapoptotische Potential des murinen PXT1-Proteins gezeigt werden (Kaczmarek 2009, Kaczmarek et al. 2011). Da große Homologien zwischen dem humanen und murinen PXT1 bestehen, die besonders im Bereich funktioneller Domänen nachzuweisen sind (4.1), ist von Gemeinsamkeiten in der Funktion von beiden PXT1-Proteinen auszugehen. Sowohl bei dem murinen als auch bei dem humanen PXT1 kodiert die Nukleotidsequenz am 5'-Terminus für eine proapoptotische Domäne. Bei der Maus handelt es sich um die BH3-ähnliche Domäne (BH3-like domain) (Du et al. 2011) und beim Menschen zum einen um die BH3 interacting domain (BID) (Yin 2000, Ren et al. 2010, Sai et al. 2011) bei der langen Form des PXT1Proteins und zum anderen homolog zur Maus um die BH3-ähnliche Domäne bei der kurzen Form des PXT1-Proteins. Beide Domänen sind charakteristisch für Mitglieder der $B C L-2$ ( $B$ cell leukemia/lymphoma-2)-Familie, welche in die Regulation der Apoptose involviert sind (Adams und Cory 2001, Skommer et al. 2007). Die BCL-2 (B cell leukemia/lymphoma-2)Familienmitglieder besitzen eine oder mehrere charakteristische BH(BCL2 Homology)Domänen, neben der erwähnten $B H 3$-Domäne existieren noch $B H 1,2$ und 4. Verschiedene Kombinationen der einzelnen $B H$-Domänen miteinander in einem Protein können eine prooder antiapoptotische Potenz besitzen. Bei Proteinen, die nur die BH3-Domäne enthalten, BH3-only, ist eine apoptoseinduzierende Wirkung bekannt (Hartman und Czyz 2012, Muer et al. 2012), beispielsweise beim Protein des Beclinl-Gens, dessen Protein ein Interaktionspartner von Mitgliedern der BCL-2-Familie ist (Erlich et al. 2007) oder dem Protein des Makes-caterpillaris-floopy-1 (Mcf1)-Gen (Dowling et al. 2007).

Neben dem Protein mit der BH3-ähnlichen Domäne wurde beim Menschen auch ein größeres Protein identifiziert, das die BH3 interacting domain (BID) enthält. Ebenso wie die BH3ähnlichen Domäne kann die Lebensfähigkeit von Zellen durch die BID kritisch beeinflusst werden (Billen et al. 2009, Maas et al. 2011). Eine Überexpression dieser Domäne kann dabei zu einer massiven Verkürzung des Zelllebens führen (Tsuno et al. 2012). 
Auf der Grundlage der Potenz dieser beiden proapoptotischen Domänen, die im humanen als auch im murinen PXT1-Protein identifiziert wurden, als auch die unterschiedlichen Expressionsmuster, wurde in dieser Arbeit die DNA von Patienten mit Fertilitätsstörungen auf Mutationen innerhalb von PXT1 gescreent, welche nicht identifiziert werden konnten.

In den Arbeiten von Kaczmarek (2009) und Kaczmarek et al. (2011) konnte bereits gezeigt werden, dass die Überexpression der BH3-ähnlichen Domäne in zwei transfizierten Zelllinien zum programmierten Zelltod führt. Hingegen waren durch die Deletion dieser Domäne signifikant weniger apoptotische Zellen histologisch nachweisbar. Bei den Pxt1-KnockoutTieren konnte kein offensichtlicher Phänotyp festgestellt werden (nicht publizierte Daten von P. Grzmil). Die Folge der Deletion dieser BH3-ähnlichen Domäne konnte bei dem bereits erwähnten Protein des $M c f l$-Gen in ähnlicher Weise nachgewiesen werden. Im Unterschied zu PXT1 dämpfte eine Doppelmutation innerhalb der Sequenz der BH3-ähnlichen Domäne dieses Gen, die die proapoptotische Potenz scheinbar inaktiviert bzw. drosselt (Dowling et al. 2007). Obwohl kein offensichtlicher Phänotyp den Pxtl-Knockout-Tieren nachweisbar war, zeigte die Analyse auf DNA-Strangbrüche in Spermien in diesen Knockout-Tieren eine signifikant erhöhte Anzahl von DNA-Schäden im Vergleich zu den Wildtyp-Tieren (C57BL/6J).

Keimzellen reagieren sehr empfindlich auf DNA-Schäden. In der Arbeit von Venkatesh et al. (2011) wurde die Schwere der Fertilitätsstörung in Abhängigkeit vom DNAFragmentationsindex (DFI) untersucht. Dabei zeigte sich, dass je schwerer Fertilitätsstörungen (Oligozoospermie) ausgeprägt sind, desto höher deren DNAFragmentationsindex (DFI) war. Diese Ergebnisse zeigen, dass eine erhöhte Anzahl an DNAStrangbrüchen in Spermien letzten Endes zum Zelltod führt. Neben der Fertilität beeinflussen zahlreiche DNA-Strangbrüche auch die Blastozystenentwicklung und die Schwangerschaftsrate negativ (Spano et al. 2005, Simon et al. 2010).

Die Ergebnisse zum Pxtl-Gen lassen insgesamt vermuten, dass seine Aufgabe in der Elimination von beschädigten Spermien zu finden ist. Obwohl es nur Evidenz über die BH3ähnlichen Domäne am Mausmodell gibt und beim Menschen zusätzlich eine weitere proapoptotische Domäne identifiziert ist, wird trotzdem von Parallelen in der Funktion der beider Proteine ausgegangen. Es ist bekannt, dass BID-Proteine durch das p53 transkriptionell reguliert werden. Gleichermaßen erleichtert p53 den Proteinen den Kernexport zur Initiation des programmierten Zelltodes als Reaktion auf irreparable DNA-Schäden (Song et al. 2011). Eine Genfunktion, die die Entsorgung beschädigter Spermien umfasst, ist bereits von einer Isoform des p63, bezeichnet als GTAp63 (Beyer et al. 2011), beim Menschen bekannt. Als 
Homolog des p53 (Yang et al. 1998, Yang und McKeon 2000), dem Wächter des Genoms (Lane 1992), kontrolliert es den Zellzyklus und den natürlichen Zelltod (Allocati et al. 2012). Speziell im Bereich der Fertilität sichern p53-Familienmitglieder die genomische Integrität der Keimzellen und beim Verlust der Gene p53, p63 und p73 kommt es zur Reduktion des Fertilitätspotentials (Hu et al. 2011).

Da sich neben exogenen Faktoren wie Hitze (Paul et al. 2008) auch durch endogene Faktoren wie dem Enzym DNaseI, das die internukleosomale DNA abbaut (Oliveri et al. 2001), DNAStrangbrüche induzieren lassen, wurde in dieser Arbeit die Anzahl an DNA-Strangbrüchen, induziert durch DNaseI mit steigender Inkubationsdauer untersucht. Dabei zeigte sich kein signifikanter Unterschied zwischen den Pxt1-Knockout-Tieren und deren Kontroll-Tieren (C57BL/6J). Insgesamt ist aber nicht auszuschließen, dass Pxt1 durch andere Stressfaktoren, die zu DNA-Strangbrüchen führen, induziert wird. Um diese Hypothese zu klären, sind jedoch weitere Analysen notwendig.

\subsection{Ausblick}

Für weiterführende Analysen ergeben sich folgende Ansätze:

Ein erster Ansatzpunkt ist das alternative Spleißen, dem das humane PXT1 unterliegt, aber das murine nicht. Dabei ist z. B. zu analysieren, ob die Ähnlichkeiten zwischen den Hominidea dem einher gehen, $d$. h. ob sie ebenso wie die humane hnRNA alternativ gespleißt werden und dieselben Transkripte nachweisbar sind. Beim Vergleich der einzelnen, identifizierten Spezies, die Pxtl exprimieren, sollte auch ein Augenmerk auf deren Expressionsmuster gelegt werden, da im Vergleich das humane PXT1-Gen prädominant im Testis und das murine Pxt1 Gen testisspezifisch exprimiert wird. Weitere Fragen zur Expression der humanen und murinen Homologe kann die Identifizierung der Promotoren beitragen.

In dieser Arbeit wurde die Funktion von PXT1 als Wächter der Spermatogenese vorgeschlagen. Diese Hypothese sollte weiter analysiert werden. Dabei ist es wichtig, die Pxt1-Knockout-Mäuse genauer zu analysieren, insbesondere darauf, welche Faktoren die DNA-Strangbrüche bei Mutanten induzieren. Sollte diese Hypothese richtig sein, kann man erwarten, dass bei Patienten mit einer loss-of-function-Mutation im PXT1-Gen eine erhöhte Rate von Spermien mit DNA-Strangbrüchen nachzuweisen ist. Dazu kann man bei solchen Patienten das $P X T 1-$ Gen sequenzieren.

In Bezug auf das proapoptotische Potential und die Funktion des humanen PXT1-Gens wurde in dieser Arbeit ein Screening auf Mutationen im Exonbereich bei Patienten mit Fertilitätsstörungen (Azoospermie, Oligozoospermie) durchgeführt, in der Hoffnung eine 
gain-of-function-Mutation zu identifizieren (z. B. eine Mutation im 3'-UTR-Bereich, die zur Überexpression von PXT1 führen kann). Dabei sollte sich auf die regulatorische Funktion der identifizierten zwei miRNA-Bindungsstellen im 3'-UTR konzentriert werden, die die Translation beeinflussen können. Da nur eine kleine Kohorte mit 55 Patienten untersucht werden konnte, wäre es für weitere Analysen sinnvoll, die Patientenkohorte zu erweitern und eventuell das Patientenkollektiv auf Azoospermiker einzuschränken. Bei diesen sollte die Wahrscheinlichkeit, eine Mutation zu finden, größer als bei Oligozoospermikern sein. Zunächst müsste auch die bindende miRNA, die an PXT1-3'-UTR binden, identifiziert und deren Expression untersucht werden. Mithilfe eines Luciferase-Assays wäre es möglich, die Bindung dieser miRNA an die Bindungsstellen an der PXT1-mRNA und deren Auswirkung auf die $P X T 1$-Expression zu untersuchen. 
Zusammenfassung

Im Rahmen dieser Arbeit wurden Untersuchungen zur Organisation, Expression und Funktion des humanen PXT1-Gens (ID: 222659) durchgeführt.

Die Expression von drei putativen Exons in 5'-Richtung, die der cDNA-Klon BC031105 (IMAGE: 5297409) enthielt, konnte in dieser Arbeit bestätigt werden. Weitere zusätzliche Exons konnten nicht identifiziert werden. Mithilfe von RT-PCR-Untersuchungen konnte gezeigt werden, dass sich das Exon 1 aus drei unterschiedlich gespleißten Einheiten (Exons) zusammensetzt. Die Ergebnisse der Sequenzanalyse zeigten dabei, dass das humane PXT1Gen dem alternativen Spleißen unterliegt, wobei besonders die 5'-UTR und davon Exon 1b, 1c, 2, aber auch Exon 4, betroffen sind. Insgesamt konnten 6 Transkripte identifiziert werden. Jedoch ein Transkript, das alle Exons enthält, konnte nicht amplifiziert werden. Bei der Analyse fiel auf, dass Exon 1c und 2 nie gemeinsam in einem Transkript nachweisbar sind. Vermutlich besitzen sie gegensätzliche regulatorische Eigenschaften. Die Auswirkungen auf die Proteinstruktur durch die zusätzlichen Exons zeigen sich in einer Verlängerung des ORF kodierend für einst 51 Aminosäuren auf 134. Das hat zur Folge, dass sich in dem längeren Protein die BH3 interacting domain (BID) befindet, die eine proapoptotische Funktion besitzt. Da Exon 4 dem alternativen Spleißen unterliegt, existiert ein verkürztes Protein, in dessen mRNA sich ein vorzeitiges Stopkodon befindet. Aus diesem Grund besitzt diese Proteinform keine proapoptotische Domäne. Einen anderen Aspekt der zusätzlichen Exons zeigt die Analyse in der DNA-Datenbank. Die Sequenzen der Exons 1a und 1b überlappen sich mit dem KCTD20-Gen, das für einen Kaliumkanal kodiert.

Im Unterschied zum murinen Pxt1-Gen, das testisspezifisch exprimiert wird (Burfeind 1999, Grzmil et al. 2007), konnte in dieser Arbeit gezeigt werden, dass das humane Homolog trotz Prädominanz im Testis auch in anderen Geweben nachweisbar ist, wenngleich wesentlich schwächer als im Testis.

Zur Klärung einer eventuellen proapoptotischen Funktion von Pxtl in Keimzellen wurde zunächst am Mausmodell die Anzahl an DNA-Strangbrüchen untersucht. Verglichen wurden die Pxt1-Knockout-Maus mit Wildtyp-Tieren der Stämme 129/SvJ und C57BL/6J. Die Pxt1Knockout-Maus zeigt eine signifikant erhöhte Anzahl an Spermien mit DNA-Strangbrüchen im Vergleich zu C57BL/6J-Mäusen. Dieses Ergebnis bestätigt die Annahme, dass das PXT1/Pxt1-Gen eine Art Entsorgungsfunktion für beschädigte Spermien ausübt. Im zeitlichen Verlauf zeigte sich aber, dass die Spermien der Knockout-Tiere nicht sensibler als die Wildtyp-Tiere auf DNaseI reagieren. Für weitere Funktionsuntersuchungen wurden 55 Patienten mit Fertilitätsstörungen (Azoo- oder Oligozoospermie) auf Punktmutationen im 
PXT1 untersucht. Dabei wurde keine Mutation identifiziert. Im Verlauf dieser Analyse wurde auch auf Deletionen untersucht. Dabei zeigte sich, dass bei Patienten mit einer Oligozoospermie, neben einer Deletion in Exon 1, auch Duplikationen sowohl in homozygoter als auch in heterozygoter Form nachweisbar waren. Neben den Duplikationen in Exon 1, wie bei den Oligozoospermie-Patienten, konnten bei den Azoospermikern zusätzlich noch Duplikationen (homozygot und heterozygot) in den Exons 2 und 3 nachgewiesen werden. Mithilfe der arraybasierten Comparativen Genomischen Hybridisierung (aCGH) wurde die Duplikation bei einem Patienten speziell im Exon 1 bestätigt. Bei dem Vergleich mit einem Kontrollkollektiv (100 Kontrollen) zeigt sich jedoch, dass diese Duplikation eine genomische Variation darstellt, die bei $41 \%$ der Kontrollen heterozygot und bei $10 \%$ in homozygoter Form in der allgemeinen Population vorkommt. Bei der Deletion und den Duplikationen im PXT1-Gen ist nicht von Veränderungen auszugehen, die einen Krankheitswert besitzen. 


\section{$6 \quad$ Literaturverzeichnis}

Adams JM and Cory S (2001): Life-or-death decisions by the Bcl-2 protein family. Trends Biochem Sci 26, 61-66

Allocati N, Di Ilio C, De Laurenzi V (2012): p63/p73 in the control of cell cycle and cell death. Exp Cell Res 318(11), 1285-1290

Bannister LA, Pezza RJ, Donaldson JR, de Rooij DG, Schimenti KJ, Camerini-Otero RD, Schimenti JC (2007): A dominant, recombination-defective allele of Dmc1 causing malespecific sterility. PLoS Biol 5(5), e105

Barda S, Paz G, Yogev L, Yavetz H, Lehavi O, Hauser R, Botchan A, Breitbart H, Kleiman SE (2012): Expression of BET genes in testis of men with different spermatogenetic impairments. Fertil Steril 97(1), 46-52

Bartel DP (2009): MicroRNAs. targets recognition and regulatory function. Cell $\underline{136}, 215-233$

Begun D, Lindfors H, Kern A, Jones C (2007): Evidence for de novo evolution of testisexpressed genes in the Drosophila yakuba/Drosophila erecta clade. Genetics $\underline{176}, 1131-1137$

Behre HM, Kliesch S, Meschede D, Nieschlag E: Hypogonadismus und Infertilität des Mannes. In: Gerok W, Hartmann F, Pfreundschuh M et al.: Klinik der Gegenwart III 2, Urban \& Schwarzenberg Verlag, München-Wien-Baltimore 1994, 1-73

Bennett D (1975): The t-Locus of the mouse. Cell $\underline{6}, 441-454$

Bennett WI, Gall AM, Southard JL, Sidman RL (1971): Abnormal spermatogenesis in quaking, a myelindeficient mutant mouse. Biol Reprod $\underline{5}, 30-58$

Beyer U, Moll-Rocek J, Moll UM, Dobbelstein M (2011): Endogenous retrovirus drives hitherto unknown proapoptotic p63 isoforms in the male germ line of humans and great apes. Proc Natl Acad Sci USA 108(9), 3624-3629 
Billen LP, Shamas-Din A, Andrews, DW (2009): Bid: a Bax-like BH3 protein. Oncogene 27, 93-104

Black DL (2003): Mechanisms of alternative pre-messenger RNA splicing. Annu Rev Biochem 그, 291-336

Blendy JA, Kaestner KH, Weinbauer GF, Nieschlag E, Schütz G (1996): Severe impairement of spermatogenesis in mice lacking the CREM gene. Nature $\underline{380}, 162-165$

Boehm D, Herold S, Kuechler A, Liehr T, Laccone F (2004): Rapid detection of subtelomeric deletion/duplication by novel real-time quantitative PCR using SYBR-green dye. Hum Mutat $\underline{23}, 368-378$

Burfeind C: Isolierung und Charakterisierung des spermatozytenspezifisch exprimierten Gens TSGK-1 der Maus. Med. Diss. Göttingen 1999

Cao W, Haig-Ladewig L, Gerton GL, Moss SB (2006): Adenylate kinases 1 and 2 are part of the accessory structures in the mouse sperm flagellum. Biol Reprod 75(4), 492-500

Carninci P and Hayashizaki Y (1999): High-efficiency full length cDNA cloning. Methods Enzymol 303, 19-44

Carninci P, Kasukawa T, Katayama S, Gough J, Frith MC et al.; FANTOM Consortium; RIKEN Genome Exploration Research Group and Genome Science Group (Genome Network Project Core Group) (2005): The transcriptional landscape of the mammalian genome. Science 309(5740), 1559-1563

Chintapalli V, Wang J, Dow J (2007): Using FlyAtlas to identify better Drosophila models of human disease. Nat Genet $\underline{39}, 715-720$

Chizaki R, Yao I, Katano T, Matsuda T, Ito S (2011): Restricted Expression of Ovol2/MOVO in XY Body of Mouse Spermatocytes at the Pachytene Stage. J Androl 33(2), 277-286 
Choi E and Cho C (2011): Expression of a sperm flagellum component encoded by the Als2cr12 gene. Gene Expr Patterns 11(5-6), 327-333

Choi E, Lee J, Oh J, Park I, Han C, Yi C, Kim DH, Cho BN, Eddy EM, Cho C (2007): Integrative characterization of germ cell-specific genes from mouse spermatocyte unigene library. BMC Genomics $\underline{8}, 256$

Clancy S (2008): RNA splicing: introns, exons and spliceosome. Nat Educ 1(1).

Cooper TG, Noonan E, von Eckardstein S, Auger J, Baker HW, Behre HM, Haugen TB, Kruger T, Wang C, Mbizvo MT, Vogelsong KM (2010): World Health Organization reference values for human semen characteristics. Hum Reprod Update 16, 231-245

Denoeud F, Kapranov P, Ucla C, Frankish A, Castelo R, Drenkow J et al. (2007): Prominent use of distal $5^{\prime}$ transcription start sites and discovery of a large number of additional exons in ENCODE regions. Genome Res 17, 746-759

Diez-Roux G, Banfi S, Sultan M, Geffers L, Anand S et al. (2011): A high-resolution anatomical atlas of the transcriptome in the mouse embryo. PLoS Biol 9(1), e1000582

Dowling AJ, Waterfield NR, Hares MC, Le Goff G, Streuli CH, ffrench-Constant RH (2007): The Mcf1 toxin induces apoptosis via the mitochondrial pathway and apoptosis is attenuated by mutation of the BH3-like domain. Cell Microbiol 9(10), 2470-2484

Du H, Wolf J, Schafer B, Moldoveanu T, Chipuk JE, Kuwana T (2011): BH3 domains other than Bim and Bid can directly activate Bax/Bak. J Biol Chem 286(1), 491-501

Erlich S, Mizrachy L, Segev O, Lindenboim L, Zmira O, Adi-Harel S, Hirsch JA, Stein R, Pinkas-Kramarski R (2007): Differential interactions between Beclin1 and Bcl-2 family members. Autophagy $\underline{3(6)}, 561-568$

Fischer U, Englbrecht C, Chari A (2011): Biogenesis of spliceosomal small nuclear ribonucleoproteins. Wiley Interdiscip Rev RNA 2(5), 718-731 
Florence B and Faller DV (2001): You bet-cha: a novel family of transcriptional regulators. Front Biosci $\underline{6}, 1008-1018$

Fougerousse F, Bullen P, Herasse M, Lindsay S, Richard I, Wilson D, Suel L, Durand M, Robinson S, Abitbol M, Beckmann JS, Strachan T (2000): Human-mouse difference in the embryonic expression patterns of developmental control genes and disease genes. Hum Mol Genet $\underline{9(2)}, 165-173$

Gan H, Lin X, Zhang Z, Zhang W, Liao S, Wang L, Han C (2011): piRNA profiling during specific stages of mouse spermatogenesis. RNA 17(7), 1191-1203

Gould SJ, Keller GA, Subramani S (1988): Identification of peroxisomal targeting signals located at the carboxy terminus of four peroxisomal proteins. J Cell Biol 107, 897-905

Grellscheid S, Dalgliesh C, Storbeck M, Best A, Liu Y, Jakubik M, Mende Y, Ehrmann I, Curk T, Rossbach K, Bourgeois CF, Stévenin J, Grellscheid D, Jackson MS, Wirth B, Elliott DJ (2011): Identification of evolutionarily conserved exons as regulated targets for the splicing activator tra2 $\beta$ in development. PLoS Genet 7(12), e1002390

Grzmil P, Burfeind C, Preuss T, Dixkens C, Wolf S, Engel W, Burfeind P (2007): The putative peroxisomal gene Pxt1 is exclusively expressed in the testis. Cytogenet Genome Res $\underline{119(1-2)}, 74-82$

Grzybowka EA, Wilczynska A, Siedlecki JA (2001): Regulatory function of 3'UTRs. Biochem Biophys Res Commun 288, 291-295

Gu W and Hecht NR (1996): Translation of a testis-specific Cu/Zn superoxide dismutase (SOD-1) mRNA is regulated by a 65-kilodalton protein which binds to its 5' untranslated region. Mol Cell Biol 16(8), 4535-4543

Hartman ML and Czyz M (2012): Pro-apoptotic Activity of BH3-only and BH3 Mimetics: from Theory to Potential Cancer Therapy. Anticancer Agents Med Chem 12(8), 966-981 
Hata K, Kusumi M, Yokomine T, Li E, Sasaki H (2006): Meiotic and epigenetic aberrations in Dnmt3L-deficient male germ cells. Mol Reprod Dev 73(1), 116-122

Haynes SR, Dollard C, Winston F, Beck S, Trowsdale J, Dawid I (1992): The bromodomain: a conserved sequence found in human, Drosophila and yeast proteins. Nucleic Acids Res $\underline{20(10)}, 2603$

Holroyd C and Erdmann R (2001): Protein translocation machineries of peroxisomes. FEBS Lett $\underline{13}, 6-10$

Hu W, Zheng T, Wang J (2011): Regulation of Fertility by the p53 Family Members. Genes Cancer 2(4), 420-430

Hughes T (2006): Regulation of gene expression by alternative untranslated regions. Trends Genet 22, 119-122

Itman C, Wong C, Whiley PA, Fernando D, Loveland KL (2011): TGFß superfamily signaling regulators are differentially expressed in the developing and adult mouse testis. Spermatogenesis $\underline{1(1)}, 63-72$

Jaroszynski L, Zimmer J, Fietz D, Bergmann M, Kliesch S, Vogt PH (2010): Translational control of the AZFa gene DDX3Y by 5'UTR exon-T extension. Int J Androl 34(4), 313-326

Jiang X, Li D, Yang J, Wen J, Chen H, Xiao X, Dai Y, Yang J, Tang Y (2011): Charakterization of a Novel Human Testis-Specific Gene: Testis Deveolpmental Related Gene 1 (TDRG1). Tohoki J Exp Med 225(4), 311-318

Kaczmarek K: On the Functional Analysis of Murine Peroxisomal Testis Specific 1 (Pxt1) Gene. Biol. Diss. Göttingen 2009

Kaczmarek K, Niedzialkowska E, Studencka M, Schulz Y, Grzmil P (2009): Ccdc33, a predominantly testis-expressed gene, encodes a putative peroxisomal protein. Cytogenet Genome Res 126(3), 243-252 
Kaczmarek K, Studencka M, Meinhardt A, Wieczerzak K, Thoms S, Engel W, Grzmil P (2011): Overexpression of peroxisomal testis specific 1 protein induces germ cell apoptosis and leads to infertility in male mice. Mol Biol Cell 22(10), 1766-1779

Katayama S, Tomaru Y, Kasukawa T, Waki K, Nakanishi M, et al. (2005): RIKEN Genome Exploration Research Group; Genome Science Group (Genome Network Project Core Group), FANTOM Consortium. Antisense transcription in the mammalian transcriptome. Science $\underline{309}, 1564-1566$

Kawai J, Shinagawa A, Shibata K, Yoshino M, Itoh M et al.; RIKEN Genome Exploration Research Group Phase II Team and the FANTOM Consortium (2001): Functional annotation of a full-length mouse cDNA collection. Nature $\underline{409(6821)}, 685-690$

Ko MS, Kitchen JR, Wang X, Threat TA, Wang X, Hasegawa A, Sun T, Grahovac MJ, Kargul GJ, Lim MK, Cui Y, Sano Y, Tanaka T, Liang Y, Mason S, Paonessa PD, Sauls AD, DePalma GE, Sharara R, Row LB, Eppig J, Morrell C, Doi H (2000): Large-scale cDNA analysis reveals phased gene expression patterns during preimplantation mouse development. Development 127(8), 1737-1749

Kogan SC, Doherty M, Gitschier J (1987): An improved method for prenatal diagnosis of genetic disease by analysis of amplified DNA sequences. N Engl J Med $\underline{317}, 985-990$

Kokkinaki M, Lee TL, He Z, Jiang J, Golestaneh N, Hofmann MC, Chan WY, Dym M (2010): Age effects gene expression in mouse spermatogonial stem/progenitor cells. Reproduction 139(6), 1011-1020

Kraszucka K, Burfeind P, Nayernia K,1 Köhler M, Schmid M, Yaylaoglu M, Engel W (1999): Developmental Stage- and Germ Cell-Regulated Expression of a Calcium-Binding Protein mRNA in Mouse Sertoli Cells. Mol Reprod Dev 54, 232-243

Kutty RK, Kutty G, Samuel W, Duncan T, Bridges CC, El-Sherbeeny A, Nagineni CN, Smith SB, Wiggert B (2000): Molecular Characterization and Developmental Expression of NORPEG, a Novel Gene Induced by Retinoic Acid. J Biol Chem 276(4), 2831-2840 
Lane DP (1992): Cancer. p53, guardian of the genome. Nature $\underline{358}, 15-16$

La Salle S, Oakes CC, Neaga OR, Bourc'his D, Bestor TH, Trasler JK (2007): Loss of spermatogonia and wide-spread DNA methylation defects in newborn male mice deficient in DNMT3L. BMC Dev Biol 7, 104

Levine M, Jones C, Kern A, Lindfors H, Begun D (2006): Novel genes derived from noncoding DNA in Drosophila melanogaster are frequently X-linked and show testis-biased expression. Proc Natl Acad Sci USA $\underline{103}$, 9935-9939

Liu Y, Jiang M, Li C, Yang P, Sun H, Tao D, Zhang S, Ma Y (2011): Human t-complex protein 11 (TCP11), a testis specific gene product, is potential determinant of the sperm morphology. Tohoku J Exp Med 224(2), 111-117

Lomonosova E and Chinnadurai G (2008): BH3-only proteins in apoptosis and beyond: an overview. Oncogene 27 Suppl. 1, 2-19

Lukowski SW, Bombieri C, Trezise AE (2011): Disrupted post-transcriptional regulation of the cystic fibrosis transmembrane conductance regulator (CFTR) by a 5'UTR mutation is associated with a CFTR-related disease. Hum Mutat 32(10), e2266-82

Lyon MF and Hawkes SG (1970): X-likes gene for testicular feminization in the mouse. Nature 227, 1217-1219

Lyon MF and Searle AG: Genetic variations and Strains of Laboratory Mouse. $2^{\text {nd }}$ ed. Oxford University Press, Oxford 1989

Ma YX, Zhang SZ, Wu QQ, Sun Y, Qiu WM, Xu WM (2003): Cloning, expression, and alternative splicing of the novel isoform of hTCP11 gene. Zhongguo Yi Xue Ke Xue Yuan Xue Bao 25(2), 122-128

Maas C, de Vries E, Tait SW, Borst J (2011): Bid can mediate a pro-apoptotic response to etoposid and ionizing radiation without cleavage in its unstructured loop and in the absence of p53. Oncogene $\underline{30(33)}, 3636-3647$ 
McKenna MC and Bell SK: Classification of Mammals: Above the Species Level. Columbia University Press, Oxford 2000

Mével-Ninio M, Terracol R, Salles C, Vincent A, Payre F (1995): Ovo, a Drosophila gene required for ovarian development, is specifically expressed in the germline and shares most of its coding sequences with shavenbaby, a gene involved in embryo patterning. Mech Dev $\underline{49}$, $83-95$

Mohan KV, Som I, Atreya CD (2002): Identification of a type I peroxysomal targeting signal in a viral protein and demonstration of its targeting to the organelle. J Virol 76(5), 2543-2547

Moncini S, Salvi A, Zuccotti P, Viero G, Quattrone A, Barlati S, De Petro G, Venturin M, Riva P (2011): The role of miR-103 and miR-107 in regulation of CDK5R1 expression and in cellular migration. PLoS One $\underline{6(5)}$, e20038

Moore CH de, Meijer H, Lissenden S (2005): Mechanisms of translational control by the 3’UTR in development and differtiation. Semin Cell Dev Biol 16, 49-58

Morich C: Analysis of the PXT1-dependent apoptotic pathway in mouse male germ cells. Biol. Masterarbeit, Göttingen 2012

Morrison TB, Weis JJ, Wittwer CT (1998): Quantification of low-copy transcripts by continuous SYBR Green I monitoring during amplification. Biotechniques $\underline{24}, 954-958$

Moutier R: New mutations causing sterility restricted to the male in rats and mice. The Laboratory Animal in the Study of Reproduction. 1. Auflage, Gustav Fischer Verlag, Stuttgart 1976

Muer A, Overkamp T, Gillissen B, Richter A, Pretzsch T, Milojkovic A, Dorken B, Daniel PT, Hemmati P (2012): p14ARF-induced apoptosis in p53-deficient cells is mediated by the BH3-only protein independent de-pression of Bak through down-regulated of Mcl-1 and BclxL. J Biol Chem 287(21), 17343-17352 
Mungall AJ, Palmer SA, Sims SK, Edwards CA, Ashurst JL, Wilming L, Jones MC, Horton R, Hunt SE, Scott CE, et al. (2003): The DNA sequence and analysis of human chromosome 6. Nature $\underline{425(6960)}, 805-11$

Nantel F, Monaco L, Foulkes NS, Masquilier D, LeMeur M, Henriksén K, Dierich A, Parvinen M, Sassone-Corsi P (1996): Spermiogenesis deficiency and germ-cell apoptosis in CREM-mutant mice. Nature $\underline{380}, 159-162$

Nieschlag E and Behre HM: Andrologie Grundlagen und Klinik der reproduktiven Gesundheit des Mannes, 2. Auflage, S. 94-95, Springer Verlag, Münster 2000

Nowak RW: Walker's Mammals of the World. Johns Hopkins University Press, Baltimore 1999

Ohta H, Tohda A, Nishimune Y (2003): Proliferation and differentiation of spermatogonial stem cells in the w/wv mutant mouse testis. Biol Reprod $\underline{69(6)}, 1815-1821$

Okazaki Y, Furuno M, Kasukawa T, Adachi J, Bono H Kondo S, Nikaido I, Osato N, Saito R, Suzuki H, et al.; FANTOM Consortium; RIKEN Genome Exploration Research Group Phase I \& II Team (2002): Analysis of the mouse transcriptome based on functional annotation of 60,770 full-length cDNAs. Nature 420(6915), 563-573

Oliveri M, Daga A, Cantoni C, Lunardi C, Millo R, Puccetti A (2001): DNase I mediates internucleosomal DNA degradation in human cells undergoing drug-induced apoptosis. Eur J Immunol $\underline{31(3)}, 743-751$

Paillisson A, Levasseur A, Gouret P, Callebaut I, Bontoux M, Pontarotti P, Monget P (2007): Bromodomain testis-specific protein is expressed in mouse oocyte and evolve faster than its ubiquitously expressed paralogs BRD2, -3, and -4. Genomics $\underline{\text { 89(2) }}$, 215-223

Paul C, Murray AA, Spears N, Saunders PT (2008): A single, mild, transient scrotal heat stress causes DNA damage, subfertility and impairs formation of blastocysts in mice. Reproduction 136(1), 73-84 
Preuss T: Analysen zur Expression, subzellulären Lokalisation und Funktion eines putativen peroxisomalen Proteins der Maus. Biol. Diplomarbeit, Göttingen 2002

Raab LS, Hamilton DW, Hancock LW (1994): Proacrosin gene expression in rat spermatogenetic cells. J Androl 15(3), 244-249

Ren D, Tu HC, Kim H, Wang GX, Bean GR, Takeuchi O, Jeffers JR, Zambetti GP, Hsieh JJ, Cheng EH (2010): BID, BIM, and PUMA are essential for activation of the BAX- and BAKdependent cell death program. Science 330(6009), 1390-1393

Ritchie DB, Schellenberg MJ, MacMillan AM (2009): Spliceosome structure: piece by piece. Biochim Biophys Acta 1789(9-10), 624-633

Robinson MO, McCarrey JR, Simon MI (1989): Transcriptional regulatory regions of testisspecific PGK2 defined in transgenic mice. Proc Natl Acad Sci USA $\underline{86}, 8437-8441$

Sai T, Matsuda F, Goto Y, Maeda A, Sugimoto M, Gao HM, Kabir AK, Li JY, Manabe N (2011): Effect of RNA Interference of BID and BAX mRNAs on Apoptosis in Granulosa Cell-derived KGN Cells. J Reprod Dev $\underline{58(1)}$, 112-116

Saiki RK, Gelfand DH, Stoffel S, Scharf SJ, Higuchi R, Horn GT, Mullis KB and Erlich HA (1988): Primer-directed enzymatic amplification of DNA with a thermostable DNA polymerase. Science 239(4839), 487-491

Sanger F, Nicklen S, Coulson AR (1977): DNA sequencing with chain-terminating inhibitors. Proc Natl Acad Sci 74(12), 5463-5467

Sasaki T, Marcon E, McQuire T, Arai Y, Moens PB and Okada H (2008): Bat3 deficiency accelerates the degradation of Hsp70-2/HspA2 during spermatogenesis. J Cell Biol 182, 449458

Shibata K, Itoh M, Aizawa K, Nagaoka S, Sasaki N, Carninci P, Konno H, Akiyama J, Nishi K, Kitsunai T, et al. (2000): RIKEN Integrated Sequence Analysis (RISA) System-384 Format Sequencing Pipeline with 384 Multicapillary Sequencer. Genome Res 10, 1757-1771 
Shibata M, Nakao H, Kiyonari H, Abe T, Aizawa S (2011): MicroRNA-9 regulates neurogenesis in mouse telencephalon by targeting multiple transcription factors. J Neurosci $\underline{31(9)}, 3407-3422$

Simon L, Brunborg G, Stevenson M, Lutton D, McManus J, Lewis SE (2010): Clinical significance of sperm DNA damage in assisted reproduction outcome. Hum Reprod 25(7), 1594-1608

Skommer J, Wlodkowic D, Deptala A (2007): Larger than life: Mitochondria and the Bcl-2 family. Leuk Res $\underline{31}, 277-286$

Smith RW, Anderson RC, Smith JW, Brook M, Richardson WA, Gray NK (2011): DAZAP1, an RNA-binding protein required for development and spermatogenesis, can regulate mRNA translation. RNA 17(7), 1282-1295

Song G, Wang W, Hu T (2011): p53 facilitates BH3-only BID nuclear export to induce a apoptosis in the irrepairable DNA damage response. Med Hypotheses $\underline{77(5)}$, 850-852

Spano M, Seli E, Bizzaro D, Manicardi GC, Sakkas D (2005): The significance of sperm nuclear DNA strand breaks on reproductive outcome. Curr Opin Obstet Gynecol 17(3), 255260

Strausberg RL, Feingold EA, Grouse LH, Derge JG, Klausner RD, Collins FS, Wagner L, Shenmen CM, Schuler GD, Altschul SF, et al.; Mammalian Gene Collection Program Team (2002): Generation and initial analysis of more than 15,000 full-length human and mouse cDNA sequences. Proc Natl Acad Sci USA 99(26), 16899-16903

Thress K, Henzel W, Shillinglaw W, Kornbluth S (1998): Scythe: a novel reaper-binding apoptotic regulator. EMBO J $\underline{17}, 6135-6143$

Tsukahara T, Kimura S, Ichimiya S, Torigoe T, Kawaguchi S, Wada T, Yamashita T, Sato N (2009): Scythe/BAT3 regulates apoptotic cell death induced by papillomavirus binding factor in human osteosarcoma. Cancer Sci $\underline{100}, 47-53$ 
Tsuno T, Mejido J, Zhao T, Phillips T, Myers TG, Bekisz J, Zoon KC (2012): BID is a critical factor controlling cell viability regulated by IFN- $\alpha$. J Immunother $\underline{35(1)}, 23-31$

Vasudevan S (2011): Posttranscriptional Upregulation by MicroRNAs. Wiley Interdiscip Rev RNA $\underline{3(3)}, 311-330$

Venkatesh S, Singh A, Shamsi MB, Thilagavathi J, Kumar R, Mitra DK, Dada R (2011): Clinical significance of sperm DNA damage threshold value in the assessment of male infertility. Reprod Sci 18(10), 1005-1013

Wahl MC, Will CL, Luhrmann R (2009): The spliceosome: design principles of a dynamic RNP machine. Cell 136(4), 701-718

Wang W, Su J, Li F, Li R, Gu Y, Liu C, Yang P, Zhu M, Chen L, Tian W, Zhou H, Mao Y, Zhang L, Jiang J, Wu C, Hua D, Chen W, Lu B, Ju J, Zhang X (2011): A frequent somatic mutation in CD274 3'-UTR leads to protein over-expression in gastric cancer by disruption miRNA-570 binding. Hum Mutat 33(3), 480-484

Watahiki A, Waki K, Hayatsu N, Shiraki T, Kondo S, Nakamura M, Sasaki D, Arakawa T, Kawai J, Harbers M, Hayashizaki Y, Carnici P (2004): Libraries enriched for alternatively spliced exons reveal splicing patterns in melanocytes and melanomas. Nat Methods $\underline{1(3)}$, 233239

Webster KE, O`Bryan MK, Fletcher S, Crewther PE, Aapola U, Craig J, Harrison DK, Aung H, Phutikanit N, Lyle R, Meachem SJ, Antonarakis SE, de Kretser DM, Hedger MP, Peterson P, Carroll BJ, Scott HS (2005): Meiotic and epigenetic defects in Dnmt3L-knockout mouse spermatogenesis. Proc Natl Acad Sci USA 102(11), 4068-4073

Western PS, Ralli RA, Wakeling SI, Lo C, van den Bergen JA, Miles DC, Sinclair AH (2011): Mitotic Arrest in Teratoma Susceptible Fetal Male Germ Cells. PloS One $\underline{6(6)}$, e20736

White-Cooper H and Bausek N (2010): Evolution and spermatogenesis. Phil Trans R Soc B $\underline{365}, 1465-1480$ 
Xiao P, Tang A, Yu Z, Gui Y, Cai Z (2008): Gene expression profile of 2058 spermatogenesis-related genes in mice. Biol Pharm Bull 31(2), 201-206

Yang A and McKeon F (2000): P63 and P73: P53 mimics, menaces and more. Nat Rev Mol Cell Biol 1, 199-207

Yang A, Kaghad M, Wang Y, Gillett E, Fleming MD, Dötsch V, Andrews NC, Caput D, McKeon F (1998): p63, a p53 homolog at 3q27-29, encodes multiple products with transactivating, death-inducing, and dominant-negative activities. Mol Cell $\underline{2}$, 305-316

Yin XM (2000): Signal transduction mediated by BID, a pro-death Bcl-2 familiy protein, connects the death receptor and mitochondria apoptosis pathway. Cell Research $\underline{10}, 161-167$

Yuan W, Zheng Y, Huo R, Lu L, Huang XY, Yin LL, Li JM, Zhou ZM, Sha JH (2005): Expression of a novel alternative transcript of the novel retinal pigment epithelial cell gene NORPEG in human testes. Asian J Androl 7(3), 277-288

Zimmermann S, Schöttler P, Engel W and Adham IM (1997): Mouse Leydig Insulin-like (Ley I-L) Gene: Structure and Expression During Testis und Ovary Development. Mol Reprod Dev $\underline{47}, 30-38$ 


\section{Danksagung}

Herrn Prof. Dr. med. Dr. h. c. W. Engel, Direktor des Instituts für Humangenetik der Universität Göttingen, danke ich ganz herzlich für die Überlassung des Themas und für seine große Geduld, die er mir bei der schriftlichen Ausarbeitung dieser Arbeit entgegenbrachte.

Ein besonderer Dank gilt Herrn Dr. P. Grzmil, der mir als Betreuer stets mit seiner fachlichen Kompetenz zur Seite stand und mich bei der Planung, Durchführung der Experimente, der Auswertung und der Niederschrift unterstützte. Vielen Dank für die unkomplizierte Zusammenarbeit, für die Geduld und die jederzeit offene Tür bei Fragen und Problemen.

Im gleichen Maße möchte ich mich auch bei den Mitarbeitern meines Laborteams (AG Grzmil), besonders bei Frau J. Mänz, bedanken, die mir bei allen Problemen und Fragen hilfreich zur Seite gestanden haben, die mir eine angenehme Arbeitsatmosphäre geschaffen haben und mit deren aktiver Unterstützung eine erfolgreiche Fertigstellung dieser Arbeit möglich gewesen war.

Auf diesem Wege möchte ich mich auch bei allen Mitarbeitern des Instituts für Humangenetik bedanken, die mir während meiner Arbeit ebenfalls immer hilfsbereit zur Seite gestanden haben. Ein besonderer Dank gilt Frau Dr. J. Nolte, Frau S. Lührig sowie Frau J.Ullrich.

Den Frauen R. und J. Hildebrandt möchte ich für das Korrekturlesen der Arbeit danken.

Ich danke Ihnen allen! 